Article

\title{
Synthesis, Biological Evaluation, and Structure-Activity Relationships of 4-Aminopiperidines as Novel Antifungal Agents Targeting Ergosterol Biosynthesis
}

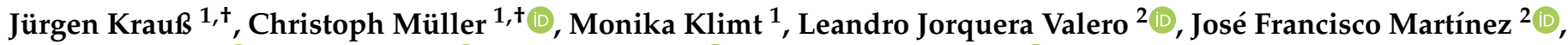 \\ Martin Müller $^{3}\left(\mathbb{C}\right.$, Karin Bartel ${ }^{3}\left[\right.$, Ulrike Binder ${ }^{2}(\mathbb{D}$ and Franz Bracher $1, * \mathbb{(})$ \\ 1 Department of Pharmacy-Center for Drug Research, Ludwig-Maximilians University Munich, \\ 81377 Munich, Germany; hjkra@cup.uni-muenchen.de (J.K.); \\ christoph.mueller@cup.uni-muenchen.de (C.M.); monika.klimt@cup.uni-muenchen.de (M.K.) \\ 2 Institute of Hygiene and Medical Microbiology, Department of Hygiene, Microbiology and Public Health, \\ Medical University Innsbruck, Schöpfstr. 41, 6020 Innsbruck, Austria; \\ leandro.jorquera01@estudiant.upf.edu (L.J.V.); josefrancisco.martinezh@um.es (J.F.M.); \\ ulrike.binder@i-med.ac.at (U.B.) \\ 3 Department of Pharmacy, Pharmaceutical Biology, Ludwig-Maximilians University Munich, \\ 81377 Munich, Germany; martin.mueller.lmu@gmail.com (M.M.); karin.bartel@cup.uni-muenchen.de (K.B.) \\ * Correspondence: franz.bracher@cup.uni-muenchen.de; Tel.: +43-89-2180-77301 \\ + These authors contributed equally to this work.
}

Citation: Krauß, J.; Müller, C.; Klimt, M.; Valero, L.J.; Martínez, J.F.; Müller, M.; Bartel, K.; Binder, U.; Bracher, F. Synthesis, Biological Evaluation, and Structure-Activity Relationships of 4-Aminopiperidines as Novel Antifungal Agents Targeting Ergosterol Biosynthesis. Molecules 2021, 26, 7208. https://doi.org/ $10.3390 /$ molecules 26237208

Academic Editor: Athanassios C. Tsipis

Received: 4 November 2021 Accepted: 25 November 2021 Published: 28 November 2021

Publisher's Note: MDPI stays neutral with regard to jurisdictional claims in published maps and institutional affiliations.

Copyright: (c) 2021 by the authors Licensee MDPI, Basel, Switzerland. This article is an open access article distributed under the terms and conditions of the Creative Commons Attribution (CC BY) license (https:// creativecommons.org/licenses/by/ $4.0 /)$.
Abstract: The aliphatic heterocycles piperidine and morpholine are core structures of well-known antifungals such as fenpropidin and fenpropimorph, commonly used as agrofungicides, and the related morpholine amorolfine is approved for the treatment of dermal mycoses in humans. Inspired by these lead structures, we describe here the synthesis and biological evaluation of 4-aminopiperidines as a novel chemotype of antifungals with remarkable antifungal activity. A library of more than 30 4-aminopiperidines was synthesized, starting from $N$-substituted 4-piperidone derivatives by reductive amination with appropriate amines using sodium triacetoxyborohydride. Antifungal activity was determined on the model strain Yarrowia lipolytica, and some compounds showed interesting growth-inhibiting activity. These compounds were tested on 20 clinically relevant fungal isolates (Aspergillus spp., Candida spp., Mucormycetes) by standardized microbroth dilution assays. Two of the six compounds, 1-benzyl- $N$-dodecylpiperidin-4-amine and $N$-dodecyl-1-phenethylpiperidin-4-amine, were identified as promising candidates for further development based on their in vitro antifungal activity against Candida spp. and Aspergillus spp. Antifungal activity was determined for 18 Aspergillus spp. and 19 Candida spp., and their impact on ergosterol and cholesterol biosynthesis was determined. Toxicity was determined on HL-60, HUVEC, and MCF10A cells, and in the alternative in vivo model Galleria mellonella. Analysis of sterol patterns after incubation gave valuable insights into the putative molecular mechanism of action, indicating inhibition of the enzymes sterol C14-reductase and sterol C8-isomerase in fungal ergosterol biosynthesis.

Keywords: 4-aminopiperidine; antifungals; reductive amination; Aspergillus spp.; Candida spp.; Mucorales spp.

\section{Introduction}

Fenpropidin and fenpropimorph [1,2] (Figure 1) are well-established antifungals with a broad application in agrochemistry since the 1980s. The structurally related morpholine derivative amorolfine (Loceryl ${ }^{\circledR}$ ) is used in human dermatology, especially for the treatment of onychomycosis and various local dermal mycoses. The mechanism of action of these antifungals is inhibition of ergosterol biosynthesis. These and related morpholines and piperidines inhibit, to various extents, the enzymes sterol C14-reductase and sterol C8isomerase of the post-squalene part of ergosterol biosynthesis [3,4]. At physiological $\mathrm{pH}$ 
protonated, the core element for this enzyme inhibition is the morpholine/piperidine ring, which can imitate the carbocationic high-energy intermediates (HEIs) of the conversions catalysed by these two enzymes [5-8].
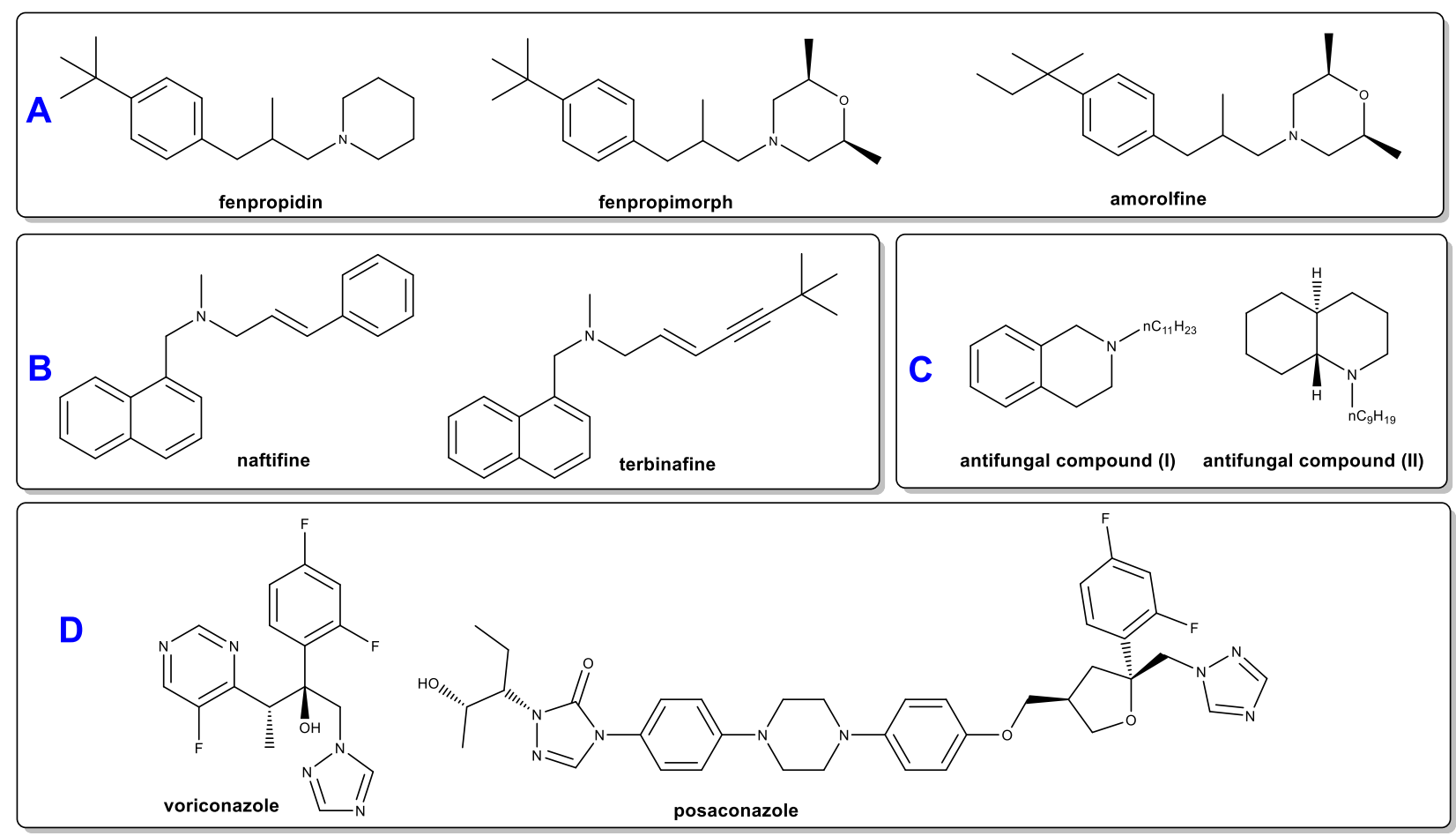

Figure 1. Structures of established antifungals. (A) piperidines/morpholines: fenpropidin, fenpropimorph, amorolfine; (B) approved allylamines: naftifine, terbinafine; (C) antifungal compounds (I) [9] and (II) [10] from our previous work; (D) approved azoles: voriconazole, posaconazole.

In the last decades, an increase in fungal resistance against commonly used antifungals was seen in clinical fungal isolates such as Aspergillus fumigatus and Candida species; furthermore, an increase in emerging fungal pathogens, such as Mucorales, was observed [11-14]. Consequently, the antifungal therapy of immunocompromised patients is becoming even more difficult and the need for development of new antifungals is an urgent demand. In parallel to the clinical developments, the demand for novel antifungal agrochemicals is similarly high, as resistance is emerging in this field, too, and a number of old antifungals used in crop protection are meanwhile hampered by safety concerns [15].

One promising strategy in the development of new antifungal compounds with advantages such as higher potency, a broader spectrum, fewer side effects, and a better ecological balance sheet and to break resistance is to start from well-established antifungals as lead structures by means of design and further optimization of hybrids of different active chemotypes [16].

In continuation of our research on the development of antifungals starting from simple aliphatic amines such as benzylamines, (partly) hydrogenated quinolines, and isoquinolines $[9,10,17,18]$ (Figure 1C), we merged essential fragments from these chemotypes and evaluated the 4-aminopiperidine motif as a core structure for novel antifungals. The introduction of a second protonable nitrogen into a sterol biosynthesis inhibitor designed to imitate a carbocationic HEI had shown great benefit in our recent investigations on oxidosqualene cyclase inhibitors [19]. The nature of the residues at both nitrogen atoms of the 4-aminopiperidine core structure was inspired by arylalkylamines (e.g., fenpropidin, Figure 1A), as well as allylamine-type drugs (squalene epoxidase inhibitors) such as naftifine and terbinafine (Figure 1B) on the one side, and medium to long, linear or branched alkyl chains (Figure 1C; see evidence described in ref. $[9,10,17]$ ) on the other side. 
<smiles>[R1]N1CCC(=O)CC1</smiles>

$\mathrm{R}^{1}: \mathrm{PhCH}_{2}$ $\mathrm{R}^{1}: \mathrm{PhCH}_{2} \mathrm{CH}_{2}$ 1b $\mathrm{R}^{1}: \mathrm{Boc}$<smiles>[R1]N1CCC(=O)CC1</smiles>

$\mathrm{R}^{1} \cdot \mathrm{Bn}$ $\mathrm{R}^{1}: \mathrm{PhCH}_{2} \mathrm{CH}_{2}$
We expected that fine-tuning of the antifungal activity of this new class of compounds should be possible by systematic modification of both $N$-substituents.

\section{Results and Discussion}

\subsection{Chemistry}

Commercially available $N$-substituted 4-piperidone derivatives $1 \mathbf{a}-\mathbf{c}$ were subjected to reductive amination with diverse aliphatic amines, using sodium triacetoxyborohydride as the reducing agent $[17,20]$, to give the secondary amines $\mathbf{2} \mathbf{a}-\mathbf{j}, \mathbf{3 a}-\mathbf{g}, \mathbf{4} \mathbf{a}-\mathbf{f}$ and the tertiary amines $\mathbf{7 a}, \mathbf{b}$ in moderate to virtually quantitative yields (Scheme 1). In order to ensure stability and sufficient water solubility, all resulting amines could be converted into their corresponding dihydrochlorides (monohydrochlorides in case of the $N$-Boc compounds 4a-f) by precipitation with hydrogen chloride in diethyl ether.

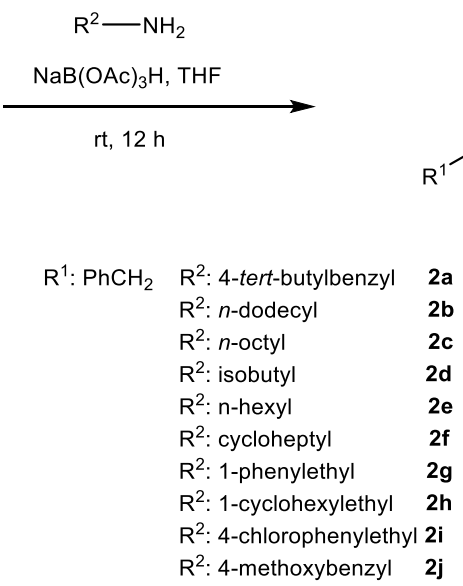<smiles>[R]NC1CCN([R])CC1</smiles>
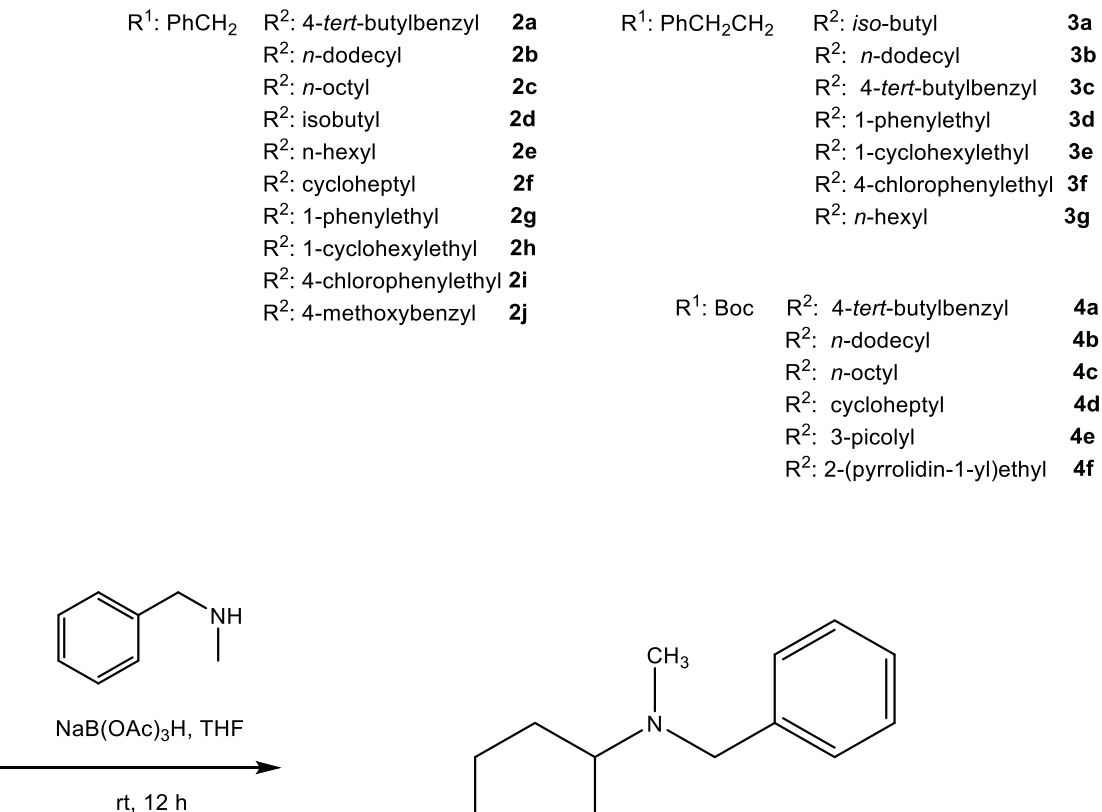

$\mathrm{rt}, 12 \mathrm{~h}$<smiles>[R1]N1CCC(N(C)Cc2ccccc2)CC1</smiles>

$$
\begin{array}{ll}
\mathrm{R}^{1}: \mathrm{Bn} & \mathbf{7 a} \\
\mathrm{R}^{1}: \mathrm{PhCH}_{2} \mathrm{CH}_{2} & \mathbf{7 b}
\end{array}
$$

Scheme 1. Synthesis of compounds $2 \mathbf{a}-\mathbf{j}, \mathbf{3} \mathbf{a}-\mathbf{g}, \mathbf{4 a}-\mathbf{f}$ and $\mathbf{7 a}, \mathbf{b}$.

The $N$-Boc protecting group of $4 \mathbf{a}-\mathbf{c}, \mathbf{e}, \mathbf{f}$ could be removed by trifluoroacetic acid treatment [21] to give the corresponding unprotected piperidines $5 \mathbf{a}-\mathbf{c}, \mathbf{e}, \mathbf{f}$ in good yields (Scheme 2). Attempted deprotection with hydrogen chloride in diethyl ether [22] resulted only in incomplete conversions in same cases. 

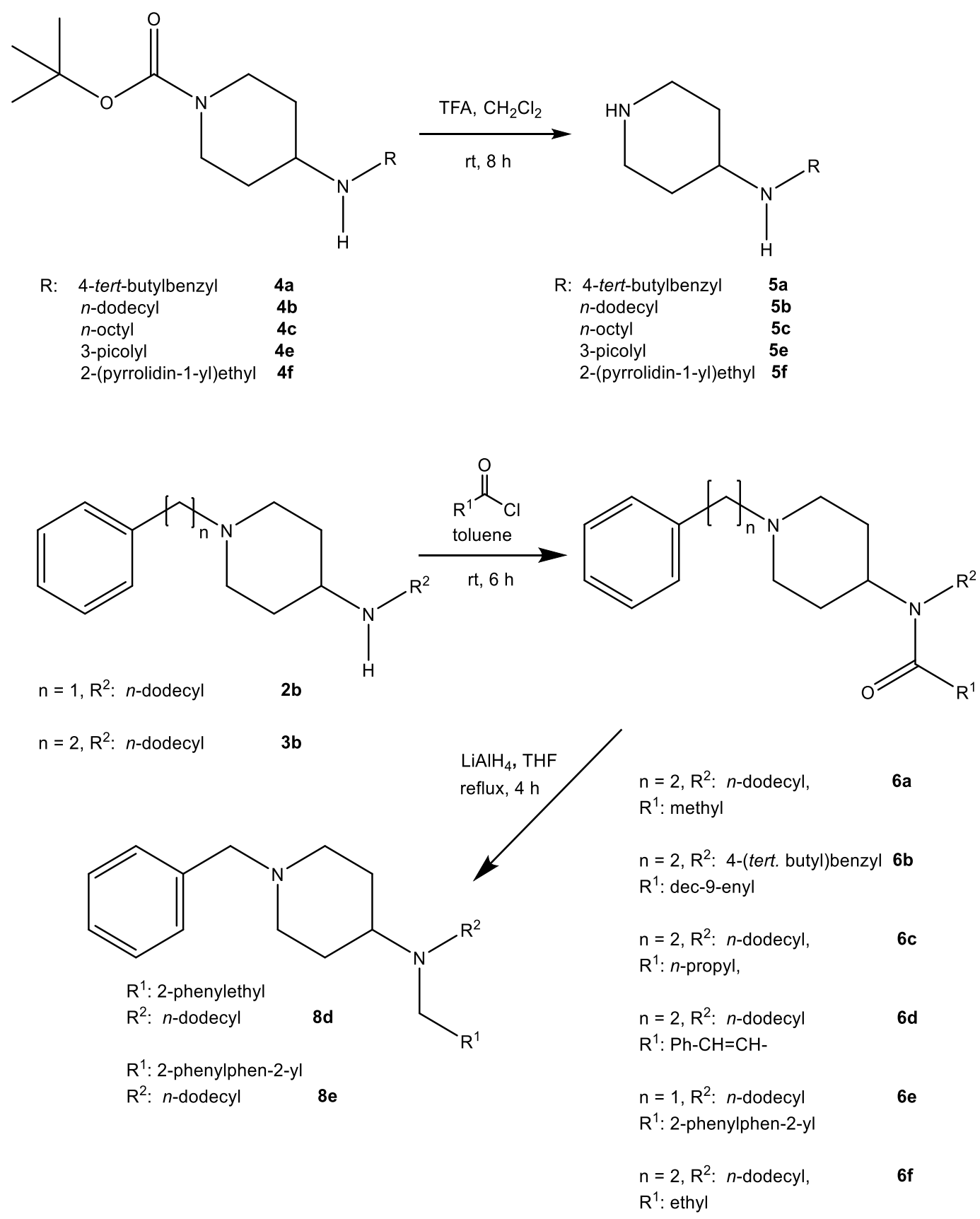

Scheme 2. Synthesis of compounds $5 \mathbf{a}-\mathbf{f}, \mathbf{6 a}-\mathbf{f}$, and $\mathbf{8 d}, \mathbf{e}$.

In order to investigate the importance of having two protonable nitrogen atoms in the molecules, the secondary amines $\mathbf{2} \mathbf{b}$ and $\mathbf{3 b}$ were reacted with diverse carboxylic acid chlorides (acetyl chloride, 10-undecenoyl chloride, butanoyl chloride, propanoyl chloride, cinnamoyl chloride, and 2-phenylbenzoyl chloride) to give the amides $\mathbf{6 a}-\mathbf{f}$. Notably, the amides $\mathbf{6} \mathbf{d}$ and $\mathbf{6 e}$ were reduced with $\mathrm{LiAlH}_{4}$ in THF to give the corresponding bulky tertiary amines $\mathbf{8 d}$ and $\mathbf{8 e}$. The alkene group of $\mathbf{6} \mathbf{d}$ was hydrogenated in the same reaction. 


\subsection{Biology \\ 2.2.1. Screening for In Vitro Antifungal Activity}

First, the antifungal activity (minimum inhibitory concentration, MIC) of the resulting compounds was evaluated in an in-house microdilution assay against the non-pathogenic yeast strain Yarrowia lipolytica (Supporting Information, Table S1). Furthermore, the compounds causing the highest growth inhibition in Y. lipolytica (and 6a, the acetamide derivative of $\mathbf{3 b}$ ) were subjected to an extended antifungal activity screening according to the standardized method of the European Committee of Antifungal Susceptibility Testing [23]. Commonly used antifungal agents (amorolfine, voriconazole, Figure 1) were used for comparison (Table 1).

Table 1. Antifungal activity ( $\mathrm{MIC}_{100}$ for Yarrowia lipolytica, $\mathrm{MIC}_{90}$ for molds, and $\mathrm{MIC}_{80}$ for yeasts) of six novel 4aminopiperidine derivatives, amorolfine hydrochloride (A), and voriconazole (V) against the model strain Y. lipolytica and clinically relevant fungal species; ()$=$ tested fungal isolates in total.

\begin{tabular}{|c|c|c|c|c|c|c|c|c|c|}
\hline \multirow{2}{*}{ Strain } & \multicolumn{9}{|c|}{ MIC Values $[\mu \mathrm{g} / \mathrm{mL}]$} \\
\hline & Compound & $\mathbf{A}$ & $\mathbf{V}$ & $2 b$ & $2 c$ & $3 b$ & $4 b$ & $5 b$ & $6 \mathbf{a}$ \\
\hline Model strain & Y. lipolytica (1) & 0.6 & 0.4 & 2 & 25 & 0.8 & 3 & 5 & 75 \\
\hline \multirow{3}{*}{ Aspergillus spp. } & A. flavus (1) & $>16$ & 0.25 & 16 & $>16$ & $4-8$ & 16 & 16 & $>16$ \\
\hline & A. fumigatus (2) & $>16$ & 0.125 & 8 & $>16$ & $2-8$ & 16 & 16 & $>16$ \\
\hline & A. terreus (2) & $8-16$ & 0.125 & $4-8$ & $8-16$ & $1-2$ & 8 & $4-8$ & $4-8$ \\
\hline \multirow{3}{*}{ Candida spp. } & C. auris (1) & 16 & $>16$ & 4 & 64 & $2-4$ & 16 & 8 & $>16$ \\
\hline & C. glabrata (1) & $>16$ & $>16$ & 4 & 32 & $1-4$ & $8-16$ & $4-8$ & $>16$ \\
\hline & C. krusei (5) & $1->16$ & $0.5->16$ & $2-4$ & $2-64$ & $1-4$ & $1-16$ & $4-8$ & $>16$ \\
\hline \multirow{7}{*}{$\begin{array}{l}\text { Mucor- } \\
\text { mycetes }\end{array}$} & A. elegans (1) & 16 & $>16$ & $>16$ & $>16$ & 8 & $>16$ & $>16$ & $>16$ \\
\hline & L. corymbifera (1) & 16 & $>16$ & $>16$ & $>16$ & $>16$ & $>16$ & $>16$ & 16 \\
\hline & L. ramosa (1) & 8 & 8 & 8 & $>16$ & 8 & 16 & 16 & $>16$ \\
\hline & M. circinelloides (1) & 16 & $>16$ & 16 & $>16$ & 4 & 16 & 16 & 16 \\
\hline & R. arrhizus (1) & 8 & 16 & 16 & $>16$ & 8 & $>16$ & 16 & $>16$ \\
\hline & R. microsporus (2) & 8 & 16 & 8 & $>16$ & 8 & 16 & 8 & 16 \\
\hline & S. racemosum (1) & 16 & $>16$ & $>16$ & $>16$ & $>16$ & $>16$ & $>16$ & 16 \\
\hline
\end{tabular}

The compounds $\mathbf{2} \mathbf{b}, \mathbf{3 b}, \mathbf{4} \mathbf{b}$, and $\mathbf{5 b}$ showed a complete growth inhibition $\left(\mathrm{MIC}_{100}\right)$ in the same range as the reference antifungals amorolfine hydrochloride and voriconazole against the model strain Yarrowia lipolytica. For clinically relevant species, complete growth inhibition $(80 \%$ or $90 \%)$ was observed in a species- and strain-dependent manner. The lowest minimal inhibitory concentration (MIC) values were determined for compound $\mathbf{3 b}$ against Candida spp. and Aspergillus spp. (MIC range $1-4 \mu \mathrm{g} / \mathrm{mL}$ for yeasts and $1-8 \mu \mathrm{g} / \mathrm{mL}$ for Aspergilli). In both groups, MIC values were significantly lower (min. 2 dilution steps) than for amorolfine hydrochloride. Similar reduction in MICs was observed for $\mathbf{2 b}$. Except for $A$. terreus, confrontation of spores with amide 6 a did not result in a complete growth inhibition for Aspergilli or Candida spp. at the concentrations tested. Similarly, no complete growth inhibition was detected for A. flavus and A. fumigatus for compound 2c. All other candidates efficiently inhibited growth in these groups. For the group of Mucormycetes, MICs were considerable higher than for the yeasts, in many strains not reaching $90 \%$ growth inhibition at the concentrations tested. Again, the lowest MICs were obtained for $3 \mathbf{b}$ against this group of fungi (MIC range $4->16 \mu \mathrm{g} / \mathrm{mL}$ ). As Mucormycetes exhibit high resistance to commonly used antifungals, having a compound at hand causing complete growth inhibition when applied on spores is a promising result [24].

A number of structure-activity relationships can be deduced from these screening results: Both a benzyl and a phenylethyl substituent at the piperidine nitrogen can lead to high antifungal activity (see compounds $\mathbf{2} \mathbf{b}$ and $\mathbf{3 b}$ ), as long as they are combined with $\mathrm{N}$-alkyl substituents with more than seven carbon atoms at the 4 -amino group. Shorter, branched, or cyclic alkyl residues at the 4-amino group are detrimental to activity; the 
same holds for most of the arylalkyl residues (except 4-tert-butylbenzyl in 2a). Outstanding antifungal activity was found for the $N$-dodecyl $\left(C_{12}\right)$ residue (see $\mathbf{2 b}$ and $\mathbf{3 b}$ ). In case this residue was attached to the 4-amino group, even compounds that are unsubstituted at the piperidine nitrogen $(5 \mathbf{b})$ or substituted with a Boc group there $(4 \mathbf{b})$ showed noteworthy activity. These findings for the $N$-dodecyl residue are in good accordance with SAR detected for antifungal $N$-alkyl perhydroisoquinolines [9] and $N$-alkyl perhydroquinolines [10], ergosterol biosynthesis inhibitors with amorolfine-like mode of action (inhibition of the enzymes sterol C14-reductase and/or sterol C8-isomerase).

Acylation of the secondary exocyclic amino group (6a-f, Supporting Information, Table S1) led to a virtually complete loss of antifungal activity; the same holds for the introduction of small (7a,b, Supporting Information, Table S1) or large residues there (8d/e, Supporting Information, Table S1).

\subsubsection{Evaluation of the Antifungal Activity of $\mathbf{2 b}$ and $\mathbf{3 b}$ on Clinical Isolates}

The compounds $\mathbf{2} \mathbf{b}$ and $\mathbf{3 b}$ showed the most promising growth-inhibiting activity on Aspergillus spp. and Candida spp. In the next step, we determined the antifungal activity on a greater collection of clinical isolates of Aspergillus spp. $(n=18)$ and Candida spp. $(n=19)$, to rule out strain specific differences in antifungal susceptibility (Table 2 ). In addition to MIC values, the minimal fungicidal concentrations (MFCs) were determined for selected Candida and Aspergillus isolates. MFCs are used to characterize the antifungal activity either into fungistatic or fungicidal. As seen before in the small set of strains, the MIC values for $\mathbf{2 b}$ and $\mathbf{3 b}$ were lower compared to those for amorolfine hydrochloride. In the case of C. krusei, the MIC values for amorolfine hydrochloride were highly variable between the individual isolates while they were consistent for the new substances. Compound $\mathbf{3 b}$ showed lower MICs than $\mathbf{2 b}$. For the Aspergillus spp., MICs could be defined for all strains ranging from $4 \mu \mathrm{g} / \mathrm{mL}$ to $16 \mu \mathrm{g} / \mathrm{mL}$, while no $\mathrm{MIC}_{90}$ was detected for amorolfine hydrochloride at the concentrations tested. Interestingly, while no MFC could be observed for any of the tested species for amorolfine hydrochloride, the new compounds led to a clearly defined MFC (Supporting Information, Figure S1), resulting in no growth/no colony-forming units (CFUs) at concentrations that resembled the MIC or were one dilution step higher than the MIC. These data indicate that contrary to amorolfine hydrochloride, the novel substances do exhibit fungicidal activity on selected Candida and Aspergillus isolates at concentrations that resemble the MIC, or only one dilution step higher. These data point to a higher antifungal activity of the novel compounds compared to the approved ergosterol biosynthesis inhibitor amorolfine hydrochloride. Rex et al. [25] have already pointed out in a review that MFCs might be the values more relevant to predict clinical outcome compared to solely MIC values.

Table 2. Antifungal activity of amorolfine hydrochloride (A), $\mathbf{2 b}$, and $\mathbf{3 b}$ against clinical isolates (Aspergillus and Candida species). MIC ranges represent the $\mathrm{MIC}_{90}$ values obtained for 6 Aspergillus isolates and the $\mathrm{MIC}_{80}$ values obtained for 6-7 isolates of each Candida species in all experiments. MFC ranges represent the MFCs determined for selected Aspergillus (1 per species) and Candida (1 isolate of C. albicans and C. tropicalis and 2 isolates of C. glabrata and C. krusei) isolates; ()$=$ tested fungal isolates in total. All experiments were carried out in duplicates.

\begin{tabular}{|c|c|c|c|c|c|c|c|}
\hline \multirow{2}{*}{ Strain } & \multirow[b]{2}{*}{ Compound } & \multicolumn{3}{|c|}{ MIC Ranges ( $\mu \mathrm{g} / \mathrm{mL})$} & \multicolumn{3}{|c|}{ MFC Ranges ( $\mu \mathrm{g} / \mathrm{mL})$} \\
\hline & & A & $2 b$ & $3 b$ & A & $2 b$ & $3 b$ \\
\hline \multirow{3}{*}{ Aspergillus spp. } & A. flavus (6) & $>16$ & $8-16$ & $8-16$ & $>16$ & 16 & 16 \\
\hline & A. fumigatus (6) & $>16$ & $8-16$ & $4-8$ & $>16$ & 16 & 16 \\
\hline & A. terreus (6) & $>16$ & $8-16$ & $4-16$ & $>16$ & 16 & 16 \\
\hline \multirow{4}{*}{ Candida spp. } & C. albicans (6) & $4-16$ & $4-8$ & $2-4$ & $>16$ & 8 & $4-8$ \\
\hline & C. glabrata (7) & $4->16$ & $4-8$ & $1-4$ & $>16$ & $4-8$ & $2-8$ \\
\hline & C. krusei (6) & $0.5->16$ & $2-4$ & $1-4$ & $16->16$ & $4-8$ & $2-4$ \\
\hline & C. tropicalis (6) & $8->16$ & $4-8$ & $2-4$ & $>16$ & 8 & 8 \\
\hline
\end{tabular}




\subsubsection{Evaluation of Toxicity in Human Cell Lines and an Alternative In Vivo Model}

In order to evaluate potential development of the compounds as antifungals applied in mammalian systems, toxicity tests were carried out with $\mathbf{2} \mathbf{b}$ and $\mathbf{3 b}$ on 3 different human cell lines in a standard proliferation assay [26]. For this purpose, we used HL-60 cells, HUVEC cells, and MCF10A. HUVEC cells are primary endothelial cells that are commonly used in research to assess cytotoxicity for the blood vessel system [27], MCF10A cells represent a healthy epithelial cell line that is frequently used in cytotoxicity studies [28], and HL-60 cells are used as an alternative to primary neutrophils and used to assess cytotoxicity for immune cells [29]. By combining cytotoxicity studies in these cell lines, we gained data on general toxicity of the compounds in human cells. The antifungals amorolfine hydrochloride (used as topical formulation), posaconazole, and voriconazole (both used for the treatment of invasive fungal infections) were used as reference drugs. The results are shown in Table 3.

Table 3. Cytotoxic activity of selected compounds against human cell lines. Cell viability was determined by MTT assay (HL-60) and CTB assay (HUVEC, MCF10A); mean $\mathrm{IC}_{50}$ values $(n=3)$ for amorolfine hydrochloride $(\mathbf{A})$, posaconazole $(\mathbf{P})$, and voriconazole $(\mathbf{V})$, and for the promising compounds $\mathbf{2 b}$ and $\mathbf{3 b}$ are shown.

\begin{tabular}{ccccccc}
\hline \multirow{2}{*}{ Cell Line } & \multicolumn{7}{c}{ IC $_{50}(\mu \mathbf{M}(\mu \mathrm{g} / \mathbf{m L}))$} \\
\cline { 2 - 6 } & Compound & $\mathbf{A}$ & $\mathbf{P}$ & $\mathbf{V}$ & $\mathbf{2 b}$ & $\mathbf{3 b}$ \\
\hline HL-60 & $17(6.0)$ & $5(3.5)$ & $>50(>17.5)$ & $7(2.5)$ & $4(1.5)$ \\
\hline HUVEC & $50(17.7)$ & $14(9.8)$ & $>50(>17.5)$ & $5(1.8)$ & $5(1.9)$ \\
\hline MCF10A & $>50(>17.7)$ & $22(15.4)$ & $>50(>17.5)$ & $6(2.1)$ & $7(2.6)$ \\
\hline
\end{tabular}

Compared to the reference drugs amorolfine hydrochloride and voriconazole, compounds $\mathbf{2} \mathbf{b}$ and $\mathbf{3 b}$ showed enhanced cytotoxicity. In HL-60 cells, the $\mathrm{IC}_{50}$ value for posaconazole was in the same range as compound $\mathbf{2} \mathbf{b}$ and $\mathbf{3 b}$.

Galleria mellonella larvae have been widely used as an alternative infection in vivo model for fungal diseases [30] and have also been utilized to study the in vivo activity and toxicity of commonly used or novel antimicrobial agents [31]. Therefore, the larval system was used to determine a potential impact on survival of larvae injected with three different doses of either compound $\mathbf{2} \mathbf{b}$ or $\mathbf{3 b}$; amorolfine hydrochloride was used for comparison. All dilutions were made in PBS, which served as negative control. The Kaplan Meyer curves (Figure 2) show that none of the compounds tested significantly reduced survival compared to PBS control (log rank test; $p<0.05$ ), indicating no toxic activity in this model system. These results are promising for the further testing of the in vivo activity of the new compounds in animal models. Nevertheless, the survival data presented do not give insight into the potential impact these compounds might have on the larval immune system, the stability of the compounds in the larval hemolymph, and their tissue availability [32]. Further assays are necessary to investigate in detail (a) whether the larval model is suitable to test the in vivo efficiency of these novel compounds, and (b) whether treatment leads to an increase in the survival of fungus-infected larvae. 

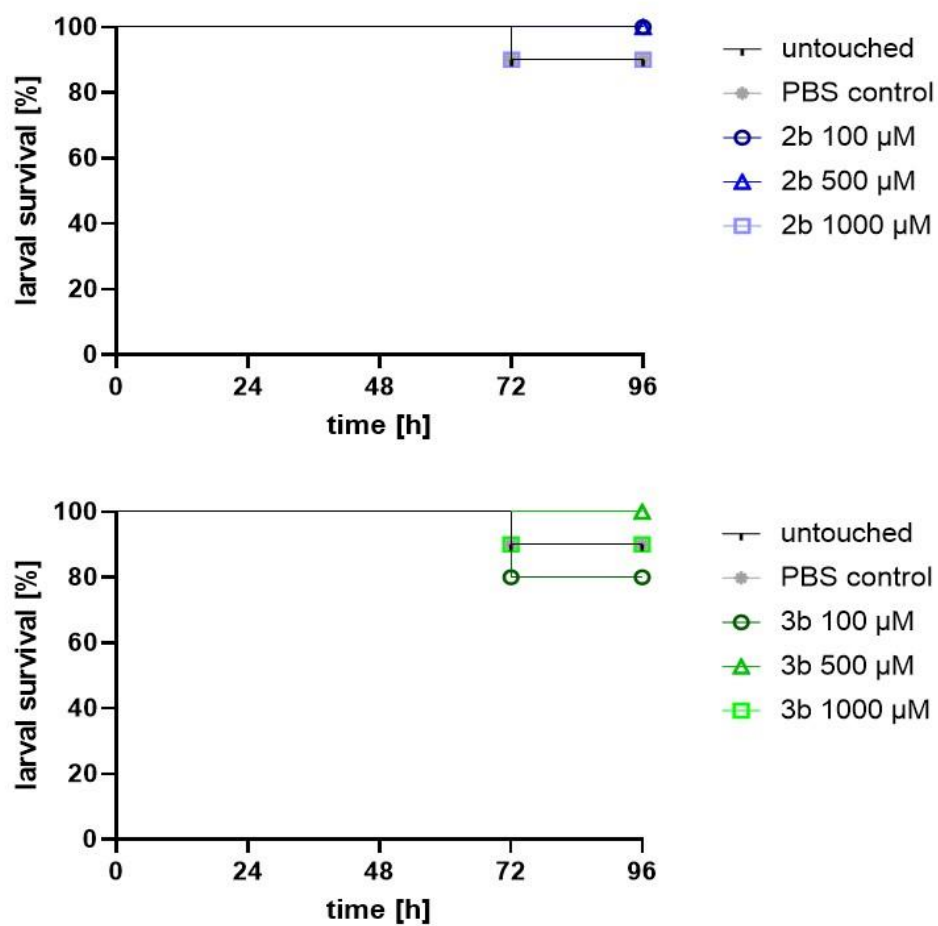

- untouched
- PBS control
- 3b $100 \mu \mathrm{M}$
$\triangle$ 3b $500 \mu \mathrm{M}$
- 3b $1000 \mu \mathrm{M}$

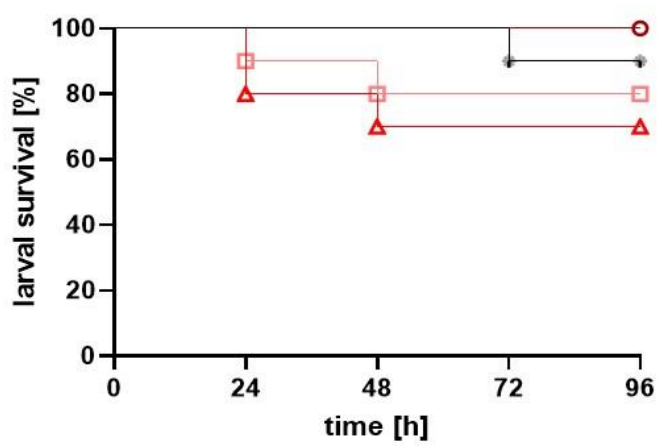

T untouched

* PBS control

- $\mathrm{A} 100 \mu \mathrm{M}$

$\triangle \mathrm{A} 500 \mu \mathrm{M}$

$\because \mathrm{A} 1000 \mu \mathrm{M}$

Figure 2. Impact of antifungal compounds $\mathbf{2} \mathbf{b}, \mathbf{3} \mathbf{b}$ and amorolfine hydrochloride (A) on the survival of Galleria mellonella larvae. The Kaplan Meyer curves represent average survival rates of 40 larvae per sample ( 2 independent experiments). Each larva was injected with $20 \mu \mathrm{L}$ of the respective antifungal solution, and dilutions were made in PBS. Untouched larvae and larvae injected with PBS served as controls. Test compound concentration was chosen according to MIC data: $100 \mu \mathrm{M}$ represents the MIC/g larvae for $\mathbf{2 b}$ and $\mathbf{3 b} ; 500 \mu \mathrm{M}$, the MIC for amorolfine hydrochloride; and $1000 \mu \mathrm{M} 10$-fold, the MIC of $\mathbf{2 b}$ and $\mathbf{3 b}$.

\subsubsection{Identification of Target Enzymes in Ergosterol and Cholesterol Biosynthesis}

The orienting tests for antifungal activity shown in Section 2.2.1 clearly indicated SAR related to those identified by us for antifungal $N$-alkyl perhydroisoquinolines [9] and $N$ alkyl perhydroquinolines [10] before. In the isoquinoline series, we found that even almost equipotent compounds can inhibit different target enzymes. In contrast to amorolfine and related $\mathrm{N}$-alkylmorpholines/-piperidines, which inhibit both sterol C8-iso-merase and sterol C14-reductase, these compounds were found to be inhibitors of either one or the other of these two enzymes. The $N$-alkyl perhydroquinolines, however, exclusively inhibit the enzyme sterol C8-isomerase. This prompted us to investigate the effect of the top compounds $\mathbf{2} \mathbf{b}$ and $\mathbf{3 b}$ from this investigation on the post-lanosterol part of ergosterol biosynthesis using a cellular assay [3]. 
In total, 15 different sterols were identified in A. fumigatus (mold), C. albicans (yeast), and C. glabrata (yeast) confronted with sublethal concentrations of amorolfine hydrochloride (A), $\mathbf{2} \mathbf{b}$ and $\mathbf{3 b}$ (Table 4). To calibrate target identification, we used the well-established antifungal amorolfine hydrochloride. Under amorolfine treatment, a more than 10 -fold accumulation of ergosta-8,14,24(28)-trien-3 $\beta$-ol, ergosta-5,8,24(28)-trien-3 $\beta$-ol, and ergosta8,24(28)-dien-3 $\beta$-ol was detected compared to the control sample in all strains. An accumulation of ergosta-8,14,24(28)-trien-3 $\beta$-ol indicates an inhibition of the enzyme sterol C14-reductase, and an accumulation of ergosta-5,8,24(28)-trien-3 $\beta$-ol and ergosta-8,24(28)dien-3 3 -ol indicates an inhibition of sterol C8-isomerase [3,4]. As expected, the mode of action of amorolfine is a dual inhibition of sterol C14-reductase and sterol C8-isomerase. Although there was no accumulation of lichesterol (ergosta-5,8,22-trien-3 $\beta$-ol), the marker sterol for sterol C8-isomerase [3], this is due to the additional upstream enzyme inhibition of sterol C14-reductase, which leads to an accumulation of sterols with a remaining double bond at C14/15. The appearance of hydroxyfecosterol in both yeast strains can be explained by inhibition or improper working of sterol C8-isomerase similar to the appearance of 14-methylergosta-8,24(28)-dien-3 $\beta, 6 \alpha$-diol under azole treatment $[3,4,33,34]$.

Table 4. Identification of the target enzyme(s) in ergosterol biosynthesis. Heatmap of the detected sterols. The relative sterol amount has been normalized to that of untreated samples [33]. Red: marker sterols according to Müller et al. [3]; boxes in red colour $>10$-fold change, in blue colour no changes were observed, and in purple colour $<0.1$-fold change. A, amorolfine hydrochloride; n.d., not detected; (), trivial name; ?, unknown position of the second hydroxy group. Test concentrations: Aspergillus fumigatus: amorolfine hydrochloride $(4.0 \mu \mathrm{g} / \mathrm{mL}), \mathbf{2 b}(3.5 \mu \mathrm{g} / \mathrm{mL}), \mathbf{3 b}(4 \mu \mathrm{g} / \mathrm{mL})$; Candida albicans: amorolfine $(4.0 \mu \mathrm{g} / \mathrm{mL}), \mathbf{2 b}(3.5 \mu \mathrm{g} / \mathrm{mL}), \mathbf{3 b}(4.0 \mu \mathrm{g} / \mathrm{mL})$; Candida glabrata: amorolfine hydrochloride $(7.5 \mu \mathrm{g} / \mathrm{mL}), \mathbf{2 b}(3.5 \mu \mathrm{g} / \mathrm{mL}), \mathbf{3 b}$ $(4.0 \mu \mathrm{g} / \mathrm{mL})$.

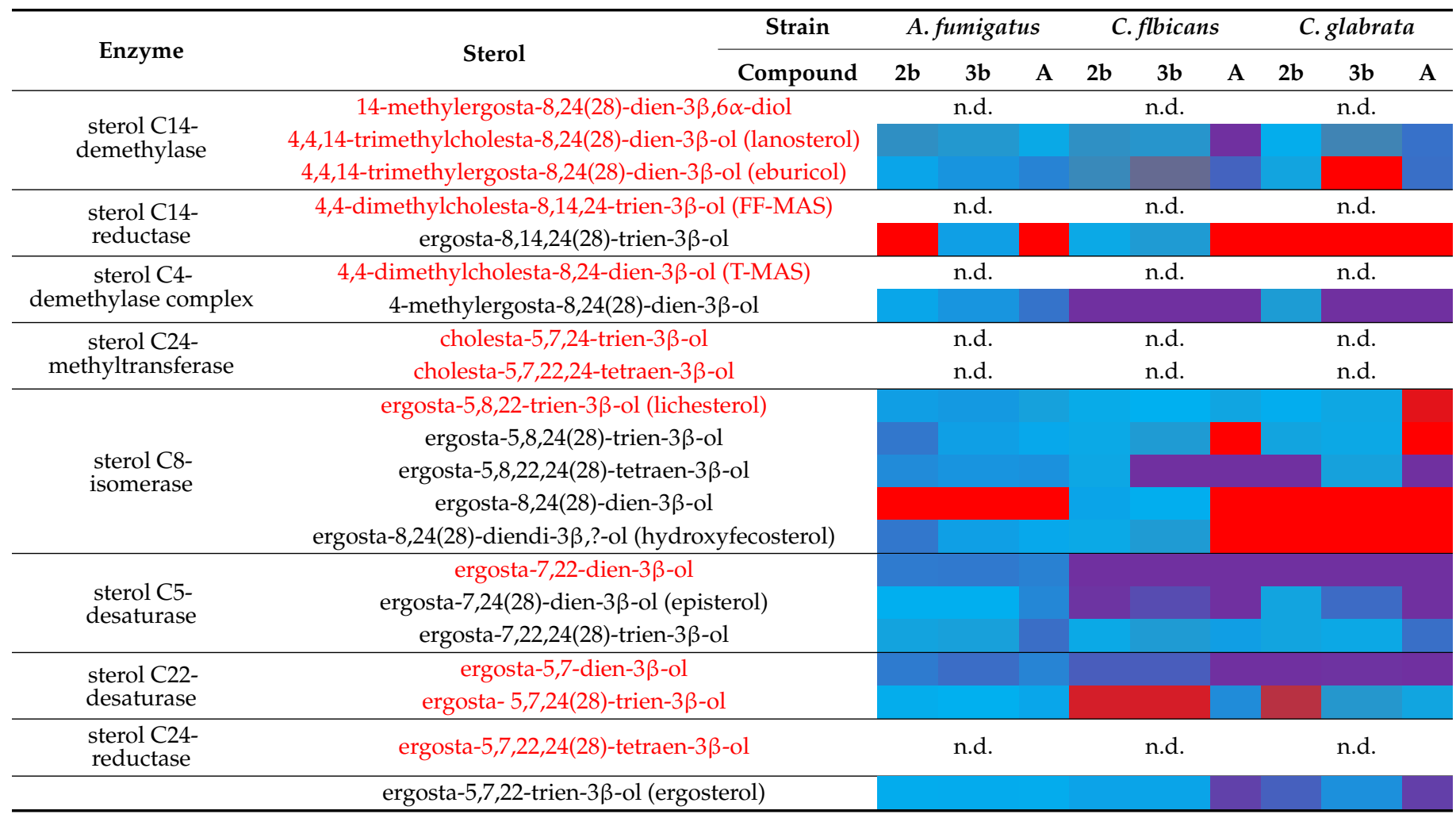

Compound $\mathbf{2 b}$ showed a similar sterol pattern in A. fumigatus and C. glabrata as amorolfine, indicating a similar mode of action. In C. albicans, the low MIC values (Table 2) cannot fully be explained by a moderate accumulation (less than ten-fold) of ergosta5,7,24(28)-trien-3 $\beta$-ol, which is a marker sterol for inhibition of sterol C5-desaturase [3]. There was no hint for inhibition of the enzyme sterol C14-reductase or the enzyme sterol 
C8-isomerase in this yeast. Compound $\mathbf{3 b}$ showed similar results as $\mathbf{2 b}$ in C. albicans. A dual inhibition of sterol C14-reductase and sterol C8-isomerase was only detected in $C$. glabrata. In A. fumigatus, an accumulation of ergosta-8,24(28)-dien-3 $\beta$-ol was detected, which indicates inhibition of sterol C8-isomerase.

Since ergosterol biosynthesis in fungi and cholesterol biosynthesis in humans are very similar and share numerous closely related enzymes, we investigated the effects of these compounds on cholesterol biosynthesis in a cellular assay [35] as well.

In the cholesterol biosynthesis assay, we investigated, in addition to the most active compounds $\mathbf{2 b} / \mathbf{3 b}$ (Table 5), a number of additional compounds $(2 \mathbf{c}, \mathbf{2 f}, \mathbf{2 g}, \mathbf{3 c}, \mathbf{4 b}, \mathbf{4 c}$, $5 \mathbf{b}$, and $\mathbf{6 b}$; see Supporting Information, Table S2) from this library in order to get a first insight into SAR on this alternative target as well. Not unexpectedly, most of the compounds showed impact on enzymes of the post-lanosterol part of this biosynthesis, with multi-enzyme inhibition dominating at higher concentrations and inhibition of both sterol C8-isomerase and sterol C14-reductase at lower concentrations. The analysis of the sterol pattern of the reference inhibitor amorolfine hydrochloride (Table S2) showed only an accumulation of cholesta-8,14-dien-3 $\beta$-ol, which indicates inhibition of sterol C14-reductase and sterol C8-isomerase at every test level $(0.1 \mu \mathrm{M}, 1 \mu \mathrm{M}, 10 \mu \mathrm{M})$. Antifungal compound $\mathbf{2 b}$ (Table 5) as well as $\mathbf{2 f}$ (Supporting Information, Table S2) showed inhibition of sterol C8-isomerase and sterol C14-reductase at $0.1 \mu \mathrm{M}$, and a multi-enzyme inhibition at higher concentrations. The other strong antifungal compound, $\mathbf{3} \mathbf{b}$ (Table 5), was identified as a multi-enzyme inhibitor at $1 \mu \mathrm{M}$ (inactive at $0.1 \mu \mathrm{M}$, toxic at $10 \mu \mathrm{M}$ ). Only compound 4c (Supporting Information, Table S2) was selective for sterol C14-reductase and sterol C8-isomerase at $1 \mu \mathrm{M}$ and $10 \mu \mathrm{M}$ (inactive at $0.1 \mu \mathrm{M}$ ). Notably, compound $2 \mathrm{~g}$ did not show any effect on cholesterol biosynthesis.

Table 5. Identification of the target enzyme(s) of compounds $\mathbf{2} \mathbf{b}$ and $\mathbf{3 b}$ in cholesterol biosynthesis on HL-60 cells. Mainly accumulating sterols under incubation and identified target enzymes. (), trivial name; n.d., not determined [35].

\begin{tabular}{|c|c|c|}
\hline Compound & Mainly Accumulating Sterol(s) & Inhibited Enzyme(s) \\
\hline $2 b$ & 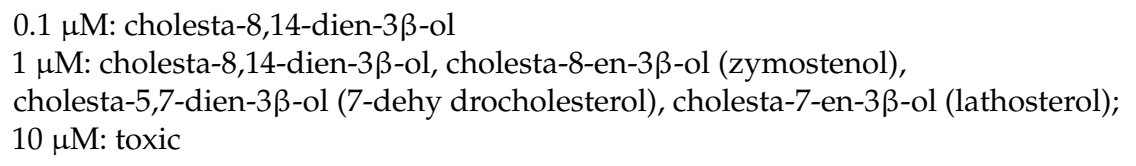 & $\begin{array}{l}0.1 \mu \mathrm{M} \text { : sterol C14-reductase, } \\
\text { sterol C8-isomerase } \\
1 \mu \mathrm{M} \text { : multi-enzyme inhibition } \\
10 \mu \mathrm{M}: \text { n.d. }\end{array}$ \\
\hline $3 b$ & $\begin{array}{l}0.1 \mu \mathrm{M} \text { : no accumulation; } \\
1 \mu \mathrm{M} \text { : cholesta-8,14-dien-3 } \beta \text {-ol, cholesta-8-en-3 } \beta \text {-ol (zymostenol), } \\
\text { cholesta-5,7-dien-3 } \beta \text {-ol (7-dehydrocholesterol), cholesta-7-en-3 } \beta \text {-ol (lathosterol); } \\
10 \mu \mathrm{M} \text { : toxic }\end{array}$ & $\begin{array}{l}0.1 \mu \mathrm{M}: \text { n.d. } \\
1 \mu \mathrm{M}: \text { multi-enzyme inhibition } \\
10 \mu \mathrm{M}: \text { n.d. }\end{array}$ \\
\hline
\end{tabular}

\section{Conclusions}

A library of more than 30 novel 4-aminopiperidines was prepared by reductive amination of 4-piperidone derivatives with a broad variety of aliphatic amines. A screening on the model yeast Yarrowia lipolytica disclosed that compounds $\mathbf{2} \mathbf{b}$ and $\mathbf{3 b}$ are almost equipotent to established antifungals. In tests on clinically relevant species (Candida spp., Aspergillus spp., Mucormycetes), compounds $\mathbf{2} \mathbf{b}$ and $\mathbf{3 b}$ favourably compared with the approved antifungals amorolfine and voriconazole. Analysis of SAR revealed that the combination of a benzyl or phenylethyl residue at the piperidine nitrogen with an $n$-dodecyl residue at the 4-amino group is most beneficial to enhance antifungal activity. The two top compounds $\mathbf{2} \mathbf{b}$ and $\mathbf{3 b}$ are, as expected, inhibitors of the fungal ergosterol biosynthesis enzymes sterol C14-reductase and sterol C8-isomerase. However, additional molecular targets cannot be excluded. Determination of MIC values and minimal fungicidal concentrations (MFCs) for selected Candida and Aspergillus isolates revealed that, contrary to amorolfine, the novel substances do exhibit fungicidal activity. Antifungal activity was further determined on a greater collection of clinical isolates of Aspergillus spp. and Candida spp., and here $3 \mathbf{b}$ was clearly superior to amorolfine. The top compounds $\mathbf{2} \mathbf{b}$ and $\mathbf{3 b}$ exhibit cytotoxicity on 
human cell lines, but not on the Galleria mellonella larvae in an alternative (more complex) test system. The moderate cytotoxicity on human cell lines can in part be explained by inhibition of cholesterol biosynthesis. This aspect needs deeper investigation in the future if these or related compounds are considered for further development.

The 4-aminopiperidine core has been identified as an interesting lead structure for development of novel antifungals. It might be the basis for the development of antifungals targeting (at least among others) ergosterol biosynthesis. Due to the easy availability starting from cheap building blocks, application as agrofungicides might be considered as well.

\section{Experimental}

\subsection{Chemistry \\ 4.1.1. General}

All solvents used were of HPLC grade or p.a. grade and/or purified according to standard procedures. Chemical reagents were purchased from Sigma Aldrich (Schnelldorf, Germany) and Acros (Geel, Belgium). IR spectra: Jasco (Pfungstadt, Germany) FT/IR 4600 series (KBr pellet method or ATR Zn/Se); MS: Hewlett Packard MS-Engine (Agilent, Santa Clara, CA, USA), electron ionization (EI) $70 \mathrm{eV}$, chemical ionization (CI) with $\mathrm{CH}_{4}$ $(300 \mathrm{eV})$; MS spectra: Thermo Q Exactive GC Orbitrap or Finnigan MAT 95 spectrometer; HR-ESI-MS spectra: Thermo Finnigan LTQ FT; NMR: Avance III HD 400 MHz Bruker BioSpin ( $\left.{ }^{1} \mathrm{H}: 400 \mathrm{MHz},{ }^{13} \mathrm{C}: 100 \mathrm{MHz}\right) ; 500 \mathrm{MHz}$ Avance III HD $500 \mathrm{MHz}$ Bruker BioSpin $\left({ }^{1} \mathrm{H}: 500 \mathrm{MHz},{ }^{13} \mathrm{C}: 125 \mathrm{MHz}\right.$ ); melting points: Büchi Melting Point B-540 (not corrected; Büchi Labortechnik GmbH, Essen, Germany); flash column chromatography (FCC): silica gel 60 (230-400 mesh, E. Merck, Darmstadt); polarimeter: Perkin Elmer 241 (Perkin Elmer, Rodgau, Germany).

\section{General Procedure 1 (Reductive Amination)}

In total, $1.0 \mathrm{mmol}$ of the ketone and $1.5 \mathrm{mmol}$ of the amine were dissolved in $20 \mathrm{~mL}$ dry THF, and $2.0 \mathrm{mmol}$ sodium triacetoxyborohydride was added. The suspension was stirred at room temperature for $12 \mathrm{~h}$. Then, $20 \mathrm{~mL}$ of a saturated aqueous $\mathrm{NaHCO}_{3}$ solution was added and the mixture was extracted with ethyl acetate $(3 \times 20 \mathrm{~mL})$. The combined organic layers were dried over $\mathrm{Na}_{2} \mathrm{SO}_{4}$ and the solvent was evaporated. The residue was purified by flash column chromatography (ethyl acetate:triethylamine 10:1).

General Procedure 2 (Cleavage of Boc-Protecting Group)

The Boc-protected amine $(1.0 \mathrm{mmol})$ was dissolved in $20 \mathrm{~mL}$ dichloromethane, and $10 \mathrm{~mL}$ trifluoroacetic acid was added. The solution was stirred at room temperature for $8 \mathrm{~h}$ and then $20 \mathrm{~mL} \mathrm{10 \%} \mathrm{aqueous} \mathrm{sodium} \mathrm{hydroxide} \mathrm{solution} \mathrm{was} \mathrm{added.} \mathrm{The} \mathrm{mixture} \mathrm{was}$ extracted with dichloromethane $(3 \times 20 \mathrm{~mL})$ and the combined organic layers were dried over $\mathrm{Na}_{2} \mathrm{SO}_{4}$. The solvent was evaporated and the residue was purified by flash column chromatography (ethyl acetate:triethylamine 10:1) [10].

General Procedure 3 (Synthesis of Amides)

In total, $1.0 \mathrm{mmol}$ of the amine was dissolved in $20 \mathrm{~mL}$ toluene and $1.2 \mathrm{mmol}$ of the acid chloride was added. After addition of $3.0 \mathrm{~mL}$ triethylamine, the mixture was stirred at room temperature for $6 \mathrm{~h}$. The solvent was evaporated and the residue was dissolved in $20 \mathrm{~mL}$ $2 \mathrm{M}$ aqueous sodium hydroxide solution and extracted with ethyl acetate $(3 \times 20 \mathrm{~mL})$. The combined organic layers were dried over $\mathrm{Na}_{2} \mathrm{SO}_{4}$ and the solvent was evaporated. The residue was purified by flash column chromatography (ethyl acetate:triethylamine 10:1).

1-Benzyl-N-(4-(tert-butyl)benzyl)piperidin-4-amine (2a): The compound was prepared according to general procedure 1 from $568 \mathrm{mg}$ ( $3.0 \mathrm{mmol}$ ) 1-benzyl-4-piperidone, $734 \mathrm{mg}$ ( $4.5 \mathrm{mmol})$ 4-tert-butylbenzylamine, and $1.34 \mathrm{~g}(6.0 \mathrm{mmol})$ sodium triacetoxyborohydride to give $707 \mathrm{mg}(70 \%)$ of $\mathbf{2 a}$ as a colourless oil. ${ }^{1} \mathrm{H}-\mathrm{NMR}\left(400 \mathrm{MHz}\right.$, dichloromethane- $\left.d_{2}\right)$

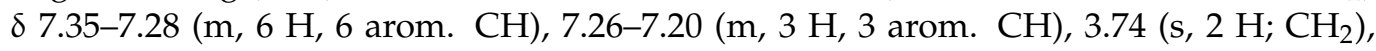


$3.46\left(\mathrm{~s}, 2 \mathrm{H}, \mathrm{CH}_{2}\right), 2.85-2.73\left(\mathrm{~m}, 2 \mathrm{H}, 2 \mathrm{CH}_{2}\right), 2.56-2.44(\mathrm{~m}, 1 \mathrm{H}, \mathrm{CH}), 2.07-1.96(\mathrm{~m}, 2 \mathrm{H}$, $\left.2 \mathrm{CH}_{2}\right), 1.89-1.80\left(\mathrm{~m}, 2 \mathrm{H}, 2 \mathrm{CH}_{2}\right), 1.48-1.24\left(\mathrm{~m}, 2 \mathrm{H}, 2 \mathrm{CH}_{2}\right), 1.30\left(\mathrm{~s}, 9 \mathrm{H}, 3 \mathrm{CH}_{3}\right) .{ }^{13} \mathrm{C}-\mathrm{NMR}$ $\left(100 \mathrm{MHz}\right.$, dichloromethane- $\left.d_{2}\right) \delta 150.91$ (quat. C), 140.47 (quat. C), 139.55 (quat. C), 130.27 (2 arom. CH), 129.36 (2 arom. CH), 128.97 (2 arom. CH), 128.05 (arom. CH), 126.44 (2 arom. $\mathrm{CH}), 64.31\left(\mathrm{CH}_{2}\right), 55.68(\mathrm{CH}), 53.70\left(\mathrm{CH}_{2}\right), 51.68\left(2 \mathrm{CH}_{2}\right), 35.61$ (quat. C), $34.18\left(2 \mathrm{CH}_{2}\right)$, $32.44\left(3 \mathrm{CH}_{3}\right)$. IR $(\mathrm{KBr}) \vee\left(\mathrm{cm}^{-1}\right)=2956,2867,2800,1455,1363,1268,1111,819,791,737$, 698. MS (EI): m/z: 336 (M+, 2), 245 (5), 189 (37), 173 (65), 91 (100). HRMS (EI) calcd. for $\mathrm{C}_{23} \mathrm{H}_{32} \mathrm{~N}_{2}$ : 336.2567. Found: 336.2561.

1-Benzyl-N-dodecylpiperidin-4-amine (2b): The compound was prepared according general procedure 1 from $568 \mathrm{mg}$ (3.0 mmol) 1-benzyl-4-piperidone, $834 \mathrm{mg}$ (4.5 mmol) ndodecylamine and $1.34 \mathrm{~g}(6.0 \mathrm{mmol})$ sodium triacetoxyborohydride to give $699 \mathrm{mg}(65 \%)$ of $\mathbf{2} \mathbf{b}$ as a colourless oil. ${ }^{1} \mathrm{H}-\mathrm{NMR}\left(400 \mathrm{MHz}\right.$, dichloromethane- $\left.d_{2}\right) \delta 7.34-7.14(\mathrm{~m}, 5 \mathrm{H}, 5$ arom. $\mathrm{CH}), 3.45\left(\mathrm{~s}, 2 \mathrm{H}, \mathrm{CH}_{2}\right), 2.84-2.75\left(\mathrm{~m}, 2 \mathrm{H}, 2 \mathrm{CH}_{2}\right), 2.57\left(\mathrm{t}, J=7.0 \mathrm{~Hz}, 2 \mathrm{H}, \mathrm{CH}_{2}\right)$, $2.42(\mathrm{tt}, J=10.5,4.1 \mathrm{~Hz}, 1 \mathrm{H}, \mathrm{CH}), 1.99\left(\mathrm{td}, J=11.7,2.3 \mathrm{~Hz}, 2 \mathrm{H}, \mathrm{CH}_{2}\right), 1.85-1.74(\mathrm{~m}, 2 \mathrm{H}$, $\left.2 \mathrm{CH}_{2}\right), 1.48-1.37\left(\mathrm{~m}, 2 \mathrm{H}, \mathrm{CH}_{2}\right), 1.34-1.20\left(\mathrm{~m}, 20 \mathrm{H}, 10 \mathrm{CH}_{2}\right), 0.87\left(\mathrm{t}, \mathrm{J}=6.9 \mathrm{~Hz}, 3 \mathrm{H}, \mathrm{CH}_{3}\right)$. ${ }^{13} \mathrm{C}-\mathrm{NMR}\left(100 \mathrm{MHz}\right.$, dichloromethane- $\left.d_{2}\right) \delta 140.41$ (quat. C), 130.28 (2 arom. $\left.\mathrm{CH}\right), 129.36$ (2 arom. CH), 128.07 (arom. $\mathrm{CH}), 64.28\left(\mathrm{CH}_{2}\right), 56.35(\mathrm{CH}), 53.77\left(2 \mathrm{CH}_{2}\right), 48.00\left(\mathrm{CH}_{2}\right), 33.95$ $\left(2 \mathrm{CH}_{2}\right), 33.24\left(\mathrm{CH}_{2}\right), 31.55\left(\mathrm{CH}_{2}\right), 30.99\left(\mathrm{CH}_{2}\right), 30.96\left(3 \mathrm{CH}_{2}\right), 30.90\left(\mathrm{CH}_{2}\right), 30.67\left(\mathrm{CH}_{2}\right)$, $28.73\left(\mathrm{CH}_{2}\right), 24.01\left(\mathrm{CH}_{2}\right), 15.20\left(\mathrm{CH}_{3}\right) . \mathrm{IR}(\mathrm{KBr}) \vee\left(\mathrm{cm}^{-1}\right)=2915,2849,2797,1469,1453$, 1365, 1345, 1125, 1112, 792, 736, 727, 716, 694. MS (EI) m/z: 358 (M+ 2), 267 (22), 173 (100), 91 (70). HRMS (EI) calcd. for $\mathrm{C}_{24} \mathrm{H}_{42} \mathrm{~N}_{2}$ : 358.3348. Found: 358.3345.

1-Benzyl-N-octylpiperidin-4-amine (2c): The compound was prepared according to general procedure 1 from $568 \mathrm{mg}$ (3.0 mmol) 1-benzyl-4-piperidone, $581 \mathrm{mg}$ (4.5 mmol) noctylamine and $1.34 \mathrm{~g}(6.0 \mathrm{mmol})$ sodium triacetoxyborohydride to give $544 \mathrm{mg}(60 \%)$ of 2c as a colourless oil. ${ }^{1} \mathrm{H}-\mathrm{NMR}(500 \mathrm{MHz}$, chloroform- $d) \delta 7.28-7.21$ (m, $4 \mathrm{H}, 4$ arom. CH), 7.18-7.14 (m, $1 \mathrm{H}$, arom. CH), $3.42\left(\mathrm{~s}, 2 \mathrm{H}, \mathrm{CH}_{2}\right), 2.84-2.67\left(\mathrm{~m}, 2 \mathrm{H}, 2 \mathrm{CH}_{2}\right), 2.52(\mathrm{t}, \mathrm{J}=7.3 \mathrm{~Hz}$, $\left.2 \mathrm{H}, \mathrm{CH}_{2}\right), 2.36(\mathrm{dt}, J=10.6,6.6 \mathrm{~Hz}, 1 \mathrm{H}, \mathrm{CH}), 1.99-1.85\left(\mathrm{~m}, 2 \mathrm{H}, 2 \mathrm{CH}_{2}\right), 1.83-1.69(\mathrm{~m}, 2 \mathrm{H}$, $\left.2 \mathrm{CH}_{2}\right), 1.44-1.35\left(\mathrm{~m}, 2 \mathrm{H}, 2 \mathrm{CH}_{2}\right), 1.35-1.26\left(\mathrm{~m}, 2 \mathrm{H}, \mathrm{CH}_{2}\right), 1.26-1.14\left(\mathrm{~m}, 10 \mathrm{H}, 5 \mathrm{CH}_{2}\right), 0.81$ $\left(\mathrm{t}, J=6.9 \mathrm{~Hz}, 3 \mathrm{H}, \mathrm{CH}_{3}\right)$. MS (EI) m/z = $302\left(\mathrm{M}^{+}, 3\right), 211$ (20), 173 (100), 146 (16), 91 (88). ${ }^{13} \mathrm{C}-\mathrm{NMR}(100 \mathrm{MHz}$, chloroform-d) $\delta 138.67$ (quat. C), 129.08 (2 arom. CH), 128.13 (2 arom. $\mathrm{CH}), 126.87$ (arom. $\mathrm{CH}), 63.10\left(\mathrm{CH}_{2}\right), 55.07(\mathrm{CH}), 52.57\left(2 \mathrm{CH}_{2}\right), 46.92\left(\mathrm{CH}_{2}\right), 32.90\left(2 \mathrm{CH}_{2}\right)$, $31.84\left(\mathrm{CH}_{2}\right), 30.51\left(\mathrm{CH}_{2}\right), 29.54\left(\mathrm{CH}_{2}\right), 29.28\left(\mathrm{CH}_{2}\right), 27.46\left(\mathrm{CH}_{2}\right), 22.67\left(\mathrm{CH}_{2}\right), 14.11\left(\mathrm{CH}_{3}\right)$. $\mathrm{IR}(\mathrm{KBr}) \vee\left(\mathrm{cm}^{-1}\right)=2924,2853,2799,1466,1454,1365,1119,792,735,697$. MS (EI) m/z: 300 $\left(\mathrm{M}^{+}, 0.2\right), 299$ (1), 211 (13), 173 (100), 158 (26), 146 (14), 91 (72), 82 (20). HRMS (EI) calcd. for $\mathrm{C}_{20} \mathrm{H}_{32} \mathrm{~N}_{2}\left(\mathrm{M}^{+}-2\right): 300.2566$. Found: 300.2514.

1-Benzyl-N-isobutylpiperidin-4-amine (2d): The compound was prepared according to general procedure 1 from $568 \mathrm{mg}$ ( $3.0 \mathrm{mmol})$ 1-benzyl-4-piperidone, $329 \mathrm{mg}$ (4.5 mmol) isobutylamine and $1.34 \mathrm{~g}(6.0 \mathrm{mmol})$ sodium triacetoxyborohydride to give $502 \mathrm{mg}(68 \%)$ of $2 \mathrm{~d}$ as a colourless oil. ${ }^{1} \mathrm{H}-\mathrm{NMR}(400 \mathrm{MHz}$, chloroform- $d) \delta 7.29-7.06(\mathrm{~m}, 5 \mathrm{H}, 5$ arom. CH), 3.42 (s, $\left.2 \mathrm{H}, \mathrm{CH}_{2}\right), 2.85-2.67\left(\mathrm{~m}, 2 \mathrm{H}, \mathrm{CH}_{2}\right), 2.39-2.29(\mathrm{~m}, 1 \mathrm{H}, \mathrm{CH}), 2.35$ (d, J = 6.8 Hz, $2 \mathrm{H}$, $\left.\mathrm{CH}_{2}\right), 1.99-1.89\left(\mathrm{~m}, 2 \mathrm{H}, \mathrm{CH}_{2}\right), 1.82-1.72\left(\mathrm{~m}, 2 \mathrm{H}, \mathrm{CH}_{2}\right), 1.63$ (hept, $J=6.7 \mathrm{~Hz}, 1 \mathrm{H}, \mathrm{CH}$ ), $1.31\left(\mathrm{qd}, J=11.4,3.5 \mathrm{~Hz}, 2 \mathrm{H}, \mathrm{CH}_{2}\right), 0.83\left(\mathrm{~d}, J=6.6 \mathrm{~Hz}, 6 \mathrm{H}, 2 \mathrm{CH}_{3}\right) .{ }^{13} \mathrm{C}-\mathrm{NMR}(100 \mathrm{MHz}$, chloroform-d) $\delta 138.65$ (quat. C), 129.10 (2 arom. CH), 128.14 (2 arom. CH), 126.89 (arom. $\mathrm{CH}), 63.10\left(\mathrm{CH}_{2}\right), 55.03(\mathrm{CH}), 54.90\left(2 \mathrm{CH}_{2}\right), 52.55\left(\mathrm{CH}_{2}\right), 32.86\left(2 \mathrm{CH}_{2}\right), 28.57(\mathrm{CH}), 20.76$ $\left(2 \mathrm{CH}_{3}\right) . \mathrm{IR}(\mathrm{KBr}) \vee\left(\mathrm{cm}^{-1}\right)=2948,2935,2799,1467,1454,1365,1117,979,791 . \mathrm{MS}(\mathrm{EI}) \mathrm{m} / z$ : $246\left(\mathrm{M}^{+}, 4\right), 173(73), 146(27), 91$ (100), 82 (16). HRMS (EI) calcd. for $\mathrm{C}_{13} \mathrm{H}_{19} \mathrm{~N}_{2}\left(\mathrm{M}^{+}-\mathrm{C}_{3} \mathrm{H}_{7}\right)$ : 203.1548. Found: 203.1516 .

1-Benzyl-N-hexylpiperidin-4-amine (2e): The compound was prepared according to general procedure 1 from $568 \mathrm{mg}$ (3.0 mmol) 1-benzyl-4-piperidone, $455 \mathrm{mg}$ (4.5 mmol) nhexylamine and $1.34 \mathrm{~g}(6.0 \mathrm{mmol})$ sodium triacetoxyborohydride to give $584 \mathrm{mg}(71 \%)$ of $2 \mathbf{e}$ as a colourless oil. ${ }^{1} \mathrm{H}-\mathrm{NMR}(500 \mathrm{MHz}$, chloroform- $d) \delta 7.27-7.22(\mathrm{~m}, 4 \mathrm{H}, 4$ arom. $\mathrm{CH}), 7.19-7.14\left(\mathrm{~m}, 1 \mathrm{H}\right.$, arom. CH), $3.42\left(\mathrm{~s}, 2 \mathrm{H}, \mathrm{CH}_{2}\right), 2.82-2.73\left(\mathrm{~m}, 2 \mathrm{H}, 2 \mathrm{CH}_{2}\right), 2.53(\mathrm{t}$, $\left.J=7.2 \mathrm{~Hz}, 2 \mathrm{H}, \mathrm{CH}_{2}\right), 2.36(\mathrm{tt}, J=10.5,4.1 \mathrm{~Hz}, 1 \mathrm{H}, \mathrm{CH}), 1.94\left(\mathrm{td}, J=11.7,2.3 \mathrm{~Hz}, 2 \mathrm{H}, 2 \mathrm{CH}_{2}\right)$, 
1.83-1.69 (m, $\left.2 \mathrm{H}, 2 \mathrm{CH}_{2}\right), 1.43-1.36\left(\mathrm{~m}, 2 \mathrm{H}, \mathrm{CH}_{2}\right), 1.35-1.28\left(\mathrm{~m}, 2 \mathrm{H}, 2 \mathrm{CH}_{2}\right), 1.26-1.16(\mathrm{~m}$, $\left.6 \mathrm{H}, 3 \mathrm{CH}_{2}\right), 0.81\left(\mathrm{t}, J=6.9 \mathrm{~Hz}, 3 \mathrm{H}, \mathrm{CH}_{3}\right) .{ }^{13} \mathrm{C}-\mathrm{NMR}(100 \mathrm{MHz}$, chloroform-d) $\delta 138.63$ (quat. C), 129.10 (2 arom. CH), 128.14 (2 arom. $\mathrm{CH}), 126.89$ (arom. $\mathrm{CH}), 63.10\left(\mathrm{CH}_{2}\right), 55.06$ $(\mathrm{CH}), 52.56\left(2 \mathrm{CH}_{2}\right), 46.91\left(\mathrm{CH}_{2}\right), 32.86\left(2 \mathrm{CH}_{2}\right), 31.79\left(\mathrm{CH}_{2}\right), 30.46\left(\mathrm{CH}_{2}\right), 27.14\left(\mathrm{CH}_{2}\right), 22.63$ $\left(\mathrm{CH}_{2}\right), 14.06\left(\mathrm{CH}_{3}\right)$. IR $(\mathrm{KBr}) \vee\left(\mathrm{cm}^{-1}\right)=2924,2853,2797,1466,1454,1365,1342,1117,1072$, 1029, 972, 792. MS (EI) m/z: $274\left(\mathrm{M}^{+}, 4\right), 173$ (99), 146 (17), 91 (100). HRMS (EI) calcd. for $\mathrm{C}_{18} \mathrm{H}_{30} \mathrm{~N}_{2}$ : 274.2409. Found: 274.2418.

1-Benzyl-N-cycloheptylpiperidin-4-amine (2f): The compound was prepared according to general procedure 1 from $568 \mathrm{mg}$ (3.0 mmol) 1-benzyl-4-piperi-done, $509 \mathrm{mg}$ (4.5 mmol) cycloheptylamine and $1.34 \mathrm{~g}(6.0 \mathrm{mmol})$ sodium triacetoxyborohydride to give $860 \mathrm{mg}$ $(100 \%)$ of $\mathbf{2} \mathbf{f}$ as a colourless oil. ${ }^{1} \mathrm{H}-\mathrm{NMR}(400 \mathrm{MHz}$, chloroform- $d) \delta 7.30(\mathrm{~d}, J=4.4 \mathrm{~Hz}$, $4 \mathrm{H}, 4$ arom. CH), 7.26-7.21 (m, $1 \mathrm{H}, 1$ arom. CH), $3.49\left(\mathrm{~s}, 2 \mathrm{H}, \mathrm{CH}_{2}\right), 2.90-2.80(\mathrm{~m}, 2 \mathrm{H}$, $\left.2 \mathrm{CH}_{2}\right), 2.76(\mathrm{tt}, J=8.1,4.0 \mathrm{~Hz}, 1 \mathrm{H}, \mathrm{CH}), 2.51(\mathrm{tt}, J=10.6,4.0 \mathrm{~Hz}, 1 \mathrm{H}, \mathrm{CH}), 2.01(\mathrm{td}, J=11.7$, $\left.2.3 \mathrm{~Hz}, 2 \mathrm{H}, 2 \mathrm{CH}_{2}\right), 1.89-1.71\left(\mathrm{~m}, 4 \mathrm{H}, 3 \mathrm{CH}_{2}\right), 1.70-1.59\left(\mathrm{~m}, 2 \mathrm{H}, 2 \mathrm{CH}_{2}\right), 1.60-1.45(\mathrm{~m}, 4 \mathrm{H}$, $\left.2 \mathrm{CH}_{2}\right), 1.46-1.22\left(\mathrm{~m}, 6 \mathrm{H}, 3 \mathrm{CH}_{2}\right) .{ }^{13} \mathrm{C}-\mathrm{NMR}(100 \mathrm{MHz}$, chloroform-d) $\delta 138.63$ (quat. C), 129.09 (2 arom. CH), 128.13 (2 arom. CH), 126.88 (arom. $\mathrm{CH}), 63.10\left(\mathrm{CH}_{2}\right), 55.16(\mathrm{CH}), 52.77$ $\left(2 \mathrm{CH}_{2}\right), 51.71(\mathrm{CH}), 35.46\left(2 \mathrm{CH}_{2}\right), 33.38\left(2 \mathrm{CH}_{2}\right), 28.13\left(2 \mathrm{CH}_{2}\right), 24.49\left(2 \mathrm{CH}_{2}\right) . \mathrm{MS}(\mathrm{EI})$ $m / z: 286\left(\mathrm{M}^{+}, 4\right), 173(98), 146(6), 91$ (100). HRMS (EI) calcd. for $\mathrm{C}_{19} \mathrm{H}_{30} \mathrm{~N}_{2}\left(\mathrm{M}^{+}\right)$: 286.2409. Found: 286.2403.

(S)-1-Benzyl-N-(1-phenylethyl)piperidin-4-amine (2g): The compound was prepared according to general procedure 1 from $568 \mathrm{mg}$ ( $3.0 \mathrm{mmol}$ ) 1-benzyl-4-piperidone, $545 \mathrm{mg}$ (4.5 mmol) (S)- $\alpha$-methylbenzenemethanamine and $1.34 \mathrm{~g}(6.0 \mathrm{mmol})$ sodium triacetoxyborohydride to give $730 \mathrm{mg}(83 \%)$ of $\mathbf{2 g}$ as a colourless oil. ${ }^{1} \mathrm{H}-\mathrm{NMR}(400 \mathrm{MHz}$, chloroform- $d) \delta 7.35-7.17$ $\left(\mathrm{m}, 10 \mathrm{H}, 10\right.$ arom. CH), $3.94(\mathrm{q}, J=6.6 \mathrm{~Hz}, 1 \mathrm{H}, \mathrm{CH}), 3.44\left(\mathrm{~s}, 2 \mathrm{H}, \mathrm{CH}_{2}\right), 2.84-2.70$ (m, $\left.2 \mathrm{H}, 2 \mathrm{CH}_{2}\right), 2.30(\mathrm{tt}, J=10.5,4.0 \mathrm{~Hz}, 1 \mathrm{H}, \mathrm{CH}), 1.99-1.83\left(\mathrm{~m}, 3 \mathrm{H}, 3 \mathrm{CH}_{2}\right), 1.72-1.62(\mathrm{~m}$, $\left.1 \mathrm{H}, \mathrm{CH}_{2}\right), 1.44-1.24\left(\mathrm{~m}, 2 \mathrm{H}, 2 \mathrm{CH}_{2}\right), 1.31\left(\mathrm{~d}, \mathrm{~J}=6.6 \mathrm{~Hz}, 3 \mathrm{H}, \mathrm{CH}_{3}\right) .{ }^{13} \mathrm{C}-\mathrm{NMR}(100 \mathrm{MHz}$, chloroform-d) $\delta 146.19$ (quat. C), 138.60 (quat. C), 129.10 (2 arom. CH), 128.38 (2 arom. CH), 128.12 (2 arom. CH), 126.87 (arom. CH), 126.75 (arom. $\mathrm{CH}), 126.50$ (2 arom. CH), 63.07 $\left(\mathrm{CH}_{2}\right), 54.48(\mathrm{CH}), 52.59\left(\mathrm{CH}_{2}\right), 52.41\left(\mathrm{CH}_{2}\right), 51.95(\mathrm{CH}), 33.66\left(\mathrm{CH}_{2}\right), 32.57\left(\mathrm{CH}_{2}\right), 25.11$ $\left(\mathrm{CH}_{3}\right) . \mathrm{IR}(\mathrm{KBr}) \vee\left(\mathrm{cm}^{-1}\right)=2924,2799,2759,1493,1467,1451,1366,1343,1117,793,761,737$, 698. MS (EI) m/z: 295 (M+ $\left.\mathrm{M}^{+}+\mathrm{H}, 0.5\right), 189$ (64), 175 (17), 172 (45), 158 (18), 146 (21), 105 (21), 91 (100). HRMS (EI) calcd. for $\mathrm{C}_{20} \mathrm{H}_{27} \mathrm{~N}_{2}\left(\mathrm{M}^{+}+\mathrm{H}\right): 295.2174$. Found: $295.2170 . \propto \frac{20}{D}=-47.7^{\circ}$ $\left(1.525, \mathrm{CHCl}_{3}\right)$.

(S)-1-Benzyl-N-(1-cyclohexylethyl)piperidin-4-amine (2h): The compound was prepared according to general procedure 1 from $568 \mathrm{mg}$ (3.0 $\mathrm{mmol})$ 1-benzyl-4-piperidone, $572 \mathrm{mg}$ (4.5 mmol) (S)-(+)-1-cyclohexylethylamine and $1.34 \mathrm{~g}(6.0 \mathrm{mmol})$ sodium triacetoxyborohydride to give $700 \mathrm{mg}(78 \%)$ of $2 \mathrm{~h}$ as a colourless oil. ${ }^{1} \mathrm{H}-\mathrm{NMR}(400 \mathrm{MHz}$, chloroform- $d$ ) $\delta$ 7.33-7.27 (m, 4 H, 4 arom. CH), 7.27-7.17 (m, $1 \mathrm{H}$, arom. $\mathrm{CH}), 3.49$ (s, $\left.2 \mathrm{H}, \mathrm{CH}_{2}\right), 2.88-2.77$ (m, $\left.2 \mathrm{H}, 2 \mathrm{CH}_{2}\right), 2.57-2.42(\mathrm{~m}, 2 \mathrm{H}, 2 \mathrm{CH}), 2.01$ (qd, $\left.J=11.5,2.6 \mathrm{~Hz}, 2 \mathrm{H}, 2 \mathrm{CH}_{2}\right), 1.89-1.59$ $\left(\mathrm{m}, 7 \mathrm{H}, 6 \mathrm{CH}_{2}, \mathrm{CH}\right), 1.45-1.05\left(\mathrm{~m}, 6 \mathrm{H}, 6 \mathrm{CH}_{2}\right), 1.06-0.87\left(\mathrm{~m}, 2 \mathrm{H}, 2 \mathrm{CH}_{2}\right), 0.95(\mathrm{~d}, \mathrm{~J}=6.4 \mathrm{~Hz}$, $\left.3 \mathrm{H}, \mathrm{CH}_{3}\right) .{ }^{13} \mathrm{C}-\mathrm{NMR}(100 \mathrm{MHz}$, chloroform-d) $\delta 138.72$ (quat. C), 129.09 (2 arom. $\mathrm{CH}$ ), 128.13 (2 arom. $\mathrm{CH}), 126.86$ (arom. $\mathrm{CH}), 63.13\left(\mathrm{CH}_{2}\right), 53.93(\mathrm{CH}), 52.73\left(\mathrm{CH}_{2}\right), 52.61\left(\mathrm{CH}_{2}\right)$, $51.99(\mathrm{CH}), 43.28(\mathrm{CH}), 33.80\left(\mathrm{CH}_{2}\right), 32.96\left(\mathrm{CH}_{2}\right), 30.01\left(\mathrm{CH}_{2}\right), 28.17\left(\mathrm{CH}_{2}\right), 26.79\left(\mathrm{CH}_{2}\right)$, $26.65\left(\mathrm{CH}_{2}\right), 26.51\left(\mathrm{CH}_{2}\right), 17.70\left(\mathrm{CH}_{3}\right) . \mathrm{IR}(\mathrm{KBr}) \vee\left(\mathrm{cm}^{-1}\right)=2921,2849,1449,1366,1264$, 1109, 1072, 890, 792, 735, 697. MS (EI) m/z: $301\left(\mathrm{M}^{+}+\mathrm{H}, 0.1\right), 217$ (16), 172 (56), 146 (37), 91 (100). HRMS (EI) calcd. for $\mathrm{C}_{20} \mathrm{H}_{33} \mathrm{~N}_{2}\left(\mathrm{M}^{+}+\mathrm{H}\right): 301.2644$. Found: $301.2638 . \propto \frac{20}{D}=14.4^{\circ}$ (c = 2.33, $\left.\mathrm{CHCl}_{3}\right)$.

1-Benzyl-N-(4-chlorophenethyl)piperidin-4-amine (2i): The compound was prepared according to general procedure 1 from $568 \mathrm{mg}$ ( $3.0 \mathrm{mmol})$ 1-benzyl-4-piperidone, $700 \mathrm{mg}(4.5 \mathrm{mmol})$ 4-chlorophenylethylamine and $1.34 \mathrm{~g}(6.0 \mathrm{mmol})$ sodium triacetoxyborohydride to give $738 \mathrm{mg}(75 \%)$ of $\mathbf{2} \mathbf{i}$ as a pale yellow oil. ${ }^{1} \mathrm{H}-\mathrm{NMR}(400 \mathrm{MHz}$, chloroform- $d) \delta 7.32-7.28(\mathrm{~m}$, $4 \mathrm{H}, 4$ arom. CH), 7.27-7.21 (m, $3 \mathrm{H}, 3$ arom. CH), 7.13 (d, J = 8.5 Hz, $2 \mathrm{H}, 2$ arom. CH), 3.48 (s, $\left.2 \mathrm{H}, \mathrm{CH}_{2}\right), 2.90-2.79\left(\mathrm{~m}, 4 \mathrm{H}, 3 \mathrm{CH}_{2}\right), 2.75\left(\mathrm{t}, J=7.0 \mathrm{~Hz}, 2 \mathrm{H}, \mathrm{CH}_{2}\right), 2.50-2.40(\mathrm{~m}, 1 \mathrm{H}$, 
$\mathrm{CH}), 2.00\left(\mathrm{td}, J=11.2,1.9 \mathrm{~Hz}, 2 \mathrm{H}, 2 \mathrm{CH}_{2}\right), 1.86-1.77\left(\mathrm{~m}, 2 \mathrm{H}, 2 \mathrm{CH}_{2}\right), 1.35(\mathrm{qd}, J=12.2,11.7$, $\left.3.8 \mathrm{~Hz}, 2 \mathrm{H}, 2 \mathrm{CH}_{2}\right) .{ }^{13} \mathrm{C}-\mathrm{NMR}(100 \mathrm{MHz}$, chloroform-d) $\delta 138.62$ (quat. C), 138.57 (quat. C), 131.89 (quat. C), 130.01 (2 arom. CH), 129.06 (2 arom. CH), 128.54 (2 arom. $\mathrm{CH}), 128.15$ (2 arom. $\mathrm{CH}), 126.90$ (arom. $\mathrm{CH}), 63.07\left(\mathrm{CH}_{2}\right), 54.88(\mathrm{CH}), 52.45\left(2 \mathrm{CH}_{2}\right), 47.93\left(\mathrm{CH}_{2}\right), 36.06$ $\left(\mathrm{CH}_{2}\right), 32.80\left(2 \mathrm{CH}_{2}\right)$. IR $(\mathrm{KBr}) \vee\left(\mathrm{cm}^{-1}\right)=2942,2883,2800,1492,1363,1091,1015,972,808$, 738, 698. MS (EI) m/z: $330\left(\mathrm{M}^{+}, 38\right), 328\left(\mathrm{M}^{+}, 96\right), 299$ (20), 289 (100), 271 (28). HRMS (EI) calcd. for $\mathrm{C}_{20} \mathrm{H}_{26} \mathrm{ClN}_{2}\left(\mathrm{M}^{+}+\mathrm{H}\right)$ : 329.1785. Found: 329.1779.

1-Benzyl-N-(4-methoxybenzyl)piperidin-4-amine (2j): The compound was prepared according to general procedure 1 from $379 \mathrm{mg}$ ( $2.0 \mathrm{mmol})$ 1-benzyl-4-piperidone, $412 \mathrm{mg}$ ( $3.0 \mathrm{mmol})$ 4-methoxybenzylamine and $892 \mathrm{mg}(4.0 \mathrm{mmol})$ sodium triacetoxyborohydride to give $610 \mathrm{mg}(98 \%)$ of $\mathbf{2 j}$ as a pale yellow oil. ${ }^{1} \mathrm{H}-\mathrm{NMR}(400 \mathrm{MHz}$, chloroform- $d) \delta 7.33-7.29(\mathrm{~m}$, $4 \mathrm{H}, 4$ arom. $\mathrm{CH}), 7.25-7.20(\mathrm{~m}, 1 \mathrm{H}$, arom. $\mathrm{CH}), 7.23(\mathrm{~d}, J=8.7 \mathrm{~Hz}, 2 \mathrm{H}, 2$ arom. $\mathrm{CH}), 6.85$ $\left(\mathrm{d}, J=8.7 \mathrm{~Hz}, 2 \mathrm{H}, 2\right.$ arom. CH), $3.79\left(\mathrm{~s}, 3 \mathrm{H}, \mathrm{OCH}_{3}\right), 3.74\left(\mathrm{~s}, 2 \mathrm{H}, \mathrm{CH}_{2}\right), 3.49\left(\mathrm{~s}, 2 \mathrm{H}, \mathrm{CH}_{2}\right)$, $2.84\left(\mathrm{dt}, J=11.6,2.8 \mathrm{~Hz}, 2 \mathrm{H}, 2 \mathrm{CH}_{2}\right), 2.50(\mathrm{tt}, J=10.5,4.1 \mathrm{~Hz}, 1 \mathrm{H}, \mathrm{CH}), 2.01(\mathrm{td}, J=11.6$, $\left.2.3 \mathrm{~Hz}, 2 \mathrm{H}, 2 \mathrm{CH}_{2}\right), 1.91-1.82\left(\mathrm{~m}, 2 \mathrm{H}, 2 \mathrm{CH}_{2}\right), 1.49-1.35\left(\mathrm{~m}, 2 \mathrm{H}, \mathrm{CH}_{2}\right) .{ }^{13} \mathrm{C}-\mathrm{NMR}(100 \mathrm{MHz}$, chloroform- $d$ ) $\delta 158.54$ (quat. C), 138.63 (quat. C), 132.94 (quat. C), 129.20 (2 arom. $\mathrm{CH}$ ), 129.10 (2 arom. $\mathrm{CH}), 128.14$ (2 arom. $\mathrm{CH}), 126.89$ (arom. $\mathrm{CH}), 113.80(2$ arom. $\mathrm{CH}), 63.12$ $\left(\mathrm{CH}_{2}\right), 55.28\left(\mathrm{OCH}_{3}\right), 54.15(\mathrm{CH}), 52.42\left(2 \mathrm{CH}_{2}\right), 50.23\left(\mathrm{CH}_{2}\right), 32.78\left(2 \mathrm{CH}_{2}\right)$. IR $(\mathrm{KBr}) v$ $\left(\mathrm{cm}^{-1}\right)=2936,2828,2092,1510,1447,1300,1239,1027,993,908,740 . \mathrm{MS}$ (EI) $m / z: 311\left(\mathrm{M}^{+}\right.$, 0.3), 219 (1), 189 (24), 172 (43), 146 (20), 136 (14), 121 (74), 91 (100). HRMS (EI) calcd. for $\mathrm{C}_{20} \mathrm{H}_{27} \mathrm{~N}_{2} \mathrm{O}\left(\mathrm{M}^{+}+\mathrm{H}\right): 311.2123$. Found: 311.2117 .

$N$-Isobutyl-1-phenethylpiperidin-4-amine (3a): The compound was prepared according to general procedure 1 from $915 \mathrm{mg}$ ( $4.5 \mathrm{mmol})$ 1-(2-phenylethyl)-4-piperidone, $4.67 \mathrm{mg}$ $(6.4 \mathrm{mmol})$ isobutylamine and $1.50 \mathrm{~g}(6.8 \mathrm{mmol})$ sodium triacetoxyborohydride to give $696 \mathrm{mg}(59 \%)$ of $3 \mathbf{a}$ as a colourless oil. ${ }^{1} \mathrm{H}-\mathrm{NMR}(500 \mathrm{MHz}$, chloroform- $d) \delta 7.30-7.26(\mathrm{~m}$, $2 \mathrm{H}, 2$ arom. $\mathrm{CH}), 7.22-7.17(\mathrm{~m}, 3 \mathrm{H}, 3$ arom. $\mathrm{CH}), 3.00-2.93\left(\mathrm{~m}, 2 \mathrm{H}, \mathrm{CH}_{2}\right), 2.83-2.77(\mathrm{~m}$, $\left.2 \mathrm{H}, \mathrm{CH}_{2}\right), 2.60-2.54\left(\mathrm{~m}, 2 \mathrm{H}, \mathrm{CH}_{2}\right), 2.48-2.39(\mathrm{~m}, 1 \mathrm{H}, \mathrm{CH}), 2.43\left(\mathrm{~d}, J=6.8 \mathrm{~Hz}, 2 \mathrm{H}, \mathrm{CH}_{2}\right)$, 2.11-2.02 (m, $\left.2 \mathrm{H}, \mathrm{CH}_{2}\right), 1.93-1.86\left(\mathrm{~m}, 2 \mathrm{H}, \mathrm{CH}_{2}\right), 1.71(\mathrm{dp}, \mathrm{J}=13.3,6.7 \mathrm{~Hz}, 1 \mathrm{H}, \mathrm{CH}), 1.46$ $\left(\mathrm{m}, 2 \mathrm{H}, \mathrm{CH}_{2}\right), 0.91\left(\mathrm{~d}, J=6.6 \mathrm{~Hz}, 6 \mathrm{H}, 2 \mathrm{CH}_{3}\right) .{ }^{13} \mathrm{C}-\mathrm{NMR}(101 \mathrm{MHz}$, chloroform-d $) \delta 140.57$ (quat. C), 128.71 (2 arom. $\mathrm{CH}), 128.35$ (2 arom. $\mathrm{CH}), 125.97$ (arom. $\mathrm{CH}), 60.68\left(\mathrm{CH}_{2}\right), 54.99$ (CH), $54.91\left(2 \mathrm{CH}_{2}\right), 52.64\left(\mathrm{CH}_{2}\right), 33.90\left(\mathrm{CH}_{2}\right), 32.91\left(2 \mathrm{CH}_{2}\right), 28.58(\mathrm{CH}), 20.76\left(2 \mathrm{CH}_{3}\right) . \mathrm{IR}$ $(\mathrm{KBr}) \vee\left(\mathrm{cm}^{-1}\right)=2947,2804,1497,1468,1373,1244,1120,1031,978,771,744$. MS (EI) $\mathrm{m} / \mathrm{z}$ : $260\left(\mathrm{M}^{+}, 0.2\right), 169(100), 126(48), 70(93)$. HRMS (EI) calcd. for $\mathrm{C}_{17} \mathrm{H}_{28} \mathrm{~N}_{2}\left(\mathrm{M}^{+}\right): 260.2253$. Found: 260.2231 .

$\mathrm{N}$-Dodecyl-1-phenethylpiperidin-4-amine (3b): The compound was prepared according to general procedure 1 from $610 \mathrm{mg}$ (3.0 mmol) 1-(2-phenylethyl)-4-piperidone, $872 \mathrm{mg}$ $(4.5 \mathrm{mmol}) n$-dodecylamine and $1.339 \mathrm{~g}(6.0 \mathrm{mmol})$ sodium triacetoxyborohydride to give $677 \mathrm{mg}(61 \%)$ of $3 \mathbf{b}$ as a pale yellow oil. ${ }^{1} \mathrm{H}-\mathrm{NMR}(400 \mathrm{MHz}$, chloroform- $d) \delta 7.31-7.26(\mathrm{~m}$, $2 \mathrm{H}, 2$ arom. $\mathrm{CH}), 7.23-7.16(\mathrm{~m}, 3 \mathrm{H}, 3$ arom. $\mathrm{CH}), 3.01-2.91\left(\mathrm{~m}, 2 \mathrm{H}, 2 \mathrm{CH}_{2}\right), 2.87-2.74(\mathrm{~m}$, $\left.2 \mathrm{H}, \mathrm{CH}_{2}\right), 2.66-2.54\left(\mathrm{~m}, 4 \mathrm{H}, 2 \mathrm{CH}_{2}\right), 2.46(\mathrm{tt}, J=10.4,3.9 \mathrm{~Hz}, 1 \mathrm{H}, \mathrm{CH}), 2.07(\mathrm{td}, J=11.6$, $\left.2.3 \mathrm{~Hz}, 2 \mathrm{H}, 2 \mathrm{CH}_{2}\right), 1.95-1.84\left(\mathrm{~m}, 2 \mathrm{H}, 2 \mathrm{CH}_{2}\right), 1.55-1.43\left(\mathrm{~m}, 2 \mathrm{H}, 2 \mathrm{CH}_{2}\right), 1.42-1.34(\mathrm{~m}$, $\left.2 \mathrm{H}, \mathrm{CH}_{2}\right), 1.34-1.20\left(\mathrm{~m}, 18 \mathrm{H}, 9 \mathrm{CH}_{2}\right), 0.87\left(\mathrm{t}, J=6.7 \mathrm{~Hz}, 3 \mathrm{H}, \mathrm{CH}_{3}\right) .{ }^{13} \mathrm{C}-\mathrm{NMR}(100 \mathrm{MHz}$, chloroform- $d$ ) $\delta 140.59$ (quat. C), 128.71 (2 arom. CH), 128.35 (2 arom. CH), 125.96 (arom. $\mathrm{CH}), 60.70\left(\mathrm{CH}_{2}\right), 55.06(\mathrm{CH}), 52.69\left(2 \mathrm{CH}_{2}\right), 46.95\left(\mathrm{CH}_{2}\right), 33.92\left(\mathrm{CH}_{2}\right), 32.97\left(\mathrm{CH}_{2}\right), 31.93$ $\left(2 \mathrm{CH}_{2}\right), 30.54\left(\mathrm{CH}_{2}\right), 29.68\left(\mathrm{CH}_{2}\right), 29.65\left(\mathrm{CH}_{2}\right), 29.63\left(2 \mathrm{CH}_{2}\right), 29.59\left(\mathrm{CH}_{2}\right), 29.36\left(\mathrm{CH}_{2}\right)$, $27.47\left(\mathrm{CH}_{2}\right), 22.70\left(\mathrm{CH}_{2}\right), 14.13\left(\mathrm{CH}_{3}\right) . \mathrm{IR}(\mathrm{KBr}) \vee\left(\mathrm{cm}^{-1}\right)=2921,2849,2805,1466,1454$, 1371, 1122, 746, 697. MS (EI) m/z: $351\left(\mathrm{M}^{+}+\mathrm{H}, 30\right), 259$ (67), 216 (45), 147 (97), 117 (33), 96 (100), HRMS: calcd. for $\mathrm{C}_{25} \mathrm{H}_{43} \mathrm{~N}_{2}\left(\mathrm{M}^{+}-\mathrm{H}\right): 371.3426$. Found: 371.3418 .

N-(4-(tert-Butyl)benzyl)-1-phenethylpiperidin-4-amine (3c): The compound was prepared according to general procedure 1 from $610 \mathrm{mg}(3.0 \mathrm{mmol}) 1$-(2-phenylethyl)-4-piperidone, $734 \mathrm{mg}$ (4.5 mmol) 4-tert-butylbenzylamine and $1.339 \mathrm{~g}(6.0 \mathrm{mmol})$ sodium triacetoxyborohydride to give $609 \mathrm{mg}(58 \%)$ of $3 \mathrm{c}$ as a pale yellow oil. ${ }^{1} \mathrm{H}-\mathrm{NMR}\left(400 \mathrm{MHz}\right.$, dichloromethane- $\left.d_{2}\right) \delta$ $7.33(\mathrm{~d}, J=8.4 \mathrm{~Hz}, 2 \mathrm{H}, 2$ arom. $\mathrm{CH}), 7.30-7.14(\mathrm{~m}, 7 \mathrm{H}, 7$ arom. $\mathrm{CH})), 3.75\left(\mathrm{~s}, 2 \mathrm{H}, \mathrm{CH}_{2}\right)$, 
$2.92\left(\mathrm{dd}, J=11.8,4.4 \mathrm{~Hz}, 2 \mathrm{H}, 2 \mathrm{CH}_{2}\right), 2.76\left(\mathrm{dd}, J=9.4,6.4 \mathrm{~Hz}, 2 \mathrm{H}, 2 \mathrm{CH}_{2}\right), 2.58-2.45(\mathrm{~m}$, $\left.3 \mathrm{H}, \mathrm{CH}_{2}, \mathrm{CH}\right), 2.05\left(\mathrm{td}, J=11.5,2.2 \mathrm{~Hz}, 2 \mathrm{H}, \mathrm{CH}_{2}\right), 1.94-1.83\left(\mathrm{~m}, 2 \mathrm{H}, 2 \mathrm{CH}_{2}\right), 1.44-1.33(\mathrm{~m}$, $\left.2 \mathrm{H}, 2 \mathrm{CH}_{2}\right), 1.30\left(\mathrm{~s}, 9 \mathrm{H}, 3 \mathrm{CH}_{3}\right) .{ }^{13} \mathrm{C}-\mathrm{NMR}\left(101 \mathrm{MHz}\right.$, dichloromethane- $\left.d_{2}\right) \delta 150.92$ (quat. C), 142.28 (quat. C), 139.53 (quat. C), 130.01 (2 arom. $\mathrm{CH}), 129.52$ (2 arom. $\mathrm{CH}), 128.98$ (2 arom. $\mathrm{CH}), 127.09$ (arom. $\mathrm{CH}), 126.45$ (2 arom. $\mathrm{CH}), 61.78\left(\mathrm{CH}_{2}\right), 55.71(\mathrm{CH}), 53.72\left(\mathrm{CH}_{2}\right)$, $51.67\left(2 \mathrm{CH}_{2}\right), 35.61$ (quat. C), $35.03\left(\mathrm{CH}_{2}\right), 34.16\left(2 \mathrm{CH}_{2}\right), 32.44\left(3 \mathrm{CH}_{3}\right)$. MS (EI) $m / z: 351$ $\left(\mathrm{M}^{+}+\mathrm{H}, 30\right), 259$ (67), 216 (45), 202 (12), 147 (97), 119 (27), 117 (27), 105 (36), 96 (100). HRMS (EI) calcd. for $\mathrm{C}_{24} \mathrm{H}_{35} \mathrm{~N}_{2}\left(\mathrm{M}^{+}+\mathrm{H}\right): 351.2795$. Found: 351.2793

(S)-1-Phenethyl-N-(1-phenethyl)piperidin-4-amine (3d): The compound was prepared according to general procedure 1 from $610 \mathrm{mg}(3.0 \mathrm{mmol})$ 1-(2-phenylethyl)-4-piperidone, 610 (4.5 mmol) (S)-1-phenylethylamine and $1.34 \mathrm{~g}(6.0 \mathrm{mmol})$ sodium triacetoxyborohydride to give $748 \mathrm{mg}(81 \%)$ of $\mathbf{3 d}$ as a pale yellow oil. ${ }^{1} \mathrm{H}-\mathrm{NMR}(400 \mathrm{MHz}$, chloroform- $d) \delta 7.36-7.11$ $(\mathrm{m}, 10 \mathrm{H}, 10$ arom. $\mathrm{CH}), 3.96(\mathrm{q}, J=6.6 \mathrm{~Hz}, 1 \mathrm{H}, \mathrm{CH}), 2.96-2.85\left(\mathrm{~m}, 2 \mathrm{H}, 2 \mathrm{CH}_{2}\right), 2.81-2.73$ (m, $\left.2 \mathrm{H}, \mathrm{CH}_{2}\right), 2.56-2.48\left(\mathrm{~m}, 2 \mathrm{H}, \mathrm{CH}_{2}\right), 2.38-2.27$ (m, $\left.1 \mathrm{H}, \mathrm{CH}\right), 2.02-1.89\left(\mathrm{~m}, 3 \mathrm{H}, 3 \mathrm{CH}_{2}\right)$, 1.78-1.68 (m, $\left.1 \mathrm{H}, \mathrm{CH}_{2}\right), 1.46-1.35\left(\mathrm{~m}, 2 \mathrm{H}, 2 \mathrm{CH}_{2}\right), 1.33\left(\mathrm{~d}, \mathrm{~J}=6.6 \mathrm{~Hz}, 3 \mathrm{H}, \mathrm{CH}_{3}\right) .{ }^{13} \mathrm{C}-\mathrm{NMR}$ (100 MHz, chloroform-d) $\delta 146.18$ (quat. C), 140.56 (quat. C), 128.69 (2 arom. CH), 128.40 (2 arom. CH), 128.34 (2 arom. CH), 126.78 (arom. CH), 126.52 (2 arom. CH), 125.96 (arom. $\mathrm{CH}), 60.66\left(\mathrm{CH}_{2}\right), 54.52(\mathrm{CH}), 52.72\left(\mathrm{CH}_{2}\right), 52.54\left(\mathrm{CH}_{2}\right), 51.94(\mathrm{CH}), 33.89\left(\mathrm{CH}_{2}\right), 33.69$ $\left(\mathrm{CH}_{2}\right), 32.62\left(\mathrm{CH}_{2}\right), 25.12\left(\mathrm{CH}_{3}\right) . \mathrm{IR}(\mathrm{KBr}) \vee\left(\mathrm{cm}^{-1}\right)=2931,2820,1602,1493,1450,1369$, $1122,1111,762,750$. HRMS (EI) calcd. for $\mathrm{C}_{21} \mathrm{H}_{29} \mathrm{~N}_{2}\left(\mathrm{M}^{+}+1\right)$ : 309.2331. Found: 309.2323. $\propto \frac{20}{D}=-52.2^{\circ}\left(\mathrm{c}=2.745, \mathrm{CHCl}_{3}\right)$.

(S)-N-(1-Cyclohexylethyl)-1-phenethylpiperidin-4-amine (3e): The compound was prepared according to general procedure 1 from $610 \mathrm{mg}$ (3.0 mmol) 1-(2-phenylethyl)-4-piperidone, $610 \mathrm{mg}$ (4.5 mmol) 1-(S)-cyclohexylethylamine and $1.34 \mathrm{~g}(6.0 \mathrm{mmol})$ sodium triacetoxyborohydride to give $797 \mathrm{mg}(85 \%)$ of $3 \mathbf{e}$ as a pale yellow oil. ${ }^{1} \mathrm{H}-\mathrm{NMR}(400 \mathrm{MHz}$, chloroform- $d$ ) 反 7.33-7.15 (m, $5 \mathrm{H}$, arom. CH), 3.00-2.89 (m, $\left.2 \mathrm{H}, 2 \mathrm{CH}_{2}\right), 2.85-2.76\left(\mathrm{~m}, 2 \mathrm{H}, \mathrm{CH}_{2}\right), 2.62-2.45$ $\left(\mathrm{m}, 4 \mathrm{H}, 2 \mathrm{CH}, 2 \mathrm{CH}_{2}\right), 2.07\left(\mathrm{qd}, J=11.6,11.1,2.1 \mathrm{~Hz}, 2 \mathrm{H}, 2 \mathrm{CH}_{2}\right), 1.93-1.80(\mathrm{~m}, 2 \mathrm{H}$, $\left.2 \mathrm{CH}_{2}\right), 1.79-1.57\left(\mathrm{~m}, 5 \mathrm{H}, \mathrm{CH}, 4 \mathrm{CH}_{2}\right), 1.47-1.29\left(\mathrm{~m}, 2 \mathrm{H}, 2 \mathrm{CH}_{2}\right), 1.30-1.05\left(\mathrm{~m}, 6 \mathrm{H}, 6 \mathrm{CH}_{2}\right)$, 1.05-0.96 (m, $\left.2 \mathrm{H}, 2 \mathrm{CH}_{2}\right), 0.96\left(\mathrm{~d}, J=6.4 \mathrm{~Hz}, 3 \mathrm{H}, \mathrm{CH}_{3}\right) .{ }^{13} \mathrm{C}-\mathrm{NMR}(100 \mathrm{MHz}$, chloroform-d) $\delta 140.60$ (quat. C), 128.71 (2 arom. CH), 128.34 (2 arom. CH), 125.96 (arom. CH), 60.72 $\left(\mathrm{CH}_{2}\right), 53.98(\mathrm{CH}), 52.83\left(\mathrm{CH}_{2}\right), 52.71\left(\mathrm{CH}_{2}\right), 51.96(\mathrm{CH}), 43.30\left(\mathrm{CH}_{2}\right), 33.93\left(\mathrm{CH}_{2}\right), 33.83$ $\left(\mathrm{CH}_{2}\right), 32.97\left(\mathrm{CH}_{2}\right), 30.02\left(\mathrm{CH}_{2}\right), 28.19\left(\mathrm{CH}_{2}\right), 26.80\left(\mathrm{CH}_{2}\right), 26.65\left(\mathrm{CH}_{2}\right), 26.52\left(\mathrm{CH}_{2}\right), 17.70$ $\left(\mathrm{CH}_{3}\right) . \mathrm{IR}(\mathrm{KBr}) \vee\left(\mathrm{cm}^{-1}\right)=2922,2849,2800,1496,1449,1372,1241,1116,1030,979,746,698$. MS (EI) m/z: 315 (M $\left.\mathrm{M}^{+}, 0.3\right), 223$ (69), 186 (20), 180 (85), 166 (19), 160 (45), 105 (38), 98 (48), 96 (100), 70 (82). HRMS (EI) calcd. for $\mathrm{C}_{21} \mathrm{H}_{35} \mathrm{~N}_{2}\left(\mathrm{M}^{+}+1\right)$ : 315.2800. Found: 315.2792.

N-(4-Chlorophenethyl)-1-phenethylpiperidin-4-amine (3f): The compound was prepared according to general procedure 1 from $610 \mathrm{mg}$ (3.0 mmol) 1-(2-phenylethyl)-4-piperidone, $700 \mathrm{mg}$ (4.5 mmol) 4-chlorophenylethylamine and $1.339 \mathrm{~g}(6.0 \mathrm{mmol})$ sodium triacetoxyborohydride to give $686 \mathrm{mg}(67 \%)$ of $\mathbf{3 f}$ as a pale yellow oil. ${ }^{1} \mathrm{H}-\mathrm{NMR}(400 \mathrm{MHz}$, chloroform- $d) \delta$ 7.36-7.08 (m, 9 H, 9 arom. CH), 3.00-2.91 (m, $\left.2 \mathrm{H}, 2 \mathrm{CH}_{2}\right), 2.88\left(\mathrm{t}, J=7.2 \mathrm{~Hz}, 2 \mathrm{H}, \mathrm{CH}_{2}\right)$, 2.83-2.71 (m, $\left.4 \mathrm{H}, 3 \mathrm{CH}_{2}\right), 2.62-2.54\left(\mathrm{~m}, 2 \mathrm{H}, \mathrm{CH}_{2}\right), 2.53-2.44(\mathrm{~m}, 1 \mathrm{H}, \mathrm{CH}), 2.12-2.03(\mathrm{~m}$, $\left.2 \mathrm{H}, \mathrm{CH}_{2}\right), 1.93-1.82\left(\mathrm{~m}, 2 \mathrm{H}, 2 \mathrm{CH}_{2}\right), 1.46-1.32\left(\mathrm{~m}, 2 \mathrm{H}, 2 \mathrm{CH}_{2}\right) .{ }^{13} \mathrm{C}-\mathrm{NMR}(100 \mathrm{MHz}$, chloroform-d) $\delta 140.53$ (quat. C), 138.56 (quat. C), 131.90 (quat. C), 130.02 (2 arom. CH), 128.70 (2 arom. CH), 128.55 (2 arom. CH), 128.36 (2 arom. CH), 125.98 (arom. CH), 60.64 $(\mathrm{CH}), 54.89(\mathrm{CH}), 52.55\left(2 \mathrm{CH}_{2}\right), 47.95\left(\mathrm{CH}_{2}\right), 36.07\left(\mathrm{CH}_{2}\right), 33.90\left(2 \mathrm{CH}_{2}\right), 32.82\left(\mathrm{CH}_{2}\right) . \mathrm{IR}$ $(\mathrm{KBr}) \vee\left(\mathrm{cm}^{-1}\right)=2938,2797,1492,1451,1358,1143,1120,1043,1014,812,739,699$. MS (EI) m/z: $343\left(\mathrm{M}^{+}+\mathrm{H}, 0.2\right), 208$ (72), 194 (12), 160 (22), 139 (60), 125 (31), 103 (39), 96 (100), 91 (22), 70 (38). HRMS (EI) calcd. for $\mathrm{C}_{21} \mathrm{H}_{28} \mathrm{~N}_{2} \mathrm{Cl}\left(\mathrm{M}^{+}+\mathrm{H}\right)$ : 343.1941. Found: 343.1936.

N-Hexyl-1-phenethylpiperidin-4-amine (3g): The compound was prepared according to general procedure 1 from $610 \mathrm{mg}$ (3.0 mmol) 1-(2-phenylethyl)-4-piperidone, $455 \mathrm{mg}$ (4.5 mmol) n-hexylamine and $1.34 \mathrm{~g}(6.0 \mathrm{mmol})$ sodium triacetoxyborohydride to give $553 \mathrm{mg}(64 \%)$ of $3 \mathrm{~g}$ as a pale yellow oil. ${ }^{1} \mathrm{H}-\mathrm{NMR}(400 \mathrm{MHz}$, chloroform- $d) \delta 7.24-7.19(\mathrm{~m}, 2 \mathrm{H}, 2$ arom. $\mathrm{CH}), 7.15-7.09$ (m, $3 \mathrm{H}, 2$ arom. $\mathrm{CH}), 2.94-2.85\left(\mathrm{~m}, 2 \mathrm{H}, \mathrm{CH}_{2}\right), 2.77-2.69\left(\mathrm{~m}, 2 \mathrm{H}, \mathrm{CH}_{2}\right)$, 
2.57- $2.47\left(\mathrm{~m}, 4 \mathrm{H}, \mathrm{CH}_{2}\right), 2.39(\mathrm{tt}, J=10.5,4.1 \mathrm{~Hz}, 1 \mathrm{H}, \mathrm{CH}), 2.00(\mathrm{td}, J=11.6,2.4 \mathrm{~Hz}, 2 \mathrm{H}$, $\left.\mathrm{CH}_{2}\right), 1.87-1.79\left(\mathrm{~m}, 2 \mathrm{H}, \mathrm{CH}_{2}\right), 1.45-1.16\left(\mathrm{~m}, 10 \mathrm{H}, 5 \mathrm{CH}_{2}\right), 0.82\left(\mathrm{t}, J=6.6 \mathrm{~Hz}, 3 \mathrm{H}, \mathrm{CH}_{3}\right)$. ${ }^{13} \mathrm{C}-\mathrm{NMR}(100 \mathrm{MHz}$, chloroform-d) $\delta 140.56$ (quat. C), 128.71 (2 arom. CH), 128.35 (2 arom. $\mathrm{CH}), 125.97$ (arom. $\mathrm{CH}), 60.68\left(\mathrm{CH}_{2}\right), 55.05(\mathrm{CH}), 52.68\left(2 \mathrm{CH}_{2}\right), 46.93\left(\mathrm{CH}_{2}\right), 33.90\left(\mathrm{CH}_{2}\right)$, $32.92\left(2 \mathrm{CH}_{2}\right), 31.80\left(\mathrm{CH}_{2}\right), 30.48\left(\mathrm{CH}_{2}\right), 27.15\left(\mathrm{CH}_{2}\right), 22.64\left(\mathrm{CH}_{2}\right), 14.07\left(\mathrm{CH}_{3}\right) . \mathrm{IR}(\mathrm{KBr}) v$ $\left(\mathrm{cm}^{-1}\right)=2926,2853,2802,1467,1455,1120,745$.

tert-Butyl 4-((4-(tert-butyl)benzyl)amino)piperidine-1-carboxylate (4a): The compound was prepared according to general procedure 1 from $450 \mathrm{mg}$ (2.3 mmol) 1-Boc-4-piperidone, $553 \mathrm{mg}$ (3.4 mmol) 4-tert-butylbenzylamine and $1.0 \mathrm{~g}$ (4.52 mmol) sodium triacetoxyborohydride to give $783 \mathrm{mg}(100 \%)$ of $4 \mathbf{a}$ as a white solid. Mp: $73-75^{\circ} \mathrm{C}$. ${ }^{1} \mathrm{H}-\mathrm{NMR}(400 \mathrm{MHz}$, chloroform- $d$, $323 \mathrm{~K}) \delta 7.33(\mathrm{~d}, J=8.4 \mathrm{~Hz}, 2 \mathrm{H}, 2$ arom. CH), 7.23 (d, J = 8.4 Hz, $2 \mathrm{H}, 2$ arom. CH), 4.04-3.91 $\left(\mathrm{m}, 2 \mathrm{H}, 2 \mathrm{CH}_{2}\right), 3.78\left(\mathrm{~s}, 2 \mathrm{H}, \mathrm{CH}_{2} \mathrm{~N}\right), 2.83\left(\mathrm{ddd}, J=13.8,11.3,2.9 \mathrm{~Hz}, 2 \mathrm{H}, 2 \mathrm{CH}_{2}\right), 2.69$ $(\mathrm{tt}, J=9.9,3.9 \mathrm{~Hz}, 1 \mathrm{H}, \mathrm{CH}), 1.92-1.80\left(\mathrm{~m}, 2 \mathrm{H}, 2 \mathrm{CH}_{2}\right), 1.45\left(\mathrm{~s}, 9 \mathrm{H}, 3 \mathrm{CH}_{3}\right), 1.32(\mathrm{~s}, 9 \mathrm{H}$, $\left.3 \mathrm{CH}_{3}\right), 1.35-1.28\left(\mathrm{~m}, 2 \mathrm{H}, 2 \mathrm{CH}_{2}\right) .{ }^{13} \mathrm{C}-\mathrm{NMR}(100 \mathrm{MHz}$, chloroform-d, $323 \mathrm{~K}) \delta 154.93(\mathrm{CO})$, 149.97 (quat. C), 137.69 (quat. C), 127.76 (2 arom. CH), 125.38 (2 arom. CH), 79.36 (quat. C), $54.33(\mathrm{CH}), 50.59\left(\mathrm{CH}_{2}\right), 42.60\left(2 \mathrm{CH}_{2}\right), 34.50$ (quat. C), $32.61\left(2 \mathrm{CH}_{2}\right), 31.43\left(3 \mathrm{CH}_{3}\right), 28.53$ $\left(3 \mathrm{CH}_{3}\right)$. MS (EI) m/z: $346\left(\mathrm{M}^{+}, 2\right), 289$ (45), 162 (100), 147 (80), 57 (56). HRMS (EI) calcd. for $\mathrm{C}_{21} \mathrm{H}_{34} \mathrm{~N}_{2} \mathrm{O}_{2}$ : 346.2620. Found: 346.2620.

tert-Butyl 4-(dodecylamino)piperidine-1-carboxylate (4b): The compound was prepared according to general procedure 1 from $598 \mathrm{mg}$ ( $3.0 \mathrm{mmol})$ 1-Boc-4-piperidone, $834 \mathrm{mg}(4.5 \mathrm{mmol})$ n-dodecylamine and $1.34 \mathrm{~g}(6.0 \mathrm{mmol})$ sodium triacetoxyborohydride to give $1.0 \mathrm{~g}(90 \%)$ of $4 \mathbf{b}$ as a colourless oil. ${ }^{1} \mathrm{H}-\mathrm{NMR}(400 \mathrm{MHz}$, chloroform-d, $323 \mathrm{~K}) \delta 4.13-3.76\left(\mathrm{~m}, 2 \mathrm{H}, 2 \mathrm{CH}_{2}\right)$, $2.80\left(\mathrm{ddd}, J=13.9,12.9,2.8 \mathrm{~Hz}, 2 \mathrm{H}, \mathrm{CH}_{2}\right), 2.61\left(\mathrm{t}, J=7.1 \mathrm{~Hz}, 2 \mathrm{H}, \mathrm{CH}_{2}\right), 2.60-2.54(\mathrm{~m}, 1 \mathrm{H}$, $\mathrm{CH}), 1.85-1.76\left(\mathrm{~m}, 2 \mathrm{H}, 2 \mathrm{CH}_{2}\right), 1.50-1.44\left(\mathrm{~m}, 2 \mathrm{H}, 2 \mathrm{CH}_{2}\right), 1.45\left(\mathrm{~s}, 9 \mathrm{H}, 3 \mathrm{CH}_{3}\right), 1.36-1.19(\mathrm{~m}$, $\left.20 \mathrm{H}, 10 \mathrm{CH}_{2}\right), 0.87\left(\mathrm{t}, 3 \mathrm{H}, \mathrm{CH}_{3}\right) .{ }^{13} \mathrm{C}-\mathrm{NMR}(100 \mathrm{MHz}$, chloroform-d) $\delta 154.83(\mathrm{CO}), 79.24$ (quat. C) $54.99(\mathrm{CH}), 46.88\left(\mathrm{CH}_{2}\right), 42.51\left(2 \mathrm{CH}_{2}\right), 32.69\left(\mathrm{CH}_{2}\right), 31.85\left(2 \mathrm{CH}_{2}\right), 30.51\left(\mathrm{CH}_{2}\right)$, $29.59\left(\mathrm{CH}_{2}\right), 29.56\left(\mathrm{CH}_{2}\right) 29.54\left(2 \mathrm{CH}_{2}\right), 29.51\left(\mathrm{CH}_{2}\right), 29.26\left(\mathrm{CH}_{2}\right), 28.43\left(3 \mathrm{CH}_{3}\right), 27.39\left(\mathrm{CH}_{2}\right)$, $22.59\left(\mathrm{CH}_{2}\right), 13.95\left(\mathrm{CH}_{3}\right)$. IR (ATR, $\mathrm{HCl}$ of $\left.4 \mathrm{~b}\right) \vee\left(\mathrm{cm}^{-1}\right)=2920,2851,2714,1683,1471,1425$, 1365, 1242, 1166, 1141, 866, 772, 720 . MS (EI) m/z: $368\left(\mathrm{M}^{+}, 8\right), 311$ (100), 127 (50), 57 (86). HRMS (EI) calcd. for $\mathrm{C}_{22} \mathrm{H}_{44} \mathrm{O}_{2} \mathrm{~N}_{2}\left(\mathrm{M}^{+}\right)$: 368.3403. Found: 368.3394 .

tert-Butyl 4-(octylamino)piperidine-1-carboxylate (4c): The compound was prepared according to general procedure 1 from $897 \mathrm{mg}$ ( $4.5 \mathrm{mmol})$ 1-Boc-4-piperidone, $872 \mathrm{mg}(6.75 \mathrm{mmol})$ n-octylamine and $2.0 \mathrm{~g}(9.0 \mathrm{mmol})$ sodium triacetoxyborohydride to give $1.1 \mathrm{~g}(78 \%)$ of $4 \mathrm{c}$ as a colourless oil. ${ }^{1} \mathrm{H}-\mathrm{NMR}(400 \mathrm{MHz}$, chloroform- $d, 323 \mathrm{~K}) \delta 4.08-3.91\left(\mathrm{~m}, 2 \mathrm{H}, 2 \mathrm{CH}_{2}\right)$, 2.87-2.73 (m, $\left.2 \mathrm{H}, 2 \mathrm{CH}_{2}\right), 2.60\left(\mathrm{t}, J=7.3 \mathrm{~Hz}, 2 \mathrm{H}, \mathrm{CH}_{2}\right), 2.61-2.52(\mathrm{~m}, 1 \mathrm{H}, \mathrm{CH}), 1.86-1.74$ $\left(\mathrm{m}, 2 \mathrm{H}, 2 \mathrm{CH}_{2}\right), 1.52-1.42\left(\mathrm{~m}, 2 \mathrm{H}, 2 \mathrm{CH}_{2}\right) .1 .45\left(\mathrm{~s}, 9 \mathrm{H}, 3 \mathrm{CH}_{3}\right), 1.35-1.22\left(\mathrm{~m}, 12 \mathrm{H}, 6 \mathrm{CH}_{2}\right)$, $0.87\left(\mathrm{t}, J=7.2 \mathrm{~Hz}, 3 \mathrm{H}, \mathrm{CH}_{3}\right) .{ }^{13} \mathrm{C}-\mathrm{NMR}(101 \mathrm{MHz}$, chloroform-d, $323 \mathrm{~K}) \delta 154.86(\mathrm{CO})$, 79.35 (quat. C), $55.12(\mathrm{CH}), 46.92\left(\mathrm{CH}_{2}\right), 42.73\left(2 \mathrm{CH}_{2}\right), 32.66\left(2 \mathrm{CH}_{2}\right), 31.83\left(\mathrm{CH}_{2}\right), 30.47$ $\left(\mathrm{CH}_{2}\right), 29.53\left(\mathrm{CH}_{2}\right), 29.27\left(\mathrm{CH}_{2}\right), 28.45\left(3 \mathrm{CH}_{3}\right), 27.44\left(\mathrm{CH}_{2}\right), 22.66\left(\mathrm{CH}_{2}\right), 14.16\left(\mathrm{CH}_{3}\right) . \mathrm{MS}$ (EI) $m / z: 312\left(\mathrm{M}^{+}, 0.8\right), 255$ (6), 143 (2), 127 (4), 113 (3), 83 (13), 41 (100). HRMS (EI) calcd. for $\mathrm{C}_{18} \mathrm{H}_{36} \mathrm{~N}_{2} \mathrm{O}_{2}$ : 312.2777. Found: 312.2771.

tert-Butyl 4-(cycloheptylamino)piperidine-1-carboxylate (4d): The compound was prepared according to general procedure 1 from $598 \mathrm{mg}$ (3.0 mmol) 1-Boc-4-piperidone, $509 \mathrm{mg}$ (4.5 mmol) cycloheptylamine and $1.34 \mathrm{~g}(6.0 \mathrm{mmol})$ sodium triacetoxyborohydride to give $870 \mathrm{mg}(98 \%)$ of $4 \mathbf{d}$ as a colourless oil. ${ }^{1} \mathrm{H}-\mathrm{NMR}(400 \mathrm{MHz}$, chloroform- $d, 323 \mathrm{~K}) \delta 4.08-3.93$ $\left(\mathrm{m}, 2 \mathrm{H}, 2 \mathrm{CH}_{2}\right), 2.87-2.71\left(\mathrm{~m}, 3 \mathrm{H}, \mathrm{CH}, 2 \mathrm{CH}_{2}\right), 2.72-2.60(\mathrm{~m}, 1 \mathrm{H}, \mathrm{CH}), 1.87-1.73(\mathrm{~m}, 4 \mathrm{H}$, $\left.4 \mathrm{CH}_{2}\right), 1.72-1.08\left(\mathrm{~m}, 12 \mathrm{H}, 6 \mathrm{CH}_{2}\right), 1.45\left(\mathrm{~s}, 9 \mathrm{H}, 3 \mathrm{CH}_{3}\right) .{ }^{13} \mathrm{C}-\mathrm{NMR}(100 \mathrm{MHz}$, chloroform-d) ઈ 154.92 (CO), 79.35 (quat. C), $55.22(\mathrm{CH}), 51.95(\mathrm{CH}), 42.97\left(2 \mathrm{CH}_{2}\right), 35.71\left(2 \mathrm{CH}_{2}\right), 33.35$ $\left(2 \mathrm{CH}_{2}\right), 28.54\left(3 \mathrm{CH}_{3}\right), 28.28\left(2 \mathrm{CH}_{2}\right), 24.50\left(2 \mathrm{CH}_{2}\right)$. IR $($ ATR $) \vee\left(\mathrm{cm}^{-1}\right)=2980,2921,2852$, 1688, 1419, 1364, 1234, 1169, 869, 769. MS (EI) m/z: $296\left(\mathrm{M}^{+}, 20\right), 239$ (6), 183 (100), 143 (54), 127 (44), 57 (54). HRMS (EI) calcd. for $\mathrm{C}_{17} \mathrm{H}_{32} \mathrm{~N}_{2} \mathrm{O}_{2}\left(\mathrm{M}^{+}\right)$: 296.2464. Found: 296.2457. 
tert-Butyl 4-((pyridin-3-ylmethyl)amino)piperidine-1-carboxylate (4e): The compound was prepared according to general procedure 1 from $1.1 \mathrm{~g}(6.2 \mathrm{mmol})$ 1-Boc-4-piperidone, $977 \mathrm{mg}$ (9.03 mmol) 3-picolylamine and $2.67 \mathrm{~g}(12.0 \mathrm{mmol})$ sodium triacetoxyborohydride to give $1.75 \mathrm{~g}(100 \%)$ of $4 \mathbf{e}$ as a colourless oil. ${ }^{1} \mathrm{H}-\mathrm{NMR}(400 \mathrm{MHz}$, chloroform- $d, 323 \mathrm{~K}) \delta 8.56$ $(\mathrm{d}, J=1.7 \mathrm{~Hz}, 1 \mathrm{H}$, arom. $\mathrm{CH}), 8.49(\mathrm{dd}, J=4.8,1.6 \mathrm{~Hz}, 1 \mathrm{H}$, arom. $\mathrm{CH}), 7.67(\mathrm{dt}, J=7.8$, $1.7 \mathrm{~Hz}, 1 \mathrm{H}$, arom. CH), $7.24(\mathrm{ddd}, J=7.8,4.8,0.7 \mathrm{~Hz}, 1 \mathrm{H}$, arom. $\mathrm{CH}), 4.07-3.91(\mathrm{~m}, 2 \mathrm{H}$, $\left.2 \mathrm{CH}_{2}\right), 3.84\left(\mathrm{~s}, 2 \mathrm{H}, \mathrm{CH}_{2} \mathrm{~N}\right), 2.92-2.75\left(\mathrm{~m}, 2 \mathrm{H}, 2 \mathrm{CH}_{2}\right), 2.67(\mathrm{ddd}, \mathrm{J}=10.0,6.0,4.0 \mathrm{~Hz}, 1 \mathrm{H}$, $\mathrm{CH}), 1.92-1.78\left(\mathrm{~m}, 2 \mathrm{H}, 2 \mathrm{CH}_{2}\right), 1.64-1.47\left(\mathrm{~m}, 2 \mathrm{H}, 2 \mathrm{CH}_{2}\right), 1.45\left(\mathrm{~s}, 9 \mathrm{H}, 3 \mathrm{CH}_{3}\right) .{ }^{13} \mathrm{C}-\mathrm{NMR}$ (100 MHz, chloroform-d, $323 \mathrm{~K}) \delta 154.88$ (quat. C), 149.70 (arom. CH), 148.59 (arom. CH), 136.04 (quat. C), 135.66 (arom. CH), 123.39 (arom. CH), 79.48 (quat. C), $54.44(\mathrm{CH}), 48.27$ $\left(\mathrm{CH}_{2}\right), 42.55\left(2 \mathrm{CH}_{2}\right), 32.60\left(2 \mathrm{CH}_{2}\right), 28.53\left(3 \mathrm{CH}_{3}\right) . \mathrm{IR}(\mathrm{KBr}) \vee\left(\mathrm{cm}^{-1}\right)=2937,2796,1683$, 1452, 1421, 1360, 1172, 1121, 1043, 843, 738, 697. MS (EI) m/z: $291\left(\mathrm{M}^{+}, 26\right), 218$ (18), 107 (23), 94 (40), 92 (47), 57 (100). HRMS: calcd. for $\mathrm{C}_{16} \mathrm{H}_{25} \mathrm{~N}_{3} \mathrm{O}_{2}$ : 291.1947. Found: 291.1942.

tert-Butyl 4-((2-(pyrrolidin-1-yl)ethyl)amino)piperidine-1-carboxylate (4f): The compound was prepared according to general procedure 1 from $598 \mathrm{mg}$ (3.0 mmol) 1-Boc-4-piperidone, $977 \mathrm{mg}$ (9.03 mmol) 1-pyrrolidineethanamine and $1.34 \mathrm{~g}(6.0 \mathrm{mmol})$ sodium triacetoxyborohydride to give $580 \mathrm{mg}(65 \%)$ of $4 \mathrm{f}$ as a colourless oil. ${ }^{1} \mathrm{H}-\mathrm{NMR}$ (400 MHz, chloroform- $d$ ) ס 4.08-3.93 (m, $\left.2 \mathrm{H}, 2 \mathrm{CH}_{2}\right), 2.89-2.73\left(\mathrm{~m}, 4 \mathrm{H}, 2 \mathrm{CH}_{2}\right), 2.67-2.55\left(\mathrm{~m}, 7 \mathrm{H}, \mathrm{CH}, 3 \mathrm{CH}_{2}\right)$, 1.88-1.72 (m, $\left.6 \mathrm{H}, 3 \mathrm{CH}_{2}\right), 1.45\left(\mathrm{~s}, 9 \mathrm{H}, 3 \mathrm{CH}_{3}\right), 1.37-1.20\left(\mathrm{~m}, 2 \mathrm{H}, \mathrm{CH}_{2}\right) .{ }^{13} \mathrm{C}-\mathrm{NMR}(100 \mathrm{MHz}$, chloroform-d) $\delta 154.92$ (CO), 79.39 (quat. C), $56.23\left(2 \mathrm{CH}_{2}\right), 55.24(\mathrm{CH}), 54.23\left(\mathrm{CH}_{2}\right), 45.30$ $\left(\mathrm{CH}_{2}\right), 42.68\left(2 \mathrm{CH}_{2}\right), 32.61\left(2 \mathrm{CH}_{2}\right), 28.53\left(3 \mathrm{CH}_{3}\right), 23.59\left(2 \mathrm{CH}_{2}\right) . \mathrm{IR}(\mathrm{KBr}) v\left(\mathrm{~cm}^{-1}\right)=3266$, 2791, 1683, 1419, 1364, 1240, 1168, 1139, 873. MS (EI) m/z: $291\left(\mathrm{M}^{+}, 2\right), 224$ (6), 84 (100). HRMS: calcd. for $\mathrm{C}_{16} \mathrm{H}_{31} \mathrm{~N}_{3} \mathrm{O}_{2}$ : 297.2416. Found: 297.2411 .

$N$-(4-(tert-Butyl)benzyl)piperidin-4-amine (5a): The compound was prepared according to general procedure 2 from $200 \mathrm{mg}(0.58 \mathrm{mmol})$ of $4 \mathbf{a}$ to give $120 \mathrm{mg}(84 \%)$ of $5 \mathbf{a}$ as a colourless oil. ${ }^{1} \mathrm{H}-\mathrm{NMR}(400 \mathrm{MHz}$, chloroform-d) $\delta 7.35$ (d, J = 8.4 Hz, $2 \mathrm{H}, 2$ arom. CH), 7.25 (d, $J=8.4 \mathrm{~Hz}, 2 \mathrm{H}, 2$ arom. CH), $3.78\left(\mathrm{~s}, 2 \mathrm{H}, \mathrm{CH}_{2}\right), 3.15\left(\mathrm{dt}, J=12.7,3.7 \mathrm{~Hz}, 2 \mathrm{H}, 2 \mathrm{CH}_{2}\right)$, 2.77-2.53 (m, $\left.3 \mathrm{H}, 2 \mathrm{CH}_{2}, \mathrm{CH}\right), 2.00-1.87$ (m, $\left.2 \mathrm{H}, 2 \mathrm{CH}_{2}\right), 1.42-1.23\left(\mathrm{~m}, 2 \mathrm{H}, 2 \mathrm{CH}_{2}\right), 1.31$ (s, $\left.9 \mathrm{H}, 3 \mathrm{CH}_{3}\right) .{ }^{13} \mathrm{C}-\mathrm{NMR}(100 \mathrm{MHz}$, chloroform-d) $\delta 149.89$ (quat. C), 137.38 (quat. C), 127.78 (2 arom. $\mathrm{CH}), 125.38$ (2 arom. $\mathrm{CH}), 53.83(\mathrm{CH}), 50.26\left(\mathrm{CH}_{2}\right), 44.66\left(2 \mathrm{CH}_{2}\right), 34.47$ (quat. C), $33.11\left(2 \mathrm{CH}_{2}\right), 31.39\left(3 \mathrm{CH}_{3}\right)$. IR $(\mathrm{ATR}) \vee\left(\mathrm{cm}^{-1}\right)=2954,2863,1461,1363,1269,1201,1128$, $830,800,720$.

$N$-Dodecylpiperidin-4-amine (5b): The compound was prepared according to general procedure 2, from $200 \mathrm{mg}(0.54 \mathrm{mmol})$ of $4 \mathbf{b}$ to give $120 \mathrm{mg}(83 \%)$ of $5 \mathbf{b}$ as a colourless oil. ${ }^{1} \mathrm{H}-\mathrm{NMR}\left(400 \mathrm{MHz}\right.$, methanol- $\left.d_{4}\right) \delta 4.03-3.89\left(\mathrm{~m}, 2 \mathrm{H}, 2 \mathrm{CH}_{2}\right), 3.07-2.97(\mathrm{~m}, 1 \mathrm{H}, \mathrm{CH})$, 2.77-2.42 (m, $\left.6 \mathrm{H}, 3 \mathrm{CH}_{2}\right), 1.87-1.69\left(\mathrm{~m}, 2 \mathrm{H}, 2 \mathrm{CH}_{2}\right), 1.47-1.37\left(\mathrm{~m}, 2 \mathrm{H}, 2 \mathrm{CH}_{2}\right), 1.31-1.07$ $\left(\mathrm{m}, 20 \mathrm{H}, 10 \mathrm{CH}_{2}\right), 0.79\left(\mathrm{t}, J=6.8 \mathrm{~Hz}, 3 \mathrm{H}, \mathrm{CH}_{3}\right) .{ }^{13} \mathrm{C}-\mathrm{NMR}\left(100 \mathrm{MHz}\right.$, methanol- $\left.d_{4}\right) \delta 54.81$ $\left(\mathrm{CH}_{2}\right), 46.03\left(2 \mathrm{CH}_{2}\right), 45.67(\mathrm{CH}), 31.67\left(\mathrm{CH}_{2}\right), 31.19\left(\mathrm{CH}_{2}\right), 29.36\left(\mathrm{CH}_{2}\right), 29.34\left(\mathrm{CH}_{2}\right), 29.30$ $\left(\mathrm{CH}_{2}\right), 29.27\left(\mathrm{CH}_{2}\right), 29.24\left(\mathrm{CH}_{2}\right), 29.08\left(\mathrm{CH}_{2}\right), 27.26\left(\mathrm{CH}_{2}\right), 27.04\left(\mathrm{CH}_{2}\right), 26.98\left(\mathrm{CH}_{2}\right), 22.33$ $\left(\mathrm{CH}_{2}\right), 13.03\left(\mathrm{CH}_{3}\right)$. IR $(\mathrm{ATR}, \mathrm{HCl}) \vee\left(\mathrm{cm}^{-1}\right)=2920,2851,2721,1471,1426,1243,1167,1142$, 866, 772, 720. HRMS (EI) calcd. for $\mathrm{C}_{17} \mathrm{H}_{35} \mathrm{~N}_{2}\left(\mathrm{M}^{+}-\mathrm{H}\right)$ : 267.8000. Found: 267.2795.

$N$-Octylpiperidin-4-amine $(5 \mathbf{c})$ : The compound was prepared according to general procedure 2 from $200 \mathrm{mg}(0.64 \mathrm{mmol})$ of $4 \mathrm{c}$ to give $120 \mathrm{mg}(88 \%)$ of $5 \mathrm{c}$ as a colourless oil. ${ }^{1} \mathrm{H}-\mathrm{NMR}$ $\left(400 \mathrm{MHz}\right.$, methanol- $\left.d_{4}\right) \delta 3.58-3.39\left(\mathrm{~m}, 3 \mathrm{H}, 2 \mathrm{CH}_{2}, \mathrm{CH}\right), 3.11(\mathrm{td}, J=13.2,2.7 \mathrm{~Hz}, 2 \mathrm{H}$, $\left.2 \mathrm{CH}_{2}\right), 3.05-2.96\left(\mathrm{~m}, 2 \mathrm{H}, \mathrm{CH}_{2}\right), 2.40-2.28\left(\mathrm{~m}, 2 \mathrm{H}, 2 \mathrm{CH}_{2}\right), 2.07(\mathrm{ddt}, J=22.3,13.8,7.1 \mathrm{~Hz}$, $\left.2 \mathrm{H}, 2 \mathrm{CH}_{2}\right), 1.80-1.67\left(\mathrm{~m}, 2 \mathrm{H}, \mathrm{CH}_{2}\right), 1.47-1.24\left(\mathrm{~m}, 10 \mathrm{H}, 5 \mathrm{CH}_{2}\right), 0.89(\mathrm{t}, J=6.8 \mathrm{~Hz}, 3 \mathrm{H}$, $\left.\mathrm{CH}_{3}\right) .{ }^{13} \mathrm{C}-\mathrm{NMR}(100 \mathrm{MHz}$, methanol-d 4$) \delta 52.14(\mathrm{CH}), 44.94\left(\mathrm{CH}_{2}\right), 42.18\left(2 \mathrm{CH}_{2}\right), 31.55$ $\left(2 \mathrm{CH}_{2}\right), 28.87\left(2 \mathrm{CH}_{2}\right), 26.38\left(\mathrm{CH}_{2}\right), 26.10\left(\mathrm{CH}_{2}\right), 24.91\left(\mathrm{CH}_{2}\right), 22.39\left(\mathrm{CH}_{2}\right), 13.34\left(\mathrm{CH}_{3}\right) . \mathrm{IR}$ $(\mathrm{KBr}) \vee\left(\mathrm{cm}^{-1}\right)=2928,1431,1200,1174,1130,836,797,721 . \mathrm{MS}(\mathrm{EI}) \mathrm{m} / z: 211\left(\mathrm{M}^{+}-1,46\right), 168$ (46), 157 (38), 84 (74), 57 (100). HRMS (EI) calcd. for $\mathrm{C}_{13} \mathrm{H}_{27} \mathrm{~N}_{2}\left(\mathrm{M}^{+}-\mathrm{H}\right)$ : 211.2180. Found: 211.2169. 
$N$-(Pyridin-3-ylmethyl)piperidin-4-amine (5e): The compound was prepared according to general procedure 2 from $670 \mathrm{mg}(2.3 \mathrm{mmol})$ of $4 \mathbf{e}$ to give $100 \mathrm{mg}(20 \%)$ of $5 \mathbf{e}$ as a brown oil. ${ }^{1} \mathrm{H}-\mathrm{NMR}\left(400 \mathrm{MHz}\right.$, methanol- $\left.d_{4}\right) \delta 8.55(\mathrm{~s}, 1 \mathrm{H}, \mathrm{NH}), 8.51-8.40(\mathrm{~m}, 2 \mathrm{H}, \mathrm{NH}$, arom. $\mathrm{CH}), 7.91-7.84(\mathrm{~m}, 1 \mathrm{H}$, arom. $\mathrm{CH}), 7.83-7.73(\mathrm{~m}, 1 \mathrm{H}$, arom. $\mathrm{CH}), 7.45-7.38(\mathrm{~m}, 1 \mathrm{H}$, arom. $\mathrm{CH}), 3.86\left(\mathrm{~s}, 2 \mathrm{H}, \mathrm{CH}_{2}\right), 3.45-3.36\left(\mathrm{~m}, 2 \mathrm{H}, 2 \mathrm{CH}_{2}\right), 3.05-2.95\left(\mathrm{~m}, 2 \mathrm{H}, 2 \mathrm{CH}_{2}\right), 2.91-2.80(\mathrm{~m}$, $1 \mathrm{H}, \mathrm{CH}), 1.71-1.55\left(\mathrm{~m}, 2 \mathrm{H}, 2 \mathrm{CH}_{2}\right), 1.38-1.24\left(\mathrm{~m}, 2 \mathrm{H}, 2 \mathrm{CH}_{2}\right)$.

$\mathrm{N}$-(2-(Pyrrolidin-1-yl)ethyl)piperidin-4-amine (5f): The compound was prepared according to general procedure 2 from $200 \mathrm{mg}(0.67 \mathrm{mmol})$ of $4 \mathbf{e}$ to give $100 \mathrm{mg}(76 \%)$ of $5 \mathbf{e}$ as a colourless oil. ${ }^{1} \mathrm{H}-\mathrm{NMR}\left(400 \mathrm{MHz}\right.$, chloroform- $d$ ) $\delta 3.25-3.11\left(\mathrm{~m}, 4 \mathrm{H}, 2 \mathrm{CH}_{2}\right), 2.76(\mathrm{t}$, $\left.J=6.3 \mathrm{~Hz}, 2 \mathrm{H}, \mathrm{CH}_{2}\right), 2.72-2.64(\mathrm{~m}, 1 \mathrm{H}, \mathrm{CH}), 2.61\left(\mathrm{t}, J=6.3 \mathrm{~Hz}, 2 \mathrm{H}, \mathrm{CH}_{2}\right), 2.55-2.47(\mathrm{~m}$, $\left.4 \mathrm{H}, 2 \mathrm{CH}_{2}\right), 2.02-1.87\left(\mathrm{~m}, 2 \mathrm{H}, 2 \mathrm{CH}_{2}\right), 1.82-1.72\left(\mathrm{~m}, 4 \mathrm{H}, 2 \mathrm{CH}_{2}\right), 1.43-1.25\left(\mathrm{~m}, 2 \mathrm{H}, 2 \mathrm{CH}_{2}\right)$. ${ }^{13} \mathrm{C}-\mathrm{NMR}\left(100 \mathrm{MHz}\right.$, chloroform-d) $\delta 55.99\left(2 \mathrm{CH}_{2}\right), 54.68(\mathrm{CH}), 54.13\left(\mathrm{CH}_{2}\right), 45.18\left(\mathrm{CH}_{2}\right)$, $44.65\left(2 \mathrm{CH}_{2}\right), 32.97\left(2 \mathrm{CH}_{2}\right), 23.43\left(2 \mathrm{CH}_{2}\right) . \mathrm{IR}(\mathrm{KBr}) \vee\left(\mathrm{cm}^{-1}\right)=2955,2912,2827,1448,1410$, 1200, 1173, 1128, 799. MS (EI) m/z: 194 (2, M+3), 113 (14), 97 (10), 84 (100). HRMS (EI) calcd. for $\mathrm{C}_{11} \mathrm{H}_{21} \mathrm{~N}_{3}\left(\mathrm{M}^{+}-2 \mathrm{H}\right):$ 195.1736. Found: 195.1729 .

N-Dodecyl-N-(1-phenethylpiperidin-4-yl)acetamide (6a): The compound was prepared according to general procedure 3 from $261 \mathrm{mg}(0.7 \mathrm{mmol})$ of $3 \mathbf{b}$ and $110 \mathrm{mg}(2.0 \mathrm{mmol})$ acetyl chloride to give $280 \mathrm{mg}(97 \%)$ of $6 \mathrm{a}$ as a colourless oil. ${ }^{1} \mathrm{H}-\mathrm{NMR}(400 \mathrm{MHz}$, chloroform- $d$ ) $\delta$ 7.33-7.25 (m, $2 \mathrm{H}, 2$ arom. CH), 7.23-7.14 (m, $3 \mathrm{H}, 3$ arom. CH), 4.47-4.35 (m, $1 \mathrm{H}, \mathrm{CH})$, 3.25-3.11 (m, $\left.2 \mathrm{H}, \mathrm{CH}_{2}\right), 3.10-2.98\left(\mathrm{~m}, 2 \mathrm{H}, \mathrm{CH}_{2}\right), 2.84-2.75\left(\mathrm{~m}, 2 \mathrm{H}, \mathrm{CH}_{2}\right), 2.65-2.56(\mathrm{~m}, 2 \mathrm{H}$, $\left.\mathrm{CH}_{2}\right), 2.09\left(\mathrm{~s}, 3 \mathrm{H}, \mathrm{CH}_{3}\right), 1.76-1.63\left(\mathrm{~m}, 3 \mathrm{H}, 2 \mathrm{CH}_{2}\right), 1.61-1.47\left(\mathrm{~m}, 3 \mathrm{H}, 2 \mathrm{CH}_{2}\right), 1.37-1.18$ $\left(\mathrm{m}, 20 \mathrm{H}, 10 \mathrm{CH}_{2}\right), 0.88\left(\mathrm{t}, J=6.8 \mathrm{~Hz}, 3 \mathrm{H}, \mathrm{CH}_{3}\right) .{ }^{13} \mathrm{C}-\mathrm{NMR}\left(100 \mathrm{MHz}, \mathrm{DMSO}-d_{6}\right) \delta 169.67$ (CO), 140.77 (quart. C), 128.99 (2 arom.), 128.63 (2 arom. $\mathrm{CH}), 126.23$ (arom. $\mathrm{CH}), 60.09$ $\left(\mathrm{CH}_{2}\right), 56.05(\mathrm{CH}), 53.25\left(2 \mathrm{CH}_{2}\right), 44.64\left(\mathrm{CH}_{2}\right), 33.49\left(\mathrm{CH}_{2}\right), 31.78\left(\mathrm{CH}_{2}\right), 31.27\left(\mathrm{CH}_{2}\right), 30.77$ $\left(\mathrm{CH}_{2}\right), 29.81\left(\mathrm{CH}_{2}\right), 29.49\left(\mathrm{CH}_{2}\right), 29.42\left(2 \mathrm{CH}_{2}\right), 29.19\left(\mathrm{CH}_{2}\right), 27.20\left(\mathrm{CH}_{2}\right), 26.91\left(2 \mathrm{CH}_{2}\right)$, $22.58\left(\mathrm{CH}_{2}\right), 22.31\left(\mathrm{CH}_{3}\right), 14.40\left(\mathrm{CH}_{3}\right) . \mathrm{IR}(\mathrm{KBr}) \vee\left(\mathrm{cm}^{-1}\right)=2923,2852,2804,1644,1455$, 1420, 1369, 1287, 1122, 1041, 747, 699. MS (EI) $\mathrm{m} / \mathrm{z}: 413\left(\mathrm{M}^{+}-\mathrm{H}, 0.1\right), 0.323$ (100), 280 (14), 238 (15). HRMS (EI) calcd. for $\mathrm{C}_{27} \mathrm{H}_{45} \mathrm{~N}_{2} \mathrm{O}\left(\mathrm{M}^{+}-\mathrm{H}\right)$ : 413.3532. Found: 413.3521.

$\mathrm{N}$-(4-(tert-Butyl)benzyl)-N-(1-phenethylpiperidin-4-yl)undec-10-enamide (6b): The compound was prepared according to general procedure 3 from $501 \mathrm{mg}(1.43 \mathrm{mmol})$ of $3 \mathrm{c}$ and $580 \mathrm{mg}$ ( $2.9 \mathrm{mmol}$ ) 10-undecenoyl chloride to give $575 \mathrm{mg}(78 \%)$ of $\mathbf{6 b}$ as a pale yellow oil. ${ }^{1} \mathrm{H}-\mathrm{NMR}$ (400 MHz, chloroform- $d$ ) $\delta 7.39-7.00(\mathrm{~m}, 9 \mathrm{H}, 9$ arom. CH), 5.80 (ddt, $J=16.9,10.1,6.6 \mathrm{~Hz}$, $1 \mathrm{H},-\mathrm{CH}=)$, 5.04-4.87 (m, $\left.2 \mathrm{H}, \mathrm{CH}_{2}\right), 4.69-4.58(\mathrm{~m}, 1 \mathrm{H}, \mathrm{CH}), 4.50\left(\mathrm{~s}, 2 \mathrm{H}, \mathrm{CH}_{2}\right), 3.09-2.95$ $\left(\mathrm{m}, 2 \mathrm{H}, 2 \mathrm{CH}_{2}\right), 2.80-2.71\left(\mathrm{~m}, 2 \mathrm{H}, \mathrm{CH}_{2}\right), 2.61-2.50\left(\mathrm{~m}, 2 \mathrm{H}, \mathrm{CH}_{2}\right), 2,24(\mathrm{t}, \mathrm{J}=7.4 \mathrm{~Hz}, 2 \mathrm{H}$, $\left.\mathrm{CH}_{2}\right), 2.16-1.98\left(\mathrm{~m}, 4 \mathrm{H}, 3 \mathrm{CH}_{2}\right), 1.71-1.53\left(\mathrm{~m}, 6 \mathrm{H}, 3 \mathrm{CH}_{2}\right), 1.43-1.18\left(\mathrm{~m}, 10 \mathrm{H}, 5 \mathrm{CH}_{2}\right), 1.31$ $\left(\mathrm{s}, 9 \mathrm{H}, 3 \mathrm{CH}_{3}\right) .{ }^{13} \mathrm{C}-\mathrm{NMR}(100 \mathrm{MHz}$, chloroform- $d$ ) $\delta 174.22$ (CO), 150.02 (quat. C), 140.27 (quat. C), 139.20 (-CH=), 135.49 (quat. C), 128.64 (2 arom. $\mathrm{CH}), 128.38$ (2 arom. $\mathrm{CH}), 126.03$ (arom. CH), 125.51 (2 arom. CH), 125.35 (2 arom. $\mathrm{CH}), 114.11\left(=\mathrm{CH}_{2}\right), 60.45\left(\mathrm{CH}_{2}\right), 53.29$ $\left(2 \mathrm{CH}_{2}\right), 53.13\left(\mathrm{CH}_{2}\right), 51.69(\mathrm{CH}), 46.20\left(\mathrm{CH}_{2}\right), 33.85$ (quat. C), $33.79\left(2 \mathrm{CH}_{2}\right), 31.37\left(3 \mathrm{CH}_{3}\right)$, $29.74\left(\mathrm{CH}_{2}\right), 29.40\left(\mathrm{CH}_{2}\right), 29.34\left(\mathrm{CH}_{2}\right), 29.32\left(\mathrm{CH}_{2}\right), 29.08\left(\mathrm{CH}_{2}\right), 28.90\left(\mathrm{CH}_{2}\right), 25.49\left(\mathrm{CH}_{2}\right)$. $\operatorname{IR}(\mathrm{KBr}) \vee\left(\mathrm{cm}^{-1}\right)=2925,2853,2802,1643,1457,1412,1373,1194,1120,1031,993,908,820$, 747, 699. MS (EI) $m / z: 516\left(\mathrm{M}^{+}, 2\right), 425$ (100), 147 (90). HRMS (EI) calcd. for $\mathrm{C}_{35} \mathrm{H}_{52} \mathrm{~N}_{2} \mathrm{O}$ : 516.4080. Found: 516.3837.

N-Dodecyl-N-(1-phenethylpiperidin-4-yl)butyramide (6c): The compound was prepared according to general procedure 3 from $373 \mathrm{mg}(1.0 \mathrm{mmol})$ of $3 \mathbf{b}$ and $160 \mathrm{mg}(1.5 \mathrm{mmol})$ butanoyl chloride to give $427 \mathrm{mg}(96 \%)$ of $6 \mathrm{c}$ as a pale yellow oil. ${ }^{1} \mathrm{H}-\mathrm{NMR}(400 \mathrm{MHz}$, chloroform- $d$ ) 8 7.33-7.27 (m, $2 \mathrm{H}$, arom. CH), 7.24-7.15 (m, $3 \mathrm{H}, 3$ arom. $\mathrm{CH}), 4.53-3.50(\mathrm{~m}, 1 \mathrm{H}, \mathrm{CH})$, 3.24-3.00 (m, $\left.4 \mathrm{H}, 3 \mathrm{CH}_{2}\right), 2.86-2.74\left(\mathrm{~m}, 2 \mathrm{H}, \mathrm{CH}_{2}\right), 2.66-2.53\left(\mathrm{~m}, 2 \mathrm{H}, \mathrm{CH}_{2}\right), 2.35-2.23(\mathrm{~m}$, $\left.2 \mathrm{H}, 2 \mathrm{CH}_{2}\right), 2.20-2.02\left(\mathrm{~m}, 2 \mathrm{H}, \mathrm{CH}_{2}\right), 1.96-1.79\left(\mathrm{~m}, 1 \mathrm{H}, \mathrm{CH}_{2}\right), 1.78-1.45\left(\mathrm{~m}, 9 \mathrm{H}, 5 \mathrm{CH}_{2}\right)$, 1.35-1.22 (m, $\left.16 \mathrm{H}, 8 \mathrm{CH}_{2}\right), 1.00-0.94\left(\mathrm{~m}, 3 \mathrm{H}, \mathrm{CH}_{3}\right), 0.91-0.85\left(\mathrm{~m}, 3 \mathrm{H}, \mathrm{CH}_{3}\right)$. IR (KBr) v $\left(\mathrm{cm}^{-1}\right)=2924,2853,1642,1456,1420,1372,1288,1241,1122,1032,747,699$. MS (EI) $\mathrm{m} / \mathrm{z}$ : $441\left(\mathrm{M}^{+}-\mathrm{H}, 0.2\right), 351$ (100), 238 (14), 105 (12). HRMS (EI) calcd. for $\mathrm{C}_{22} \mathrm{H}_{43} \mathrm{~N}_{2} \mathrm{O}\left(\mathrm{M}^{+}-\mathrm{C}_{7} \mathrm{H}_{7}\right.$ (Bn)): 351.3375. Found: 351.3387. 
N-Dodecyl-N-(1-phenethylpiperidin-4-yl)cinnamamide (6d): The compound was prepared according to general procedure 3 from $373 \mathrm{mg}(1.0 \mathrm{mmol})$ of $3 \mathbf{b}$ and $250 \mathrm{mg}(1.5 \mathrm{mmol})$ cinnamoyl chloride to give $440 \mathrm{mg}(88 \%)$ of $6 \mathrm{~d}$ as a pale yellow oil. ${ }^{1} \mathrm{H}-\mathrm{NMR}(400 \mathrm{MHz}$, chloroform- $d$ ) $\delta 7.72(\mathrm{~d}, J=15.3 \mathrm{~Hz}, 1 \mathrm{H},-\mathrm{CH}=), 7.52(\mathrm{dd}, J=7.6,1.6 \mathrm{~Hz}, 2 \mathrm{H}, 2$ arom. CH), 7.44-7.34 (m, 3 H, 3 arom. CH), 7.33-7.27 (m, 2 H, 2 arom. CH), 7.25-7.16 (m, 3 H, 3 arom. $\mathrm{CH}), 6.80(\mathrm{~d}, \mathrm{~J}=15.3 \mathrm{~Hz}, 1 \mathrm{H},-\mathrm{CH}=), 4.69-4.52(\mathrm{~m}, 1 \mathrm{H}, \mathrm{CH}), 3.38-3.27\left(\mathrm{~m}, 2 \mathrm{H}, \mathrm{CH}_{2}\right)$, 3.15-3.04 (m, $\left.2 \mathrm{H}, \mathrm{CH}_{2}\right), 2.87-2.79\left(\mathrm{~m}, 2 \mathrm{H}, \mathrm{CH}_{2}\right), 2.65-2.58\left(\mathrm{~m}, 2 \mathrm{H}, \mathrm{CH}_{2}\right), 2.24-2.15(\mathrm{~m}, 1 \mathrm{H}$, $\left.\mathrm{CH}_{2}\right), 1.84-1.69\left(\mathrm{~m}, 3 \mathrm{H}, 2 \mathrm{CH}_{2}\right), 1.38-1.23\left(\mathrm{~m}, 22 \mathrm{H}, 11 \mathrm{CH}_{2}\right), 0.87\left(\mathrm{t}, J=6.8 \mathrm{~Hz}, 3 \mathrm{H}, \mathrm{CH}_{3}\right)$. MS (EI) m/z: $502\left(\mathrm{M}^{+}, 0.3\right), 501$ (0.4), 411 (96), 281 (24), 131 (100), 103 (18). HRMS (EI) calcd. for $\mathrm{C}_{34} \mathrm{H}_{49} \mathrm{~N}_{2} \mathrm{O}\left(\mathrm{M}^{+}-\mathrm{H}\right): 501.3845$. Found: 501.3824 .

N-(1-Benzylpiperidin-4-yl)-N-dodecyl-[1,1'-biphenyl]-2-carboxamide (6e): The compound was prepared according to general procedure 3 from $717 \mathrm{mg}(2.0 \mathrm{mmol})$ of $3 \mathrm{~b}$ and $648 \mathrm{mg}$ (3 mmol) 2-phenylbenzoyl chloride (prepared from $607 \mathrm{mg}$ (3.0 mmol) biphenyl-2-carboxylic acid and $595 \mathrm{mg}(5.0 \mathrm{mmol})$ thionyl chloride) to give $900 \mathrm{mg}(78 \%)$ of $6 \mathrm{e}$ as a pale yellow oil. ${ }^{1} \mathrm{H}-\mathrm{NMR}\left(400 \mathrm{MHz}, \mathrm{DMSO}-d_{6}\right) \delta 11.25-10.65(\mathrm{~m}, 1 \mathrm{H}, \mathrm{NH}), 7.68-7.23(\mathrm{~m}, 14 \mathrm{H}$, 14 arom. CH), 4.35-3.93 (m, $\left.2 \mathrm{H}, \mathrm{CH}_{2}\right), 3.38-2.85\left(\mathrm{~m}, 7 \mathrm{H}, \mathrm{CH}, 3 \mathrm{CH}_{2}\right), 2.81-2.58(\mathrm{~m}, 2 \mathrm{H}$, $\left.\mathrm{CH}_{2}\right), 2.37-1.82\left(\mathrm{~m}, 2 \mathrm{H}, \mathrm{CH}_{2}\right), 1.57-1.44\left(\mathrm{~m}, 2 \mathrm{H}, \mathrm{CH}_{2}\right), 1.38-1.02\left(\mathrm{~m}, 18 \mathrm{H}, 9 \mathrm{CH}_{2}\right), 0.88(\mathrm{t}$, $\left.J=6.9 \mathrm{~Hz}, 3 \mathrm{H}, \mathrm{CH}_{3}\right) . \mathrm{IR}(\mathrm{KBr}) \vee\left(\mathrm{cm}^{-1}\right)=2922,2852,1623,1455,1437,1419,1302,1047,777$, 744, 700. MS (ESI) m/z: $539\left(100, \mathrm{M}^{+}+\mathrm{H}\right)$. HRMS (ESI) calcd. for $\mathrm{C}_{37} \mathrm{H}_{51} \mathrm{~N}_{2} \mathrm{O}^{+}\left(\mathrm{M}^{+}+\mathrm{H}\right)^{+}$: 539.3996. Found: 539.3999 .

N-Dodecyl-N-(1-phenethylpiperidin-4-yl)propionamide (6f): The compound was prepared according to general procedure 3 from $373 \mathrm{mg}(1.0 \mathrm{mmol})$ of $\mathbf{3 b}$ and $139 \mathrm{mg}(1.5 \mathrm{mmol})$ propionyl chloride to give $420 \mathrm{mg}(98 \%)$ of $6 \mathrm{f}$ as a pale yellow oil. ${ }^{1} \mathrm{H}-\mathrm{NMR}(400 \mathrm{MHz}$, chloroform- $d$ ) $\delta$ 7.34-7.27 (m, 2 H, 2 arom. CH), 7.25-7.16 (m, 3 H, 3 arom. CH), 4.53-4.41 and 3.62-3.49 (m, $1 \mathrm{H}, \mathrm{CH}), 3.27-3.01\left(\mathrm{~m}, 4 \mathrm{H}, 3 \mathrm{CH}_{2}\right), 2.87-2.75\left(\mathrm{~m}, 2 \mathrm{H}, \mathrm{CH}_{2}\right), 2.66-2.52$ $\left(\mathrm{m}, 2 \mathrm{H}, \mathrm{CH}_{2}\right), 2.42-2.25\left(\mathrm{~m}, 2 \mathrm{H}, 2 \mathrm{CH}_{2}\right), 2.22-2.01\left(\mathrm{~m}, 2 \mathrm{H}, \mathrm{CH}_{2}\right), 1.88(\mathrm{qd}, J=13.9,4.8 \mathrm{~Hz}$, $\left.1 \mathrm{H}, \mathrm{CH}_{2}\right), 1.79-1.63\left(\mathrm{~m}, 3 \mathrm{H}, 2 \mathrm{CH}_{2}\right), 1.59-1.46\left(\mathrm{~m}, 2 \mathrm{H}, \mathrm{CH}_{2}\right), 1.34-1.20\left(\mathrm{~m}, 20 \mathrm{H}, 10 \mathrm{CH}_{2}\right)$, 1.19-1.10 (m, $\left.3 \mathrm{H}, \mathrm{CH}_{3}\right), 0.88\left(\mathrm{t}, J=6.3 \mathrm{~Hz}, 3 \mathrm{H}, \mathrm{CH}_{3}\right) .{ }^{13} \mathrm{C}-\mathrm{NMR}(100 \mathrm{MHz}$, chloroform-d) $\delta$ 173.78 (CO), 140.12 (quat. C), 128.67 (2 arom. CH), 128.41 (2 arom. CH), 126.08 (arom. CH), $60.49\left(\mathrm{CH}_{2}\right), 55.33(\mathrm{CH}), 53.32\left(\mathrm{CH}_{2}\right), 53.23\left(2 \mathrm{CH}_{2}\right), 43.53\left(\mathrm{CH}_{2}\right), 33.87\left(\mathrm{CH}_{2}\right), 33.80\left(\mathrm{CH}_{2}\right)$, $31.92\left(\mathrm{CH}_{2}\right), 31.68\left(\mathrm{CH}_{2}\right), 30.89\left(\mathrm{CH}_{2}\right), 29.96\left(\mathrm{CH}_{2}\right), 29.63\left(\mathrm{CH}_{2}\right), 27.43\left(2 \mathrm{CH}_{2}\right), 27.22\left(\mathrm{CH}_{2}\right)$, $26.94\left(\mathrm{CH}_{2}\right), 26.74\left(\mathrm{CH}_{2}\right), 22.70\left(\mathrm{CH}_{2}\right), 14.13\left(\mathrm{CH}_{3}\right), 9.84\left(\mathrm{CH}_{3}\right) . \mathrm{IR}(\mathrm{KBr}) \vee\left(\mathrm{cm}^{-1}\right)=2918$, 2851, 2814, 1611, 1456, 1378, 1253, 1145, 1117, 857, 808, 748, 699. MS (EI) m/z: $411\left(\mathrm{M}^{+}, 2\right)$, 337 (100), 238 (16), 100 (56). HRMS (EI) calcd. for $\mathrm{C}_{28} \mathrm{H}_{48} \mathrm{~N}_{2} \mathrm{O}: 428.3767$. Found: 428.3674.

N,1-Dibenzyl-N-methylpiperidin-4-amine (7a): The compound was prepared according general procedure 1 from $568 \mathrm{mg}$ (3.0 mmol) 1-benzyl-4-piperidone, $556 \mathrm{mg}$ (4.5 mmol) Nbenzylmethylamine and $1.34 \mathrm{~g}(6.0 \mathrm{mmol})$ sodium triacetoxyborohydride to give $701 \mathrm{mg}$ $(79 \%)$ of $7 \mathrm{a}$ as a colourless oil. ${ }^{1} \mathrm{H}-\mathrm{NMR}(400 \mathrm{MHz}$, chloroform- $d) \delta 7.34-7.28(\mathrm{~m}, 8 \mathrm{H}$, 8 arom. $\mathrm{CH}$ ), 7.27-7.20 (m, $2 \mathrm{H}, 2$ arom. $\mathrm{CH}), 3.57\left(\mathrm{~s}, 2 \mathrm{H}, \mathrm{CH}_{2}\right), 3.49\left(\mathrm{~s}, 2 \mathrm{H}, \mathrm{CH}_{2}\right), 3.04-2.86$ $\left(\mathrm{m}, 2 \mathrm{H}, 2 \mathrm{CH}_{2}\right), 2.44(\mathrm{tt}, J=11.6,3.9 \mathrm{~Hz}, 1 \mathrm{H}, \mathrm{CH}), 2.19\left(\mathrm{~s}, 3 \mathrm{H}, \mathrm{CH}_{3}\right), 1.96(\mathrm{td}, J=11.7,2.3 \mathrm{~Hz}$, $\left.2 \mathrm{H}, 2 \mathrm{CH}_{2}\right), 1.84-1.74\left(\mathrm{~m}, 2 \mathrm{H}, 2 \mathrm{CH}_{2}\right), 1.68\left(\mathrm{td}, J=11.7,3.5 \mathrm{~Hz}, 2 \mathrm{H}, 2 \mathrm{CH}_{2}\right)$. ${ }^{13} \mathrm{C}-\mathrm{NMR}$ (100 MHz, chloroform-d) $\delta 140.16$ (quat. C), 138.54 (quat. C), 129.16 (2 arom. CH), 128.76 (2 arom. $\mathrm{CH}$ ), 128.19 (2 arom. $\mathrm{CH}), 128.16$ (2 arom. $\mathrm{CH}), 126.93$ (arom. CH), 126.73 (arom. $\mathrm{CH}), 63.15\left(\mathrm{CH}_{2}\right), 60.98(\mathrm{CH}), 57.98\left(\mathrm{CH}_{2}\right), 53.38\left(2 \mathrm{CH}_{2}\right), 37.79\left(\mathrm{CH}_{3}\right), 27.91\left(2 \mathrm{CH}_{2}\right)$. IR $(\mathrm{KBr}) \vee\left(\mathrm{cm}^{-1}\right)=2940,2793,1658,1452,1363,1254,1147,1122,1044,1017,970,906,880$, 789, 735, 697. MS (EI) m/z: $203\left(\mathrm{M}^{+}, 11\right), 173$ (44), 172 (30), 146 (24), 91 (100). HRMS (EI) calcd. for $\mathrm{C}_{20} \mathrm{H}_{27} \mathrm{~N}_{2}\left(\mathrm{M}^{+}+\mathrm{H}\right)$ : 295.2174. Found: 295.2167 .

N-Benzyl-N-methyl-1-phenethylpiperidin-4-amine (7b): The compound was prepared according to general procedure 1 from $610 \mathrm{mg}$ (3.0 mmol) 1-(2-phenylethyl)-4-piperidone, $556 \mathrm{mg}$ (4.5 mmol) $\mathrm{N}$-benzylmethylamine and $1.34 \mathrm{~g}(6.0 \mathrm{mmol})$ sodium triacetoxyborohydride to give $711 \mathrm{mg}(77 \%)$ of $7 \mathbf{b}$ as a colourless oil. ${ }^{1} \mathrm{H}-\mathrm{NMR}(400 \mathrm{MHz}$, chloroform- $d) \delta 7.41-7.13$ (m, $10 \mathrm{H}, 10$ arom. CH), $3.59\left(\mathrm{~s}, 2 \mathrm{H}, \mathrm{CH}_{2}\right), 3.17-3.04\left(\mathrm{~m}, 2 \mathrm{H}, 2 \mathrm{CH}_{2}\right), 2.86-2.75(\mathrm{~m}, 2 \mathrm{H}$, $\left.\mathrm{CH}_{2}\right), 2.64-2.54\left(\mathrm{~m}, 2 \mathrm{H}, \mathrm{CH}_{2}\right), 2.50-2.41(\mathrm{~m}, 1 \mathrm{H}, \mathrm{CH}), 2.21\left(\mathrm{~s}, 3 \mathrm{H}, \mathrm{CH}_{3}\right), 2.02(\mathrm{td}, J=11.8$, 
2.4 Hz, $\left.2 \mathrm{H}, 2 \mathrm{CH}_{2}\right), 1.89-1.80\left(\mathrm{~m}, 2 \mathrm{H}, 2 \mathrm{CH}_{2}\right), 1.71\left(\mathrm{qd}, J=12.3,3.8 \mathrm{~Hz}, 2 \mathrm{H}, 2 \mathrm{CH}_{2}\right)$. ${ }^{13} \mathrm{C}-\mathrm{NMR}(100 \mathrm{MHz}$, chloroform- $d$ ) $\delta 140.50$ (quat. C), 140.12 (quat. C), 128.70 (2 arom. $\mathrm{CH}$ ), 128.38 (2 arom. $\mathrm{CH}), 128.22$ (2 arom. $\mathrm{CH}), 126.76$ (arom. $\mathrm{CH}), 126.00$ (arom. $\mathrm{CH}), 60.91$ $(\mathrm{CH}), 60.69\left(\mathrm{CH}_{2}\right), 57.94\left(\mathrm{CH}_{2}\right), 53.49\left(2 \mathrm{CH}_{2}\right), 37.79\left(\mathrm{CH}_{3}\right), 33.97\left(\mathrm{CH}_{2}\right), 27.89\left(2 \mathrm{CH}_{2}\right)$. IR $(\mathrm{KBr}) \vee\left(\mathrm{cm}^{-1}\right)=2937,2800,1495,1453,1359,1313,1263,1196,1120,1043,843,738,697$. MS (EI) m/z: $308\left(\mathrm{M}^{+}, 3\right), 217$ (100), 160 (33), 174 (22), 187 (12), 146 (11), 120 (12), 105 (31), 96 (90), 91 (69), 70 (74), 42 (30). HRMS (EI) calcd. for $\mathrm{C}_{21} \mathrm{H}_{28} \mathrm{~N}_{2}$ : 308.2252. Found: 308.2246.

$\mathrm{N}$-Dodecyl-1-phenethyl-N-(3-phenylpropyl)piperidin-4-amine (8d): $503 \mathrm{mg}(1.0 \mathrm{mmol})$ of $\mathbf{6 d}$ was dissolved in $20 \mathrm{~mL}$ dry THF and $380 \mathrm{mg}(10.0 \mathrm{mmol}) \mathrm{LiAlH}_{4}$ was added at $20{ }^{\circ} \mathrm{C}$. The suspension was stirred for $1 \mathrm{~h}$ and then refluxed for $4 \mathrm{~h}$. After careful addition of $20 \mathrm{~mL}$ ice water, the mixture was extracted with ethyl acetate $(3 \times 20 \mathrm{~mL})$. The combined organic layers were dried over $\mathrm{Na}_{2} \mathrm{SO}_{4}$ and the solvent was evaporated. The crude residue was purified by flash column chromatography (ethyl acetate:triethylamine 10:1) to give $185 \mathrm{mg}$ $(38 \%)$ of $\mathbf{8 d}$ as a pale yellow oil. ${ }^{1} \mathrm{H}-\mathrm{NMR}(400 \mathrm{MHz}$, chloroform- $d) \delta 7.30-7.23(\mathrm{~m}, 4 \mathrm{H}$, arom. $\mathrm{CH}), 7.22-7.13(\mathrm{~m}, 6 \mathrm{H}, 6$ arom. $\mathrm{CH}), 3.11-2.96\left(\mathrm{~m}, 2 \mathrm{H}, \mathrm{CH}_{2}\right), 2.84-2.71(\mathrm{~m}, 2 \mathrm{H}$, $\left.\mathrm{CH}_{2}\right), 2.66-2.39\left(\mathrm{~m}, 7 \mathrm{H}, \mathrm{CH}, 4 \mathrm{CH}_{2}\right), 1.96\left(\mathrm{dd}, J=11.5 \mathrm{~Hz}, J=2.0 \mathrm{~Hz}, 2 \mathrm{H}, 2 \mathrm{CH}_{2}\right), 1.80-1.66$ $\left(\mathrm{m}, 3 \mathrm{H}, 3 \mathrm{CH}_{2}\right), 1.64-1.51\left(\mathrm{~m}, 2 \mathrm{H}, \mathrm{CH}_{2}\right), 1.48-1.33\left(\mathrm{~m}, 3 \mathrm{H}, 2 \mathrm{CH}_{2}\right), 1.35-1.09(\mathrm{~m}, 20 \mathrm{H}$, $\left.10 \mathrm{CH}_{2}\right), 0.88\left(\mathrm{t}, J=6.8 \mathrm{~Hz}, 3 \mathrm{H}, \mathrm{CH}_{3}\right) .{ }^{13} \mathrm{C}-\mathrm{NMR}(100 \mathrm{MHz}$, chloroform-d) $\delta 142.65$ (quat. C), 140.54 (quat. C), 128.71 (2 arom. $\mathrm{CH}), 128.39$ (4 arom. $\mathrm{CH}), 128.28$ (2 arom. $\mathrm{CH}), 126.00$ (arom. CH), 125.63 (arom. CH), $60.78\left(\mathrm{CH}_{2}\right), 58.70(\mathrm{CH}), 53.82\left(2 \mathrm{CH}_{2}\right), 50.78\left(\mathrm{CH}_{2}\right), 50.37$ $\left(\mathrm{CH}_{2}\right), 34.00\left(\mathrm{CH}_{2}\right), 33.81\left(\mathrm{CH}_{2}\right), 31.97\left(\mathrm{CH}_{2}\right), 30.92\left(\mathrm{CH}_{2}\right), 29.75\left(\mathrm{CH}_{2}\right), 29.74\left(\mathrm{CH}_{2}\right), 29.70$ $\left(\mathrm{CH}_{2}\right), 29.68\left(\mathrm{CH}_{2}\right), 29.41\left(\mathrm{CH}_{2}\right), 29.29\left(\mathrm{CH}_{2}\right), 28.27\left(2 \mathrm{CH}_{2}\right), 27.57\left(\mathrm{CH}_{2}\right), 22.74\left(\mathrm{CH}_{2}\right), 14.18$ $\left(\mathrm{CH}_{3}\right) . \mathrm{IR}(\mathrm{KBr}) \vee\left(\mathrm{cm}^{-1}\right)=2920,2852,1680,1539,1455,1199,1139,800,724,700$. MS (EI) $m / z: 489\left(\mathrm{M}^{+}-1,4\right), 399(22), 187(30), 160(42), 96$ (100). HRMS: calcd. for $\mathrm{C}_{34} \mathrm{H}_{54} \mathrm{~N}_{2}\left(\mathrm{M}^{+}\right)$: 490.4287. Found: 490.4277 .

$\mathrm{N}$-([1,1'-Biphenyl]-2-ylmethyl)-1-benzyl-N-dodecylpiperidin-4-amine (8e): $349 \mathrm{mg}(0.6 \mathrm{mmol})$ of 6e as hydrochloride was dissolved in $20 \mathrm{~mL}$ dry THF and $224 \mathrm{mg}(5.9 \mathrm{mmol}) \mathrm{LiAlH}_{4}$ was added at $20^{\circ} \mathrm{C}$. The suspension was stirred for $1 \mathrm{~h}$ and then refluxed for $4 \mathrm{~h}$. After careful addition of $20 \mathrm{~mL}$ ice water, the mixture was extracted with ethyl acetate $(3 \times 20 \mathrm{~mL})$. The combined organic layers were dried over $\mathrm{Na}_{2} \mathrm{SO}_{4}$ and the solvent was evaporated. The crude residue was purified by flash column chromatography (ethyl acetate/trimethylamine 10:1) to give $310 \mathrm{mg}(100 \%)$ of $8 \mathbf{e}$ as a colourless oil. ${ }^{1} \mathrm{H}-\mathrm{NMR}(400 \mathrm{MHz}$, chloroform- $d$ ) $\delta$ $7.68(\mathrm{~d}, J=8.2 \mathrm{~Hz}, 1 \mathrm{H}$, arom. CH), 7.40-7.20 (m, $12 \mathrm{H}, 12$ arom CH), $7.17(\mathrm{dd}, J=7.5,1.3 \mathrm{~Hz}$, $1 \mathrm{H}$, arom. $\mathrm{CH}), 3.53\left(\mathrm{~s}, 2 \mathrm{H}, \mathrm{CH}_{2}\right), 3.44\left(\mathrm{~s}, 2 \mathrm{H}, \mathrm{CH}_{2}\right), 2.90-2.79\left(\mathrm{~m}, 2 \mathrm{H}, 2 \mathrm{CH}_{2}\right), 2.39-2.32$ $(\mathrm{m}, 1 \mathrm{H}, \mathrm{CH}), 2.33\left(\mathrm{t}, J=7.0 \mathrm{~Hz}, 2 \mathrm{H}, \mathrm{CH}_{2}\right), 1.82\left(\mathrm{td}, J=11.0,4.0 \mathrm{~Hz}, 2 \mathrm{H}, 2 \mathrm{CH}_{2}\right), 1.52-1.48$ $\left(\mathrm{m}, 4 \mathrm{H}, 3 \mathrm{CH}_{2}\right), 1.35-1.11\left(\mathrm{~m}, 20 \mathrm{H}, 10 \mathrm{CH}_{2}\right), 0.87\left(\mathrm{t}, J=6.7 \mathrm{~Hz}, 3 \mathrm{H}, \mathrm{CH}_{3}\right) .{ }^{13} \mathrm{C}-\mathrm{NMR}$ $(100 \mathrm{MHz}$, chloroform-d) $\delta 141.88$ (quat. C), 141.63 (quat. C), 138.75 (quat. C), 138.47 (quat. C), 129.62 (arom. $\mathrm{CH}), 129.33$ (2 arom. $\mathrm{CH}), 129.25$ (arom. $\mathrm{CH}), 129.18$ (2 arom. $\mathrm{CH}), 128.12$ (2 arom. $\mathrm{CH}$ ), 127.86 (2 arom. CH), 127.14 (arom. $\mathrm{CH}), 126.89$ (arom. $\mathrm{CH}), 126.71$ (arom. $\mathrm{CH}), 125.99$ (arom. $\mathrm{CH}), 63.18\left(\mathrm{CH}_{2}\right), 57.56(\mathrm{CH}), 53.60\left(2 \mathrm{CH}_{2}\right), 51.71\left(\mathrm{CH}_{2}\right), 49.97\left(\mathrm{CH}_{2}\right)$, $31.94\left(\mathrm{CH}_{2}\right), 29.70\left(\mathrm{CH}_{2}\right), 29.69\left(2 \mathrm{CH}_{2}\right), 29.67\left(2 \mathrm{CH}_{2}\right), 29.56\left(\mathrm{CH}_{2}\right), 29.38\left(\mathrm{CH}_{2}\right), 28.62$ $\left(\mathrm{CH}_{2}\right), 27.88\left(\mathrm{CH}_{2}\right), 27.36\left(\mathrm{CH}_{2}\right), 22.71\left(\mathrm{CH}_{2}\right), 14.14\left(\mathrm{CH}_{3}\right) . \mathrm{IR}(\mathrm{KBr}) \vee\left(\mathrm{cm}^{-1}\right)=2922,2851$, 2799, 1454, 1365, 1147, 1072, 750, 699. MS (EI) m/z: $524\left(\mathrm{M}^{+}, 1\right), 425$ (23), 350 (64), 173 (89), 167 (100). HRMS: calcd. for $\mathrm{C}_{37} \mathrm{H}_{52} \mathrm{~N}_{2}\left(\mathrm{M}^{+}\right)$: 524.4130. Found: 524.4127.

\subsection{Biology}

\subsubsection{Antifungal Susceptibility Testing}

The model strain Yarrowia lipolytica (DSMZ Braunschweig, DSM No. 8218) culture was diluted with AC-Agar (Sigma Aldrich, Steinheim, Germany) to a McFarland standard of 0.5. Five microliters of this dilution was again diluted with AC-Agar to $20 \mathrm{~mL}$, and $99 \mu \mathrm{L}$ of this dilution was plated in each well of a 96-well plate. Then, $1 \mu \mathrm{L}$ of 12 dilutions of the compounds from $20 \mathrm{mg} / \mathrm{mL}$ to $10 \mu \mathrm{g} / \mathrm{mL}$ were plated in triplicate in the 96-well plate and 
the plate was incubated at $28^{\circ} \mathrm{C}$ for $48 \mathrm{~h}$. After this, the growth of Yarrowia lipolytica was determined visually and $\mathrm{MIC}_{100}$ was defined as $100 \%$ growth inhibition.

Determination of MICs of clinically relevant species was carried out according to the European Committee of Antifungal Susceptibility Testing [23]. Clinical isolates belonging to the group of Aspergilli, Candida spp., or Mucormycetes were chosen from the strain collection of the Institute of Hygiene and Medical Microbiology, Innsbruck, Austria. Details on the strain set tested are given in Supporting Information Table S3. Reference strains: Aspergillus flavus (ATCC 204304), Aspergillus fumigatus (ATCC 204305), Aspergillus terreus (ATCC 3633), and Candida krusei (ATCC 6258), were included as control strains according to EUCAST protocol. All mold isolates were adjusted to an inoculum size of $2 \times 10^{5}$ spores $/ \mathrm{mL}$, and spores were counted with a hemocytometer (Neubauer). Concentrations of Candida cells were determined using a photometer and adjusted according to McFarland standard of 0.5. For molds, $\mathrm{MIC}_{90}$, defined as $90 \%$ growth inhibition compared to controls without antifungal, was determined visually at $24 \mathrm{~h}$; if growth in the control wells was not sufficient, then it was determined at $48 \mathrm{~h}$ (A. terreus). For yeasts, MIC was determined using a plate reader and defined as $\mathrm{MIC}_{80}$ ( $80 \%$ growth inhibition). All substances were dissolved in DMSO and diluted in RPMI 1640 medium, containing 2\% glucose.

As compounds $\mathbf{2} \mathbf{b}$ and $\mathbf{3 b}$ exhibited promising growth-inhibiting activity at low concentrations, minimal fungicidial concentrations (MFCs) were determined according to literature [36,37] against selected Candida and Aspergillus isolates. In brief, $100 \mu \mathrm{L}$ of samples containing the MIC concentration, one dilution step lower than the MIC, and 1 and 2 dilution steps higher than the MIC were plated on Sabouraud agar plates and the number of CFUs was compared to the growth control (no antifungal drug). Amorolfin hydrochloride was used for comparison. Fungicidial and fungistatic activity were defined according to Warn et al. [36].

\subsubsection{Cytotoxicity Assays}

HL-60 cells (human leukemia cells, DSM No. ACC3) were obtained from DSMZ (German Collection of Microorganisms and Cell Cultures, Braunschweig, Germany) and cultivated in RPMI 1640 medium with 10\% fetal bovine serum (FBS), both from PAA Laboratories, Cölbe, Germany) without the addition of antibiotics at $37^{\circ} \mathrm{C}$ in a humidified atmosphere containing $5 \% \mathrm{CO}_{2}$. Human umbilical vein endothelial cells (HUVECs) were purchased from Promocell and cultivated with ECGM Kit Enhanced (PELO Biotech, Planegg, Germany), supplemented with $10 \%$ FBS and 1\% penicillin/streptomycin/amphothericin $B$ (all purchased from PAN Biotech, Aidenbach, Germany). MCF10A cells (healthy epithelial cell line) were purchased from ATCC and cultivated with DMEM/F-12 containing L-glutamine, $15 \mathrm{mM}$ HEPES, and $1.2 \mathrm{~g} / \mathrm{L} \mathrm{NaHCO}_{3}$ (PAN Biotech, Aidenbach, Germany), supplemented with $5 \%$ horse serum, heat-inactivated, New Zealand origin (Gibco, Fisher Scientific, Waltham, MA, USA), $100 \mathrm{ng} / \mathrm{mL}$ epidermal growth factor (Peprotech, Cranbury, NJ, USA), $10 \mathrm{ng} / \mathrm{mL}$ insulin (Santa Cruz Biotechnology, Heidelberg, Germany), $1 \mathrm{mg} / \mathrm{mL}$ hydrocortisone (Sigma Aldrich, St. Louis, MO, USA), and $100 \mathrm{ng} / \mathrm{mL}$ cholera toxin (Sigma Aldrich, St. Louis, MO, USA). Cytotoxicity was assessed using MTT and CellTiter-Blue ${ }^{\circledR}$ (CTB, Promega, Fitchburg, WI, USA) cell viability assays, both of which rely on determining the metabolic activity of living cells. HUVECs were cultured for a maximum of six passages. The MTT assay for cytotoxicity was performed with these cells as described by Horling et al. [38].

Cytotoxicity assays on HUVECs and MCF10A cells were carried out according to Schütz et al. [39]. HUVECs and MCF10A cells were seeded at a density of $5 \times 10^{3}$ cells per well of a 96-well plate.

\subsubsection{Toxicity Assay in Galleria Mellonella}

Per sample, 20 Galleria mellonella larvae, obtained from SA.GI.P. (Bagnacavallo, Italy), were injected at three different concentrations of amorolfine hydrochloride, $\mathbf{2} \mathbf{b}$ or $\mathbf{3 b}$, diluted in PBS. The control larvae were injected with $20 \mu \mathrm{L}$ of PBS or left untouched. 
Larvae were incubated at $37^{\circ} \mathrm{C}$ and survival was monitored every 24 h over 4 days. The average survival rate of two independent experiments (40 larvae in total) was plotted in Kaplan Meier curves and statistical difference determined by log rank test (utilizing GraphPad Prism). The concentrations to be tested were selected based on the average MIC values determined for each drug. Applying $20 \mu \mathrm{L}$ of $100 \mu \mathrm{M}$ represents the MIC $(4 \mu \mathrm{g} / \mathrm{mL})$ of $\mathbf{2 b}$ and $\mathbf{3 b}$ per $\mathrm{g}$ larvae, $500 \mu \mathrm{M}$ represents the MIC obtained for amorolfine hydrochloride $(16 \mu \mathrm{g} / \mathrm{mL})$, and additionally 10-fold the MIC of the novel substances was chosen.

\subsubsection{Identification of the Target Enzyme(s) in Ergosterol and Cholesterol Biosynthesis}

All fungal strains were cultivated according to Müller et al. [3]. Three milligrams of dry fungal biomass was used for sterol extraction, as described by Müller et al. [3]. The results represent the mean of two independent biological samples. The following concentrations were used: Aspergillus fumigatus amorolfine hydrochloride $(4.0 \mu \mathrm{g} / \mathrm{mL} ; 15 \mu \mathrm{g} / \mathrm{mL})$, $\mathbf{2 b}(3.5 \mu \mathrm{g} / \mathrm{mL} ; 8.0 \mu \mathrm{g} / \mathrm{mL}), 3 \mathbf{b}(4.0 \mu \mathrm{g} / \mathrm{mL})$; Candida albicans amorolfine hydrochloride $(4.0 \mu \mathrm{g} / \mathrm{mL} ; 15 \mu \mathrm{g} / \mathrm{mL}), 2 \mathbf{b}(1.8 \mu \mathrm{g} / \mathrm{mL} ; 4.0 \mu \mathrm{g} / \mathrm{mL}), 3 \mathbf{b}(4.0 \mu \mathrm{g} / \mathrm{mL}) ;$ Candida glabrata amorolfine hydrochloride $(7.5 \mu \mathrm{g} / \mathrm{mL}), \mathbf{2 b}(3.5 \mu \mathrm{g} / \mathrm{mL} ; 7.9 \mu \mathrm{g} / \mathrm{mL}), \mathbf{3 b}(4.0 \mu \mathrm{g} / \mathrm{mL})$. For all concentrations, similar results were obtained. Hence only one concentration is shown in Table 4.

Sterol pattern was determined by GC-MS, according to Müller et al. [3,40]. The quantification, managed with an external calibration with ergosterol, consists of six levels with concentrations up to $20 \mu \mathrm{g} / \mathrm{mg}$. The base peak of each sterol TMS ether was taken as a quantifier ion for calculating the peak areas for internal standard cholestane $\mathrm{m} / \mathrm{z}$ 217, ergosta-5,8,22-trien-3 $\beta$-ol (lichesterol) $m / z$ 363, ergosta-5,7,22-trien-3 $\beta$-ol (ergosterol) $m / z$ 363, ergosta-7,22-dien-3 $\beta$-ol $m / z$ 343, ergosta-7,22,24(28)-trien-3 $\beta$-ol $m / z$ 343, ergosta$5,7,24(28)$-trien-3 $\beta$-ol $m / z$ 363, ergosta-5,7-dien-3 $\beta$-ol of $m / z 365$, ergosta-7,24(28)-dien$3 \beta$-ol (episterol) $m / z$ 343, 4,4,14-trimethylcholesta-8,24-dien-3 $\beta$-ol (lanosterol) $\mathrm{m} / \mathrm{z} 393$, 4,4,14-trimethylergosta-8,24(28)-dien-3 $\beta$-ol (eburicol) $m / z$ 407, ergosta-8,14,24(28)-trien$3 \beta$-ol $\mathrm{m} / \mathrm{z} 369$, 4-methylergosta-8,24(28)-dien-3 $\beta$-ol (4-methylfecosterol) $\mathrm{m} / \mathrm{z} 379$, ergosta5,8,24(28)-trien-3 $\beta$-ol $m / z$ 363, ergosta-5,8,22,24(28)-tetraen-3 $\beta$-ol $m / z$ 466, ergosta-8,24(28)dien-3 $\beta$-ol $m / z$ 365, ergosta-8,24(28)-diendi-3 $\beta$,?-ol (hydroxyfecosterol) $m / z 468$ (according to ref. [41]), and ergosta-5,7,22,24(28)-tetraen-3 $\beta$-ol $m / z$ 361. The percentage of each sterol was determined and plotted against the percentage sterol content of the untreated sample (fold change). The target identification in distal cholesterol biosynthesis was performed according to Müller et al. [35].

Supplementary Materials: The following are available online: Supporting Information Table S1: Results of the antifungal activity screening for all compounds on Yarrowia lipolytica; Supporting Information Table S2: Results of the identification of the target enzyme(s) in cholesterol biosynthesis for compounds $\mathbf{2 b}, \mathbf{2 c}, \mathbf{2 f}, \mathbf{2 g}, \mathbf{3 b}, \mathbf{4 b}, \mathbf{4 c}, \mathbf{5 b}$, and $\mathbf{6 b}$ on HL-60 cells; Supporting Information Table S3: Fungal strains used in this study; Supporting Information Figure S1: Exemplary antifungal activity of $\mathbf{2} \mathbf{b}, \mathbf{3 b}$ and amorolfine (A) against the two major fungal pathogens, A. fumigatus and C. albicans.

Author Contributions: Conceptualization, J.K., C.M., U.B., K.B. and F.B.; methodology, J.K., M.K., C.M., M.M. and U.B.; formal analysis, J.K., C.M., L.J.V., J.F.M., U.B. and F.B.; investigation, J.K., C.M., M.K., L.J.V., J.F.M., U.B., M.M., K.B. and F.B.; resources, K:B., U.B. and F.B.; writing-original draft preparation, J.K., C.M., U.B. and F.B.; writing—review and editing, J.K., C.M., M.M, K.B., U.B. and F.B.; visualization, J.K., C.M., L.J.V., J.F.M. and U.B.; supervision, K.B., U.B. and F.B.; funding acquisition, U.B. All authors have read and agreed to the published version of the manuscript.

Funding: Medical University of Innsbruck (MUI start grant number 19970) to U.B.

Institutional Review Board Statement: Not applicable.

Informed Consent Statement: Not applicable.

Data Availability Statement: NMR data of the compounds are available from the authors upon request. 
Acknowledgments: The authors are grateful to Lisa-Maria Zenz and Carmen Kandelbauer for technical assistance with MIC determination, Michaela Lackner for providing clinical isolates, and Martina Stadler for performing the MTT assay.

Conflicts of Interest: The authors declare that there are no conflict of interests.

Sample Availability: Samples of the compounds are available from the authors.

\section{References}

1. Ziogas, B.N.; Oesterhelt, G.; Masner, P.; Steel, C.C.; Furter, R. Fenpropimorph: A three site inhibitor of ergosterol biosynthesis in Nectria haematococca var. Cucurbitae. Pestic. Biochem. Physiol. 1991, 39, 74-83. [CrossRef]

2. Baloch, R.I.; Mercer, E.I.; Wiggins, T.E.; Baldwin, B.C. Inhibition of ergosterol biosynthesis in Saccharomyces cerevisiae and Ustilago maydis by tridemorph, fenpropimorph and fenpropidin. Phytochemistry 1984, 23, 2219-2226. [CrossRef]

3. Müller, C.; Binder, U.; Bracher, F.; Giera, M. Antifungal drug testing by combining minimal inhibitory concentration testing with target identification by gas chromatography-mass spectrometry. Nat. Protoc. 2017, 12, 947-963. [CrossRef] [PubMed]

4. Müller, C.; Staudacher, V.; Krauss, J.; Giera, M.; Bracher, F. A convenient cellular assay for the identification of the molecular target of ergosterol biosynthesis inhibitors and quantification of their effects on total ergosterol biosynthesis. Steroids 2013, 78, 483-493. [CrossRef]

5. Campagnac, E.; Fontaine, J.; Lounès-Hadj Sahraoui, A.; Laruelle, F.; Durand, R.; Grandmougin-Ferjani, A. Fenpropimorph slows down the sterol pathway and the development of the arbuscular mycorrhizal fungus Glomus intraradices. Mycorrhiza 2009, 19, 365-374. [CrossRef] [PubMed]

6. Jampilek, J. Potential of agricultural fungicides for antifungal drug discovery. Expert Opin. Drug Discov. 2016, 11, 1-9. [CrossRef] [PubMed]

7. Segal, E.; Elad, D. Special Issue: Treatments for fungal infections. J. Fungi 2018, 4, 135. [CrossRef]

8. Haria, M.; Bryson, H.M. Amorolfine. A review of its pharmacological properties and therapeutic potential in the treatment of onychomycosis and other superficial fungal infections. Drugs 1995, 49, 103-120. [CrossRef]

9. Krauss, J.; Müller, C.; Kießling, J.; Richter, S.; Staudacher, V.; Bracher, F. Synthesis and biological evaluation of novel N-alkyl tetra- and decahydroisoquinolines: Novel antifungals that target ergosterol biosynthesis. Arch. Pharm. Chem. Life Sci. 2014, 347, 283-290. [CrossRef] [PubMed]

10. Krauss, J.; Hornacek, M.; Müller, C.; Staudacher, V.; Stadler, M.; Bracher, F. Synthesis and antifungal evaluation of novel N-alkyl tetra- and perhydroquinoline derivatives. Sci. Pharm. 2015, 83, 1-14. [CrossRef]

11. Brauer, V.S.; Rezende, C.P.; Pessoni, A.M.; De Paula, R.G.; Rangappa, K.S.; Nayaka, S.C.; Gupta, V.K.; Almeida, F. Antifungal agents in agriculture: Friends and foes of public health. Biomolecules 2019, 9, 521. [CrossRef]

12. Berger, S.; El Chazli, Y.; Babu, A.F.; Coste, A.T. Azole resistance in Aspergillus fumigatus: A consequence of antifungal use in agriculture? Front. Microbiol. 2017, 8, 1024. [CrossRef] [PubMed]

13. Berkow, E.L.; Lockhart, S.R. Fluconazole resistance in Candida species: A current perspective. Infect. Drug Resist. 2017, 10, 237-245. [CrossRef] [PubMed]

14. Perlin, D.S. Echinocandin resistance in Candida. Clin. Infect. Dis. 2015, 61 (Suppl. 6), S612-S617. [CrossRef] [PubMed]

15. Regueiro, J.; Olguín, N.; Simal-Gándara, J.; Suñol, C. Toxicity evaluation of new agricultural fungicides in primary cultured cortical neurons. Environ. Res. 2015, 140, 37-44. [CrossRef]

16. Anusionwu, C.G.; Aderibigbe, B.A.; Mbianda, X.Y. Hybrid molecules development: A versatile landscape for the control of antifungal drug resistance: A review. Mini Rev. Med. Chem. 2019, 19, 450-464. [CrossRef]

17. Krauss, J.; Stadler, M.; Bracher, F. Synthesis and structure-Activity relationships of novel benzylamine-type antifungals as butenafine-related antimycotics. Arch. Pharm. Chem. Life Sci. 2017, 350, 1600342. [CrossRef] [PubMed]

18. Krauss, J.; Gratzl, C.; Sturm, V.; Müller, C.; Staudacher, V.; Schmidt, C.Q.; Bracher, F. Synthesis and biological evaluation of novel alkyl-imidazolyl carbinols and their esters: Potent antimycotics. Sci. Pharm. 2013, 81, 641-650. [CrossRef]

19. Keller, M.; Wolfgardt, A.; Müller, C.; Wilcken, R.; Böckler, F.M.; Oliaro-Bosso, S.; Ferrante, T.; Balliano, G.; Bracher, F. Arylpiperidines as a new class of oxidosqualene cyclase inhibitors. Eur. J. Med. Chem. 2016, 109, 13-22. [CrossRef]

20. Abdel-Magid, A.F.; Carson, K.G.; Harris, B.D.; Maryanoff, C.A.; Shah, R.D. Reductive amination of aldehydes and ketones with sodium triacetoxyborohydride. Studies on direct and indirect reductive amination procedures. J. Org. Chem. 1996, 61, 3849-3862. [CrossRef]

21. Delsuc, N.; Léger, J.M.; Massip, S.; Huc, I. Proteomorphous objects from abiotic backbones. Angew. Chem. Int. Ed. Engl. 2007, 46, 214-217. [CrossRef]

22. Isidro-Llobet, A.; Álvarez, M.; Albericio, F. Amino acid-protecting groups. Chem. Rev. 2009, 109, 2455-2504. [CrossRef]

23. Rodriguez-Tudela, J.L.; Arendrup, M.C.; Arikan-Akdagli, S.; Barchiesi, F.; Bille, J.; Cuenca-Estrella, M.; Dannaoui, E.; Denning, D. EUCAST technical note on the method for the determination of broth dilution minimum inhibitory concentrations of antifungal agents for conidia forming moulds. Clin. Microbiol. Infect. 2008, 14, 982-984.

24. Skiada, A.; Lass-Flörl, C.; Klimko, N.; Ibrahim, A.; Roilides, E.; Petrikkos, G. Challenges in the diagnosis and treatment of mucormycosis. Med. Mycol. 2018, 56, S93-S101. [CrossRef] 
25. Rex, J.H.; Pfaller, M.A.; Walsh, T.J.; Chaturvedi, V.; Espinel-Ingroff, A.; Ghannoum, M.A.; Gosey, L.L.; Odds, F.C.; Rinaldi, M.G.; Sheehan, D.J.; et al. Antifungal susceptibility testing: Practical aspects and current challenges. Clin. Microbiol. Rev. 2001, 14, 643-658. [CrossRef]

26. Mosmann, T. Rapid colorimetric assay for cellular growth and survival: Application to proliferation and cytotoxicity assays. $J$. Immunol. Methods 1983, 65, 55-63. [CrossRef]

27. Cao, Y.; Gong, Y.; Liu, L.; Zhiu, Y.; Fang, X.; Zhang, C.; Li, Y.; Li, J. The use of human umbilical vein endothelial cells (HUVEC) as an in vitro model to assess the toxicity of nanoparticles to endothelium: A review. J. Appl. Toxicol. 2017, 37, 1359-1369. [CrossRef] [PubMed]

28. Vale, N.; Silva, S.; Duarte, D.; Crista, D.M.A.; da Silva, L.P.; Esteves da Silva, J.C.G. Normal breast epithelial MCF-10A cells to evaluate the safety of carbon dots. RSC Med. Chem. 2012, 12, 245-253. [CrossRef] [PubMed]

29. Babatunde, K.A.; Wang, X.; Hopke, A.; Lannes, N.; Mantel, P.-Y.; Irimia, D. Chemotaxis and swarming in differentiated HL-60 neutrohil-like cells. Sci. Rep. 2021, 11, 1-13.

30. Fallon, J.; Kelly, J.; Kavanagh, K. Galleria mellonella as a model for fungal pathogenicity testing. Methods Mol. Biol. 2012, 845, 469-485.

31. Piatek, M.; Sheehan, G.; Kavanagh, K. Utilising Galleria mellonella larvae for studying in vivo activity of conventional and novel antimicrobial agents. Pathog. Dis. 2020, 78, ftaa059. [CrossRef]

32. Maurer, E.; Hörtnagl, C.; Lackner, M.; Grässle, D.; Naschberger, V.; Moser, P.; Segal, E.; Semis, M.; Lass-Flörl, C.; Binder, U. Galleria mellonella as a model system to study virulence potential of mucormycetes and evaluation of antifungal treatment. Med. Mycol. 2018, 57, 351-362. [CrossRef] [PubMed]

33. Gsaller, F.; Hortschansky, P.; Furukawa, T.; Carr, P.D.; Rash, B.; Capilla, J.; Müller, C.; Bracher, F.; Bowyer, P.; Haas, H.; et al. Sterol biosynthesis and azole tolerance is governed by the opposing actions of SrbA and the CCAAT binding complex. PLoS Pathog. 2016, 12, e1005775.

34. Keller, P.; Müller, C.; Engelhardt, I.; Hiller, E.; Lemuth, K.; Eickhoff, H.; Wiesmüller, K.-H.; Burger-Kentischer, A.; Bracher, F.; Rupp, S. An antifungal benzimidazole derivative inhibits ergosterol biosynthesis and reveals novel sterols. Antimicrob. Agents Chemother. 2015, 59, 6296-6307. [CrossRef] [PubMed]

35. Müller, C.; Junker, J.; Bracher, F.; Giera, M. A gas chromatography-mass spectrometry-based whole-cell screening assay for target identification in distal cholesterol biosynthesis. Nat. Protoc. 2019, 14, 2546-2570. [CrossRef] [PubMed]

36. Warn, P.A.; Sharp, A.; Guinea, J.; Denning, D.W. Effect of hypoxic conditions on in vitro susceptibility testing of amphotericin B, itraconazole and micafungin against Aspergillus and Candida. J. Antimicrob. Chemother. 2004, 53, 743-749. [CrossRef] [PubMed]

37. Binder, U.; Maurer, E.; Lackner, M.; Lass-Flörl, C. Effect of reduced oxygen on the antifungal susceptibility of clinically relevant aspergilli. Antimicrob. Agents Chemother. 2015, 59, 1806-1810. [CrossRef]

38. Horling, A.; Müller, C.; Barthel, R.; Bracher, F.; Imming, P. A new class of selective and potent 7-dehydrocholesterol reductase inhibitors. J. Med. Chem. 2012, 55, 7614-7622. [CrossRef]

39. Schütz, R.; Müller, M.; Geisslinger, F.; Vollmar, A.; Bartel, K.; Bracher, F. Synthesis, biological evaluation and toxicity of novel tetrandrine analogues. Eur. J. Med. Chem. 2020, 207, 112810. [CrossRef]

40. Müller, C.; Neugebauer, T.; Zill, P.; Lass-Flörl, C.; Bracher, F.; Binder, U. Sterol composition of clinically relevant mucorales and changes resulting from posaconazole treatment. Molecules 2018, 23, 1218. [CrossRef]

41. Loeffler, R.S.T.; Hayes, A.L. Effects of sterol biosynthesis inhibitor fungicides on growth and sterol composition of Ustilago maydis, Botrytis cinerea and Pyrenophora teres. Pestic. Sci. 1992, 36, 7-17. [CrossRef] 